\title{
The Development of the Solution Building Inventory
}

$$
\text { by }
$$

\author{
Sara A. Smock \\ Dissertation Proposal submitted to the Faculty of \\ the Virginia Polytechnic Institute and State University \\ In partial fulfillment of the requirements for the degree of
}

\section{DOCTOR OF PHILOSOPHY}

in

Human Development

Specialization in Marriage and Family Therapy

APPROVED:

Eric E. McCollum, Ph.D., Chair

Michelle Stevenson, Ph.D.

Fred Piercy, Ph.D.

Terry Trepper, Ph.D.

March, 2006

Blacksburg, Virginia

Key Words: Solution-Focused Brief Therapy, Scale Development, Solution Building Copyright 2006. Sara A. Smock 
The Development of the Solution Building Inventory

\author{
Sara A. Smock
}

\begin{abstract}
Throughout the past 70 years, a great deal of research conducted on defining and testing problem-solving skills has led towards solution-focused practices and philosophies. As a result, some literature exists illustrating the efficacy of solutionfocused practices. However, no published research exists on the factors that contribute to solution building. This study tested for components of solution building while creating a solution building inventory. Factor analysis failed to find specific factors within solution building. The results indicated that solution building is a unidimensional concept. Implications for using the solution building inventory are discussed.
\end{abstract}

Key Words: Solution-Focused Brief Therapy, Scale Development, and Solution Building. 


\section{DEDICATION}

To my grandmother, Lucille, who sacrificed much but laughed more.

To my husband and best friend, who will always enjoy the journey. 


\section{LIST OF TABLES AND FIGURES}

Table 1: $\quad$ Problem-solving vs. solution building 6

Table 2: $\quad$ Original items evaluated for the SBI 40

Table 3: $\quad$ Second group of items rated for the SBI 43

Table 4: $\quad$ Sample characteristics 45

Table 5: $\quad$ Frequencies of the items from the SBI 47

Table 6: $\quad$ Exploratory factor analysis factor loadings 48

$\begin{array}{lll}\text { Table 7: } & \text { Reliabilities of factors } & 50\end{array}$

Table 8: $\quad$ Collapsed factors according to conceptual table $\quad 51$

Table 9: Reliabilities for the collapsed factors 53

Table 10: $\quad$ Age 54

Table 11: Ethnicity 55

Table 12: $\quad$ Marital Status $\quad 55$

Table 13: $\quad$ Religiosity 56

Table 14: $\quad$ Spirituality 56

Table 15: Frequencies of the SBI for the second wave of data 57

Table 16: Items in the dispositional hope scale 59

Table 17: Items in the life orientation test-revised 59

Table 18: $\quad$ Exploratory factor analysis factor loadings for wave two 61

Table 19: Reliabilities of factors for wave two 62

Table 20: $\quad$ Rationale for item loadings 64

Table 21: Collapsed data driven factors into theoretical factors table 65

Table 22: Reliabilities for the collapsed factors 66

$\begin{array}{lll}\text { Table 23: } & \text { SBI revised } & 69\end{array}$

$\begin{array}{lll}\text { Table 24: } & \text { Final SBI factor loadings } & 70\end{array}$

Table 25: $\quad$ Problem-solving vs. Solution Building Revised 75 


\section{TABLE OF CONTENTS}

Chapter \#

Chapter I:

Chapter II:

Chapter III:

Chapter IV:

Chapter V:

References
Section

Page \#

Introduction 1

Review of the Literature 9

Overview of the Problem-Solving Literature 9

Problem-Solving Inventory 11

$\begin{array}{ll}\text { Solution-Focused Brief Therapy } & 18\end{array}$

Tenets of SFBT 20

Exemplary Interventions $\quad 20$

Problem-Solving vs. Solution Building 22

Solution-Focused Brief Therapy Research 26

Additional Measures of Solution Building Concepts 29

General Scale Development $\quad 30$

Methodology 34

Sample Recruitment $\quad 35$

Data Collection $\quad 36$

$\begin{array}{ll}\text { Additional Measures } & 37\end{array}$

$\begin{array}{ll}\text { Statistical Analysis } & 38\end{array}$

Results $\quad 39$

Scale Development 39

Scale Pilot Testing - Wave One 45

Scale Verification with Second Sample 53

Validity of the SBI $\quad 71$

Discussion $\quad 72$

Testing of the Theoretical Model 73

Problem-Solving versus Solution Building $\quad 74$

Implications for the SBI as an Intervention 76

$\begin{array}{ll}\text { Strengths of the Study } & 78\end{array}$

Limitations of the Study $\quad 78$

Directions for Future Research $\quad 79$ 
Appendix A

IRB Synopsis, Informed Consent Forms, and

IRB Approval Letters

Appendix B

Recruitment Advertisement

112

Appendix C

Items to be Evaluated for the Solution Building Inventory

113

Appendix D

Items to be rated for the SBI

Appendix E

The SBI

118

Appendix F

Demographic Items

120

Appendix G

Syntax for Confirmatory Factor Analysis

121

for Wave 1 of Data Analysis

Appendix H

Syntax for Confirmatory Factor Analysis

for Theoretical Model

Appendix I

Syntax for CFA for $2^{\text {nd }}$ wave Data Driven Model

125

Appendix J

Syntax for CFA for Original Theoretical Model

Using Wave 2 Data

Appendix K

Syntax for CFA Revised Theoretical Model

129

Using Wave 2 Data

Appendix L

The SBI

Curriculum Vitae for Sara A. Smock 


\section{CHAPTER I}

Introduction

"I've done the best I can to say what I wanted to say, to say what I meant, and to mean what I said"

Steve de Shazer

11 September, 2005

\section{Statement of the Problem}

People have historically attended psychotherapy for aid in solving problems in their lives. Applied problem-solving is a formula to help people solve their problems in a systematic way. Specifically, applied problem-solving denotes "a highly complex, often intermittent, goal-directed sequence of cognitive, affective, and behavioral operations for adapting to what are often stressful internal and external demands (Heppner \& Krauskopf, 1987). Within the past several decades, the study of applied problem-solving has become an area of focus (e.g., D’Zurilla \& Goldfried, 1971; Heppner \& Lee, 2002; Heppner \& Wang, 2003; Shure, 1982; Sternberg, 1982).

Problem-solving approaches emerged from a systemic lens in the 1960s and 1970s. Jay Haley, Cloe Madanes, and the Mental Research Institute (MRI), formative strategic clinicians, developed systemic approaches to problem-solving. Strategic therapists use an approach which involves the therapist tracking sequences surrounding a client's problem and then altering those patterns to solve the presenting problem (Nicholas \& Schwartz, 2001). Whether a difficulty becomes a problem depends on how family members react to the situation (Watzlawich, Weakland, \& Fisch, 1974). A strategic approach allows system thinkers to apply problem-solving approaches to families.

A systemic model of problem-solving has existed, Steve de Shazer challenged the pathologizing nature of strategic problem-solving interventions. He believed that clients really want to change and rejected the idea that problems served ulterior motives. An intervention titled the "formula first session task" became the initial exploration of using a solution-focused approach (Molnar \& de Shazer, 1987). This intervention enables the client to focus on solutions instead of problems by asking the client to observe for a week 
events in their life that they want to continue. For example, a client may report that he/she enjoys taking his/her son to soccer games. The task attempted to promote the expectations from the therapist that something worthwhile was occurring in the client's life and that more worthwhile events would occur. de Shazer and his colleagues found that using a solution-focused intervention, like the "formula first session task", moved therapy from focusing on dysfunction (fixing something wrong) to construction (a solution). This shift was important because this approach showed that therapy could build on thoughts, feelings, and behaviors familiar to the client instead of introducing foreign methods of problem resolution (Molnar \& de Shazer).

de Shazer and his colleagues made different assumptions about their clients than those of problem-solving therapists. These assumptions underscore solution focused brief therapy's (SFBT) view of change and the client's ability to create desired change, and include the following: each client is unique, clients have the intrinsic resources they need to help themselves, only clients can change themselves, change is always occurring, and solutions are not necessarily tied to the problem (Lipchik, 2002). The assumptions differ from problem-solving approaches in two major ways: the client is the expert rather than the therapist --and neither the therapist nor the client has to understand the root of the problem to develop a solution (de Shazer, 1988a).

The concept of solution building remains central to SFBT throughout the literature (Berg, 1994; DeJong \& Berg, 1998; de Shazer, 1988; 1991; 1993), although the components of solution building lack clarity. Since scale development remains a common practice for identifying the components of complex processes (e.g. Heppner \& Petersen, 1982), the development of a Solution Building Inventory (SBI) will serve to identify the factors of solution building in the emergent history of SFBT. Are Problem-solving and Solution Building the Same Thing?

Problem-solving exists as "a behavioral process, whether overt or cognitive in nature, which (a) makes available a variety of potentially effective response alternatives for dealing with the problematic situation, and (b) increases the probability of selecting the most effective response from among these various alternatives" (D'Zurilla and Goldfried, 1971, p. 108). The essence of problem-solving involves understanding the origin or root of a problem in order to develop a suitable solution. Until the past few 
decades, solutions have been examined only in relationship to problems (de Shazer, 1982; Haley, 1976; Watzlawick, Weakland, \& Fisch, 1874). However, work done by de Shazer and colleagues suggests a different view of solutions.

According to DeJong and Berg (1998), the skills needed for solution building differ greatly from those needed for problem-solving. DeJong and Berg believe that problem-solving involves the client learning a new skill or method to tackle a problem. They define problem-solving as 1) gathering data to understand the problem, 2) trying to understand the underlying causes of the problem, and 3) putting a plan into effect that will "resolve" the problem. In contrast, solution building encourages clients to focus on the future by describing how they would like their life to be. In addition, solution building requires the client to search for evidence that pieces of their desired life are already occurring. Berg (1994) states that "It is also easier to repeat already successful behavior patterns than it is to try and stop or change existing problematic behavior."(p.10)

de Shazer (1993) talks about solutions differently than cognitive behaviorists. Solutions involve "doing something different to become more satisfied with his or her life"(de Shazer, 1986). The client has to imagine and believe how life could be better in spite of a problem/hardship and then do something different in order to achieve that goal. In solution building, the goal is not necessarily to get rid of a problem (because in some cases that is not possible) but to generate ideas about how things could be better in the future. In problem-solving, solutions are mere logical answers to a question. For example, if a client possesses a particular problem the solution would be "c" $(A+B=C)$. Problem-solving remains a linear process (problem $=$ solution) where solution building entails a circular pattern (de Shazer, 1991). For instance, if a client presents a problem with alcohol, his solution may include getting a hobby, spending more time with their family, or exercising frequently. Creating solutions allows a client to optimistically and realistically map out a better life despite any problems.

In addition, de Shazer (1988a, 1991, 1993) also states that a solution must be possible in order to define a problem. Clients need to possess a solution before one develops the idea of a problem. de Shazer gives the example that if " $x$ " were the "problem", one would need to know that the absence of "x" is possible (1993). In 
addition, "facts" need to occur in problem-solving to understand and work through the problem, however, to develop a solution the client nor the therapist need to know any "facts". The key point is that "solution" does not mean the same thing in problem-solving as it does in solution building. In problem-solving, a solution is a resolution to a problem while in solution building it is generating ideas about a better future despite the existence of a problem.

In summary, problem-solving and solution building differ because their goals remain distinct. A solution-focused approach entails the client identifying a solution, obtaining awareness of exceptions to their problems, and possessing hope in the future. SFBT's major assumptions differ from problem-solving because in SFBT the client is the expert and it is not important for the client or the therapist to understand the root of the problem (de Shazer, 1988a). In addition, solution building differs from problem-solving because it is not learning effective responses to certain challenges but focusing on a client's successful efforts towards their goals.

The Components of Problem-solving and Solution Building

Problem-solving components. Heppner and Petersen (1982) labeled problemsolving appraisal possessing the following three components: problem-solving confidence, approach-avoidance style, and personal control. Problem-solving confidence assesses the assurance one has while engaging in problem-solving tasks (e.g., "I make decisions and am happy with them later"). Approach-avoidance style describes how an individual either approaches or avoids problem-solving activities (e.g., "When confronted with a problem, I stop and think about it before deciding on a next step"). Personal control deals with one's perceived level of self control in relationship to their ability to solve problems (e.g., "Sometimes I get so charged up emotionally that I am unable to consider many ways of dealing with my problems").

Solution building components and therapeutic applications. The components of solution building haven't been systematically identified through statistical measures. In an effort to clearly articulate the components of solution building the researcher developed a theoretical framework of the components (see chart on page 9).

The first key component of solution building involves the client clearly identifying the solution. Solution building begins with individuals describing how they 
would like their lives to be different (DeJong \& Berg, 1998). This description is solicited clinically by asking the miracle question. The miracle question allows clients to recognize what their want their life to look like. This is different than problem-solving because a problem may still exist in the "miracle"; it may just have a different place in the client's life (for a description of the miracle question see page 29).

The second key component of solution building entails using the client's present awareness of exceptions to the problem. DeJong and Berg (1998) state that the second step in solution building involves looking for evidence that individuals have already experienced pieces of their desired life. This task is called looking for exceptions. de Shazer (1991) states that exceptions are an antecedent to solutions. Exceptions are an important part of solution building because solutions occur when these positive experiences become the rule (de Shazer, 1988b). When exceptions are the focus, instead of the problem, solution building results (de Shazer, 1991). Thus, having the client recognize times when things are a little bit better (an exception), remains an important component of solution building.

Finally, the third component is the client possessing a hope in the future. Berg and Dolan (2001) identify the essence of the SFBT approach as "the pragmatics of hope and respect"(p.1). In addition, they emphasize that SFBT claims that the future remains both negotiable and created. The miracle question again serves as a way to instill a hope for the future by suggesting that tomorrow exists and is negotiable. This preliminary outline of the components of solution building will serve to inform the research completed in this study. Since the purpose of this study is to identify the factors of solution building, the above components are proposed from theoretical rationale. 


\section{Table 1}

Problem-Solving vs. Solution Building

\begin{tabular}{|c|c|c|c|c|c|}
\hline $\begin{array}{l}\text { Problem- } \\
\text { Solving } \\
\text { Components }\end{array}$ & Definition & $\begin{array}{l}\text { Solution } \\
\text { Building } \\
\text { Components }\end{array}$ & Definition & $\begin{array}{l}\text { Example } \\
\text { Item }\end{array}$ & $\begin{array}{l}\text { Difference } \\
\text { Between } \\
\text { Problem-solving } \\
\text { and Solution } \\
\text { Building } \\
\end{array}$ \\
\hline $\begin{array}{l}\text { Approach- } \\
\text { Avoidance } \\
\text { Style }\end{array}$ & $\begin{array}{l}\text { Whether an } \\
\text { individual } \\
\text { approaches or } \\
\text { avoids } \\
\text { problem- } \\
\text { solving } \\
\text { activities }\end{array}$ & $\begin{array}{l}\text { Identifying } \\
\text { the Solution }\end{array}$ & $\begin{array}{l}\text { The client } \\
\text { identifying } \\
\text { how they } \\
\text { want their } \\
\text { life to be } \\
\text { better } \\
\text { (despite } \\
\text { problems) }\end{array}$ & $\begin{array}{l}\text { "I am better } \\
\text { than most at } \\
\text { knowing what } \\
\text { would make } \\
\text { my life better" }\end{array}$ & $\begin{array}{l}\text { Whether a } \\
\text { person does or } \\
\text { doesn't attempt } \\
\text { to solve } \\
\text { problems } \\
\text { VS. } \\
\text { Creating a } \\
\text { picture of a } \\
\text { person's } \\
\text { solution despite } \\
\text { the existence of } \\
\text { problems }\end{array}$ \\
\hline $\begin{array}{l}\text { Problem- } \\
\text { solving } \\
\text { Confidence }\end{array}$ & $\begin{array}{l}\text { Confidence in } \\
\text { engaging in a } \\
\text { wide range of } \\
\text { problem- } \\
\text { solving } \\
\text { activities }\end{array}$ & $\begin{array}{l}\text { Awareness of } \\
\text { Exceptions }\end{array}$ & $\begin{array}{l}\text { The therapist } \\
\text { helping the } \\
\text { client to see } \\
\text { evidence of } \\
\text { pieces of } \\
\text { their desired } \\
\text { life that } \\
\text { already exist }\end{array}$ & $\begin{array}{l}\text { "There are } \\
\text { times in my } \\
\text { life where I am } \\
\text { able to handle } \\
\text { difficulties } \\
\text { well" }\end{array}$ & $\begin{array}{l}\text { Confidence in } \\
\text { solving } \\
\text { problems } \\
\text { VS. } \\
\text { Displaying } \\
\text { confidence by } \\
\text { realizing that } \\
\text { one is already } \\
\text { doing things to } \\
\text { get closer to } \\
\text { one's desired } \\
\text { life }\end{array}$ \\
\hline $\begin{array}{l}\text { Personal } \\
\text { Control }\end{array}$ & $\begin{array}{l}\text { One's } \\
\text { perceived level } \\
\text { of self control } \\
\text { in relationship } \\
\text { to solving } \\
\text { problems }\end{array}$ & $\begin{array}{l}\text { Hope in the } \\
\text { Future }\end{array}$ & $\begin{array}{l}\text { The therapist } \\
\text { aids the } \\
\text { client in } \\
\text { realizing that } \\
\text { the future is } \\
\text { both } \\
\text { negotiable } \\
\text { and created }\end{array}$ & $\begin{array}{l}\text { "I believe that } \\
\text { my } \\
\text { circumstances } \\
\text { will improve" }\end{array}$ & $\begin{array}{l}\text { Self control in } \\
\text { finding the best } \\
\text { answers to } \\
\text { problems } \\
\text { VS. } \\
\text { A belief that the } \\
\text { future has hope } \\
\text { for solutions } \\
\text { despite one's } \\
\text { problems }\end{array}$ \\
\hline
\end{tabular}

Note. The problem-solving components of the PSI were taken from Heppner, 1988. 


\section{Significance of the Problem}

So why is it important to better understand solution building if problem-solving appraisal remains an established approach? First, not all therapy is problem-focused. de Shazer and colleagues have developed a theory and a preliminary line of research that suggests SFBT exists as a favorable approach, thus, many clinicians use SFBT as their primary mode of treatment. Preliminary research indicates that taking a solution-focused approach has benefits in decreasing depression (Cockburn, Thomas \& Cockburn, 1997), increasing parenting skills (Sundstrom 1993), and increasing psychosocial adjustment in returning to work after orthopedic injuries (Zimmerman, Jacobsen, MacIntyre \& Watson, 1996). Additional studies test the effectiveness of the model (e.g. Littrell, Malia, \& Vanderwood, 1995; Zimmerman, Prest, \& Wetzel, 1997). In the age of evidenced based treatments, it is essential to further measure and test widely used models.

Before further testing of solution building commences, a clear and detailed definition of the concept needs to occur. Although DeJong and Berg (1998) theoretically define the concept of solution building, a systematic description of the factors does not exist. Through the use of statistical analyses, solution building can and should be clearly defined.

In addition to defining solution building, psychotherapy needs an instrument to measure the concept. The development of a solution building instrument would be a brief but helpful account of a client's ability to create solutions. Since no known instruments measure the concept of solution building, the need for a scale is great.

The intent of this study involves the development of a solution building inventory to do the following: a) to systematically define the components of solution building, b) to create an instrument that not only measures solution building but can be used as an intervention in and of itself (to create more optimism and hope about life issues), and c) to create an opportunity for the solution building inventory to be paired with other measures in clinical outcome studies. After twenty years of clinical use, solution building needs clearly defined components and an instrument to measure them. The development of the SBI fulfills both of these needs. 


\section{Research Question}

The researcher attempts to answer one major question. The main research question for the present study asks "What is solution building and how can it be measured?"

The objectives of this project are:

1. To ascertain if there are distinct components of solution building.

2. To create a solution-building scale based on identified components a. to create a scale that can be used in the future as an intervention in itself (to create more optimism and hope about life issues

b. to create a scale that can be used in the future as a clinical outcome measure 


\section{CHAPTER II}

\section{Review of the Literature}

The following chapter will review the literature on problem-solving and solution building. An exploration of the problem-solving literature, as well as the development and testing of the problem-solving inventory (PSI), will occur. Since solution building is the main principle of solution-focused brief therapy (SFBT), an examination of the SFBT literature and research will also occur.

Overview of the Problem-Solving Literature

History. Heppner, Witty, and Dixon (2004) extensively overview the history of the process of problem-solving appraisal. They begin by describing the roots of problemsolving going back to Dewey's influential book on the subject (1933). By the 1950s and 1960s, impersonal laboratory problems were used to examine problem-solving strategies (Wickelgren, 1974). The first applied problem-solving research focused on psychological adjustment when Spivack and Shure (1974) examined how individuals problem solve in interpersonal situations. These interpersonal situations included alternative solution thinking, problem sensitivity, means-end thinking, and causal thinking. Results found a positive correlation between solving hypothetical problem-solving, developing better solutions, and enhanced psychological adjustment (Shure, 1982).

Other early problem-solving research viewed the process in stages. D'Zurilla and Goldfried (1971) developed a five stage model consisting of the following stages: general orientation, problem definition and formulation, generation of alternatives, decision making, and verification. By breaking problem-solving into categories, researchers could study specific problem-solving activities.

The association between stress and problem-solving was made during the 1970s. Initial research suggested that the greater the stress the greater psychological and physical results (Holmer \& Rahe, 1967). Research in the 1980s found that stress was not necessarily the primary factor for negative outcomes but individual differences seemed to play a larger factor (e.g., Kobasa, 1979). Lazarus and Folkman (1984) stress that the essential connection between problem-solving and stress lies in each individual and their environment. Thus, although stress is a factor it needs to be contextualized. 
Anderson's (1983) advances in information processing triggered the use of nonlinear and dynamic models in applied problem-solving (Heppner \& Krauskopf, 1987). Other concepts such as problem resolution (e.g., Heppner, Cook, Wright, \& Johnson, 1995; Heppner, Cooper, Mulholland, \& Wei, 2001) and enhancement of problem-solving training and models (e.g., Nezu, Nezu, Friedman, Faddis, \& Houts, 1998) occurred in the 1990s.

Psychotherapy has been conceptualized in recent decades as a way to aid clients in solving stressful problems (e.g. Fretz, 1981; D. N. Dixon \& Glover, 1984). Research indicates that effective psychotherapy is not just problem resolution but increasing one's problem-solving abilities (Heppner, Cooper, et al., 2001; M. J. Heppner et al., in press). Thus, problem-solving appraisal plays a significant role in psychotherapy.

During the rise of the cognitive revolution, investigators were interested in how individuals appraise their abilities (e.g., Antonovsky, 1979; Bandura, 1982). In 1986, Bandura published his work which provided evidence that self-efficacy affects behavior, motivation, thoughts, and emotional reactions to intense situations. Butler and Meichenbaum (1981) integrated metacognitive factors into the problem-solving literature by stating a focus on higher order variables affecting problem-solving. They also theorized that an individual's problem-solving appraisal might be a key factor in the problem-solving process. By the late 1970s and early 1980s, researchers realized that cognitive appraisals of one's problem-solving skills may be a vital piece of how individuals face the challenges of life (Heppner, Witty \& Dixon, 2004).

In addition to Heppner \& Peterson's (1982) efforts to assess problem-solving appraisal researchers have also used other strategies for measuring applied problemsolving (Butler \& Meichenbaum, 1981; Heppner \& Wang, 2003). The social problemsolving inventory (D'Zurilla \& Nezu, 2003) was developed to assess problem-solving attitudes and skills through self report. Another scale called the problem focused style of coping examines verbal reports of problem-solving practices that help or inhibit problem resolution (Heppner, Cook et al., 1995). The problem-solving inventory (PSI) is the only measure of problem-solving appraisal and is the most widely used inventory for applied problem-solving (Nezu et al., 1989). 
Recent research suggests that a positive correlation exists between client's focusing on their problems and positive therapeutic outcomes (Orlinsky, Grawe \& Parks, 1994). In a review by Heppner, Witty, and Dixon (2004) a person's positive problemsolving appraisal is associated with the following: positive self-concepts, higher levels of self-efficacy/assertiveness/personal agency, and low levels of social uneasiness, worry, depression, anxiety, hopelessness, suicidal ideation, and irrational beliefs. These findings suggest a growing body of research indicating the usefulness of problem-solving appraisal.

Theoretical tenets of problem-solving appraisal. Within the broad category of cognitive theory, person-environment models served as the initial theoretical basis for problem-solving appraisal first introduced by Dohrenwend and Dohrenwend (1978). This approach looks at the balance between a person's resources and the demands of the environment (e.g., D’Zurilla, 1986; Fisher, 1986; Heppner \& Krauskopf, 1987; Lazarus, DeLongis, Folkman, \& Gruen, 1985; Lazarus \& Folkman, 1984). This framework believes that the perceived resources of a person in a time of need are important to their ability to respond to a stressor.

Before the development of the PSI, however, Heppner and Petersen (1982) theoretical three problem-solving factors that fit within social learning theory. These factors are problem-solving confidence, approach-avoidance style, and personal control. Problem-solving appraisal was now thought of as a personal resource variable (Heppner \& Lee, 2002), and more specifically, a set of beliefs about one's problem-solving skills (Heppner, 1988). According to Heppner, problem-solving appraisal is seen as a general appraisal of one's problem-solving type as opposed to how one will deal with a specific stressful situation. Over 20 years of research on problem-solving appraisal, using the PSI, shows that perceived effective problem solvers possess better psychological and physical health, better coping effectiveness, and better vocational adjustment (Heppner, Witty \& Dixon, 2004).

\section{Problem-Solving Inventory}

Development of the PSI. The Problem-Solving Inventory (PSI) was first developed in 1982 by Heppner and Petersen. Although research on problem-solving existed long before the development of the PSI (Davis, 1966; Gagne, 1964; Maier, 1970; 
Newell, Shaw \& Simon, 1958) a way to measure and aid clients with decision making and problem-solving skills had not been developed. One instrument called the MeansEnds Problem-solving Procedure (MEPS) had been developed but only measured certain aspects of the problem-solving process (Platt \& Spivack, 1975). Heppner and Petersen aimed at developing a measure that would capture the aspects of problem-solving that could be used to help clients in a clinical setting.

Earlier writings had theoretized that the problem-solving process possessed several stages (Clarke, Gelatt, \& Levine, 1965; Dewey, 1933; D’Zurilla \& Goldfried, 1971; Goldfried \& Goldfried, 1975; Urban \& Ford, 1971). The five theoretical stages were: general orientation, problem definition, generation of alternatives, decision making, and evaluation. General orientation refers to one's general attitude when facing a problem. Problem definition and formulation occurs when an everyday problem presents itself and one needs to clearly define various aspects of the situation into concrete terms. Brainstorming, or generating alternatives, is the next step that aids in the likelihood of producing quality solutions (D'Zurilla and Goldfreid). Decision making is seen as evaluating the goodness of a particular course of action. Finally, evaluation or verification occurs after a solution has been generated in order for an individual to evaluate how effective the problem was resolved (Goldfried \& Goldfried).

Since no research had been done to examine the dimensions of problem-solving, it was unclear whether problem-solving actually involved stages or specific principles that cut across stages. The purpose of Heppner and Petersen's (1982) study was to identify through factor analysis the dimensions underlying the personal problem-solving process.

The initial development of the PSI was done with four groups of undergraduate students. The initial sample consisted of 150 undergraduate students in general psychology. Two instruments were given to measure the participants' problem-solving skills and one's internal locus of control. This group received the PSI, the Level of Problem-solving Skills Estimate Form (LPSSEF), and the Rotter Internal-External Locus of Control scale. Entrance exam scores on the School and College Ability Test (SCAT), the Missouri College English Test, and the Missouri Mathematics Placement Test (MMPT) were collected from all participants. The SCAT and the MMPT were given to 
measure intelligence and mathematical skills. A second sample of 62 undergraduates enrolled in general psychology was also used. This sample was given the PSI, LPSSEF, Social Desirability Scale, Myers-Briggs Type Indicator (MBTI), Means-Ends Problemsolving procedure, and the Unusual Uses Activity (UUA) from the Torrance Test of Creative Thinking. The second sample received measures of social approval, personality, interpersonal skills, and creative thinking in an attempt to determine how these factors related to the concept of problem-solving. Thirty one members of the second group were asked to return in two weeks to retake just the PSI. The fourth sample consisted of 18 participants who signed up to take a problem-solving workshop. They were given only the PSI.

The initial version of the PSI was made up of 35 items (see Table 1). A 6-point Likert-type format was used ( $1=$ strongly agree to $6=$ strongly disagree). The authors created the items as face valid measures of the five problem-solving stages. A panel of experts was not used to develop the items. Low scores indicated traits associated with successful problem-solving. After completing a factor analysis, the number of items dropped from 35 to 32 . A principle-component factor analysis yielded 10 factors. Using a scree test, the 10 factors were reduced to three. The first factor was called "problemsolving confidence" and consisted of 11 items. This factor is defined as self-assurance while doing problem-solving tasks and a belief in one's problem-solving abilities. The second factor was "approach-avoidance style" and consisted of 16 items. Approachavoidance style is defined as a general tendency to avoid or approach problem-solving tasks. Lastly, "personal control" was the third factor that possessed 5 items. Personal control is a belief that one is in control of one's behaviors and emotions while problemsolving (Larson, Piersel, Imao \& Allen, 1990).

Reliability and validity of the PSI. A reliability coefficient was calculated for each factor along with the entire measure (Heppner \& Petersen, 1982). The following are the reliabilities for the three factors: problem-solving confidence $\alpha=.85$; approachavoidance style $\alpha=.84$; and personal control $\alpha=.72$. The reliability for the entire PSI was $\alpha=.90$. The test-retest reliabilities were the following: problem-solving confidence $r=.85$; approach-avoidance style $r=.88$; personal control $r=.83$; and the total PSI $r=$ .89 . 
Construct and concurrent validity were established in several ways (Heppner \& Petersen, 1982). First, each factor score, along with the total PSI score, was correlated with the LPSSEF. All correlations were statistically significant in the expected direction. Next, each factor's score and the total PSI scores were correlated with the SCAT, the MMPT, and the subject's high school rank to test discriminant validity. No significant correlations were found suggesting that the PSI is not correlated to intelligence measures or academic achievement. Correlations between the total PSI, as well as each factor score, and the Rotter Internal-External Locus of Control, the UUA, and the MBTI were all statistically significant. The final measure of validity was produced from the fourth sample $(n=18)$ who had taken a problem-solving training course. The posttests of the group that received training were compared to the posttests of a control sample. Those that took the problem-solving training did significantly better (lower scores) on the PSI than the control group.

Factor analysis indicated that at least three dimensions of perceived problemsolving existed. These factors were identified as confidence in one's problem-solving abilities, personal control, and approach-avoidance style. The results on the reliability and validity of the PSI indicate that the measure is both internally consistent and stable over time as well as constant across similar participants.

Research on the PSI. Heppner, Witty, and Dixon (2004) state that between 1982 and 2002 more than 120 studies have been done on the PSI. A vast number of variables have been tested using the PSI. Several studies point out that ineffective problem-solving results in maladjustment (Bulter \& Meichenbaum, 1981; D'Zurilla \& Goldfried, 1971; Heppner \& Krauskopf, 1987; Heppner \& Lee, 2002; Mechanic, 1968, 1970; Spivack \& Shure, 1974). A brief review of the literature on PSI will be discussed in this section.

Studies done examining how problem-solving effects irrational beliefs and dysfunctional thoughts show that insufficient problem-solving skills contributes to these psychological processes (Heppner, Hibel, Neal, Weinstein, \& Rabinowitz, 1982; Heppner, Kampa, \& Brunning, 1987). In addition, the frequency of personal problems increases when individuals possesses ineffective problem-solving abilities (Harrison, 1994; Heppner, Baumgardner, \& Jackson, 1985; Heppner, et al., 1982; Nezu, 1985; Nezu $\&$ Ronan, 1985). Resolution of grief is another area that is challenged by ineffective 
problem-solving skills (Reid \& Dixon, 2000). Perceived ineffective problem solvers also report that they possess social uneasiness (DeClue, 1983; Heppner, et al., 1982; Larson, Allen, Imao, \& Piersel, 1993; Sabourin, Laporte, \& Wright, 1990) and fewer social skills (Elliott, Godshall, Herrick, Witty, \& Spruell, 1991; Larson, 1984). Thus, ineffective problem-solving abilities correlate with unwanted psychological consequences.

Besides using the PSI to examine psychological adjustment, the PSI has been researched on the following main areas: physical health, coping, and educational and vocational issues (Heppner, Witty \& Dixon, 2004). Thirteen studies have been conducted testing how problem-solving appraisal relates with physical health complaints, health complications, and physical limitations. Within the eight studies examining problem-solving appraisal and physical complaints and health promotion, all found that more health complaints were associated with negative problem-solving appraisal. (Felton, Liu, Parsons, \& Geslani, 1998). One study done on physical health complications found that a person's willingness to approach problems predicted better health outcomes (Herrick, Elliott, \& Crow, 1994). The remaining four health studies found that problemsolving appraisal was the best predictor community integration of brain injured individuals (Rath et al, 2000, 2003; Rabin, 2001). Overall, this research suggests a link between one's perceived ability to solve problems and fewer health problems.

Some researchers question how problem-solving in a laboratory setting compares with problem-solving in real life situations (Wickelgren, 1974). Thus, nine studies have been completed looking at the differences. While two studies did not find differences when examining the environment of problem-solving (Heppner \& Petersen, 1982; Moss, 1983) three studies did find a difference (Davey, 1994; Nezu \& Ronan, 1988; Sarmany \& Sladekova, 1990) and four more studies found complicated findings (Baumgardner et al., 1986; Larson, Potenza, Wennstedt, \& Sailors, 1995; Larson \& Sailors, 1997; Mayo \& Tanaka-Matsumi, 1996). The majority of studies done on laboratory settings found that a relationship exists between problem-solving appraisal and reactions to hypothetical problems.

Research on coping illustrates that 10 studies found an association between coping and positive problem-solving appraisal and coping (e.g. Corcoran, 1991; Heppner, 
Cook, et al., 1995). Numerous studies on coping behaviors indicate differences in cognitive processes of those who perceive themselves as effective problem-solvers versus those that believe they are ineffective problem-solvers (e.g. Heppner et al, 1988). Again, an association between coping and problem-solving appraisal seems to exist.

The PSI has shown a relationship between educational level and problem-solving appraisal (e.g. Felton, Parsons, Bartoces, 1997; Neal, 1983). Neal found that individuals with higher levels of education possessed more positive problem-solving appraisal. Nine additional studies found that problem-solving appraisal was not significantly related to intelligence and academic ability (e.g., DeClue, 1983) but is correlated with age, test anxiety, and education level (e.g., Blankstein, Flett, \& Batten, 1989). In addition, thirteen studies show that problem-solving appraisal relates to career planning and decision making (e.g., Holland, 1973).

In general, the vast body of literature on problem-solving appraisal finds a relationship between problem-solving appraisal and problem-solving effectiveness. In addition, problem-solving appraisal has been correlated with increased functioning in psychological adjustment, coping, and education. Limitations and further research on problem-solving appraisal will be discussed.

Limitations of the PSI. Since the PSI measures one's problem-solving appraisal, it is important to look at the relationship between self appraisal and actual problem-solving. Several studies indicate that one's score on the PSI does not necessarily produce valid measure of one's actual problem-solving abilities (Corcoran, 1991; Larson \& Heppner, 1989; Larson, Potenza, Wennstedt, \& Sailors, 1995; Nezu, Nezu, Perri, 1989). The rationale for differences in appraisal and ability may be explained, at least partly, by personality characteristics that may alter problem-solving outcomes (see Heppner \& Krauskopf, 1987). Larson et al. (1995) were the first to study the relationship between problem-solving appraisal and performance. The study found that there is not always a relationship between appraisal and performance. Research indicates that problem-solving appraisal may reflect the skill of problem-solving, but an individual's PSI score may not effectively represent effective problem-solving (Heppner, Witty \& Dixon, 2004).

Gender influences. Research has shown that females are more interpersonally interconnected than males (Gilligan, 1982; Jordan, Kaplan, Miller, Stiver, \& Surrey, 
1991). This interconnectedness can play a role in one's perception of problem-solving abilities. Research on problem-solving also shows gender differences (D'Zurilla, Maydeu-Olivares, \& Kant, 1998; Heppner, Cook, Strozier, \& Heppner, 1991; Marcotte, Alain, Gosselin, 1999; Sabourin, Laporte, \& Wright, 1990) although a majority of the research reports an absence of difference between males and females on the PSI (Heppner, Witty, \& Dixon, 2004).

Religious and spiritual factors. Contextual factors may make it difficult to measure problem-solving abilities exclusively through quantitative data (Suzuki \& Ahluwalia, 2004). Factors such as religion and spirituality may affect one's problemsolving appraisal. One's religious beliefs may play a major role in problem-solving and should be studied. Suzuki and Ahluwali state that the PSI research fails to address issues of religion and spirituality. In addition, Heppner, Witty, and Dixon state that there is a lack of research on socio-economic status.

Ethnic differences in problem-solving. Heppner, Witty, and Dixon (2004) report only one study that deals with the issue of racial identity in problem-solving appraisal (i.e., Neville, Heppner, \& Wang, 1997). The results from that study show a complex relationship between problem-solving and racial identity. Suzuki and Ahluwalia (2004) state that in some cultures, like Asian, decision making is done collectively and not independently. This suggests that problem-solving could also be done as a group instead of independently. In addition, individuals in Asian cultures may rate themselves as inadequate problem solvers due to their cultural influences of being humble (Kim, Atkinson, \& Umemoto, 2001). Since little research on the PSI takes into account cultural identities, trying to measure individual problem-solving abilities may be clouded by cultural issues. The development of culturally sensitive instruments and models of problem solving is needed.

\section{Future Research}

Heppner, Witty, and Dixon (2004) give a long list of future research ideas for the PSI. A brief synopsis of the ideas will be presented. First, a recommendation to use qualitative methods to determine the relationship between problem-solving appraisal and performance was suggested. This might be useful to better understand differences between appraisal and performance. In addition, they find the need to study how one's 
problem-solving appraisal develops through life. For example, does one's problemsolving ability come from having a great number of positive and negative problemsolving experiences? Finally, Heppner, Witty, and Dixon acknowledged the limiting aspects of the current research on the PSI. These aspects include problem-solving appraisal versus performance, gender issues, contextual factors, and ethnic differences. These limitations of the PSI were discussed in the previous section.

\section{Solution-Focused Brief Therapy}

Solution-focused brief therapy (SFBT) emerged in the early 1980s and is based on the work of Steve de Shazer and Insoo Kim Berg. de Shazer and Berg, along with associates of the Brief Family Therapy Center in Milwaukee, developed this new approach to therapy. SFBT is derived from the work of the Mental Research Institute (Watzlawick, Weakland, \& Fisch, 1974) in addition to the influence of Milton Erikson (Zeig, 1985). SFBT allows clients to focus on their solutions instead of their problems.

Theoretically, solution-focused theory is based on a systemic perspective (de Shazer, 1988a). SFBT is also considered to be a systemic because it views patterns of interaction as circular, not linear (de Shazer, 1991). Since SFBT is a systemic model, it values the interactions clients maintain with others.

de Shazer, Berg, Lipchik, Nunally, Molnar, and Gingerich et al. (1986) describe the underlying principle of SFBT as "utilizing what clients bring with them to help them meet their needs in such a way that they can make satisfactory lives for themselves" ( $p$. 208). In essence, therapists aid clients in developing a clear vision of what their life would look like if things were better. This approach focuses on how things will be once the solution occurs.

\section{Philosophical Stance}

Post-structuralism. Structualists believe that the meaning of words lies behind or within a person, a system, etc. (Chomsky, 1968; 1980). Poststructuralists, on the other hand, believe that meaning of language is constructed through the interaction of people (Harland, 1987). Poststructuralists view the world and social context as created by language through words (de Shazer, 1994) and further that meaning occurs through negotiation within a particular context (de Shazer, 1991; de Shazer, \& Berg, 1992; Harland, 1987). For example, a structuralist would say that there is one true meaning for 
the word depression. A poststructuralist would say that one can never truly understand the meaning of depression but that meaning can be negotiated through interaction.

SFBT is rooted in poststructural thought (de Shazer, 1994). Solutions are created by an individual and the meaning is unique to each person. Problem-solving is rooted from a structuralist perspective because problem solvers are looking for an underlining meaning of a problem in order to solve it. In problem-solving, a solution is defined as something that solves a problem. In solution building, a solution is anything that makes life better. The solution is not necessarily related to the problem in solution building (de Shazer, 1988a).

From a poststructural perspective, solutions are a product of what the problem/complaint is not (de Shazer, 1994). Since poststructualists believe that the meaning of a problem is never truly discovered, it is more meaningful to talk about what the problem isn't. For example, asking a client to state what depression isn't is more helpful and useful than defining depression. Problem-solving looks at understanding the root of depression where solution building looks at what one's life would look like without depression.

Change. According to SFBT change is not just probable, but continually happening (de Shazer, 1985). de Shazer further states that therapeutic change occurs as an interactional process. Therapy allows for the therapist and client to co-construct a new and beneficial framework for facing the future (Coyne, 1985). As new ways of thinking about one's problem arise, through solution building, change occurs. When considering the purpose of therapy and how change occurs, it is important to remember the basic rules of SFBT. Berg (1994) lists the following rules:

“1. If it ain't broke, don't fix it (originally stated by Bert Lance, 1977).

2. Once you know what works, do more of it.

3. If it doesn't work, don't do it again; do something different" (p.15-16). Using these guidelines to facilitate change, SFBT attempts to offer clients helpful tools for creating solutions.

Change through solution building is different from problem-solving because a problem doesn't have to be solved in order for a solution to exist. For example, a father still may possess the problem of being in jail but has a solution of having a better 
relationship with his family. Change occurs in solution building when things are better (even slightly better) despite the presence of a problem.

Tenets of SFBT

Solution-focused therapy is considered to possess a positive outlook (Walter \& Peller, 1992). Since SFBT aims to promote a future oriented perspective, hope and optimism are generated. In addition, by helping clients focus on their solutions, the negativity of being problem centered is reduced. When clients are encouraged to focus on their solutions, they begin to gain hope and a positive outlook on their future.

Not only does SFBT maintain an optimistic perspective, but also it empowers clients by treating them with respect. The therapist's cooperation with the client serves as an important tenet of SFBT (de Shazer, 1982). The role of the therapist is to take a not-knowing stance in order to value the thoughts and perceptions of the client. As the therapist and client work together, not against one another, during therapy they co-create solutions.

Theoretically, in order for therapy to be considered solution-focused, certain criteria should be included. Assessing for pre-session change, goal setting, usage of scaling questions, usage of the miracle question, searching for exceptions, taking a consulting break, and giving compliments serve as common interventions used in SFBT (de Shazer \& Berg, 1997). Solution building is an overarching concept of SFBT that can be achieved through these specific interventions in a therapeutic setting.

\section{Exemplary Interventions}

Miracle question. In order to aid clients in creating solutions, an important aspect of SFBT lies in the therapist asking their client the "miracle question." The following is one version of the miracle question suggested by De Jong and Berg (1998):

Now, I want to ask you a strange question. Suppose that while you are sleeping tonight and the entire house is quiet, a miracle happens. The miracle is that the problem, which brought you here, is solved. However, because you are sleeping, you don't know that the miracle has happened. So, when you wake up tomorrow morning, what will be different that will tell you a miracle has happened and the problem which brought you here is solved? (pp.77-78). 
The miracle question is a creative way in which clients can articulate what they would like their life to look like in the absence of their problem. Pichot and Dolan (2003) stress several importances of the miracle question. First, they recognize the importance of having a client picture their world in which their problem is solved. Previewing the benefits of change along with instilling hope that change can actually occur serve as additional benefits. In addition, they suggest that by allowing the clients to create their own version of what life would be like in the absence of their problem the therapist can avoid taking an expert stance. Through the process of having clients create their ideal way of being, they are able to envision the specific aspects of their goal. By having the therapist aid their client in identifying small, observable, and tangible behaviors the client will be able to acknowledge little steps towards their miracle (de Shazer, 1985). Helping the client recognize even small steps instills optimism and hope that will encourage the client to make more strides towards their miracle. One part of solution building is having individuals identify what they want their lives to look like.

Exception questions. Exception questions allow clients to identify and acknowledge times in which their problem does not exist or is not as severe. By pointing out the times when there is a reduction or absence of the problem, the client can begin to gain hope that their miracle will occur. According to de Shazer (1991), exceptions are described as "precursors to goals. .. and solutions"(p. 90). When exceptions are identified, the client begins to focus more on their goals than dwelling on their problem. Individuals can begin to build solutions when they recognize the fact that they are already making steps to where they want to be.

Coping questions. When clients tend to concentrate on their problems, one method of maintaining a solution-focused approach lies in the use of coping questions. Coping questions allow clients to discuss how they are able to cope with their problems (Berg, 1994). "How were you able to keep things from getting worse?" serves as an example of a coping question. The intent of the coping questions lies in their ability to indirectly reframe the client's perception to suggest that they do have some control over their problem by how they react (Berg, 1994).

Scaling question. In order for clients to identify where they currently stand, scaling questions are asked. During this process, clients are asked to rank their goal or 
situation on a 1-to-10 scale (Berg, 1994). "On a scale of 1 to 10, 10 being that you have reached your goal and 1 being that you are very far from your goal, where would you rate yourself on this scale?" is one example of asking clients to scale their goal. By asking clients to rank themselves, both the therapist and client are able to keep track of any progress achieved.

Not only do therapists ask clients to scale their goals, but also other areas of interest can be ranked. Motivation, confidence, and importance are other areas that can be scaled (Berg \& Reuss, 1997). Although various types of scaling questions exist, the main intent is to monitor the progress of the client. Scaling allows for one's progress of solution building to be tracked in therapy.

\section{Problem-solving vs. Solution Building}

Solution building. In the beginning of SFBT, de Shazer, Berg, and associates focused on problems. During the 1980s, however, a shift occurred in their work that led to a focus on solutions (de Shazer, 1985; de Shazer, Berg, Lipchik, Nunnaly, Molnar, Gingerich, et al., 1986). This shift arose initially out of their "formula first session task" which asked clients to observe what occurred between the $1^{\text {st }}$ and $2^{\text {nd }}$ session that they wanted to continue to happen (Molnar \& de Shazer, 1987). A shift towards focusing on solutions occurred as a result of client progress and thus the development of solutionfocused brief therapy (SFBT) arose.

de Shazer (1988a) and his team at the Brief Family Therapy Center (BFTC) began to focus on how clients wanted their lives to be better. Their purpose for focusing on solutions lay in the reality that clients have a clearer picture of what they want things to look like when the problem is vague or hard to define. By focusing exclusively on solutions, the BFTC created a new dichotomy of the problem/solution distinction. Although it may appear that solution building is the same as taking a cognitive behavioral approach, de Shazer (1993) talks about solutions differently than cognitive behavioralists. Solution building is different because to create a solution you have to know how things would be better. Knowing what one's life would look like if the problem was eliminated or decreased is an essential piece. In addition, one has to imagine and believe how life could be better in spite of a problem/hardship. In solution building the goal is not necessarily to get rid of a problem (because in some cases that is not 
possible) but to generate ideas about how things could be better in the future. In problemsolving, solutions are mere logical answers to a question. Problem-solving is a linear process (problem = solution) where solution building is not linear because the solution is not always directly related to the problem (de Shazer, 1988a). de Shazer (1991) also states that patterns of interaction should be viewed as circular not linear. The key point is that "solution" does not mean the same thing in problem-solving as it does in solution building.

Another important piece to solution building is that a solution must be present prior to defining a problem (de Shazer, 1988, 1991, 1993). One needs to have a solution before one has the idea of a problem. He gives the example that if " $x$ " were the "problem", one would need to know that the absence of " $x$ " is possible (de Shazer, 1993). A problem is only a problem because the absence of the problem is possible. For example, individuals face negative circumstances everyday but do not necessarily consider them all problems. In order for it to be a problem, the individual realizes that it is possible and feasible for the problem to be resolved. This does not mean that all problems can be solved but that there is the hope that the problem can be eliminated.

In addition, "facts" are needed in problem-solving to understand and work through the problem, however, to develop a solution one does not need to know any "facts" (de Shazer, 1993). In order to solve a problem one must know information about the problem to solve it. Solution building does not require understanding the origin of the problem. This makes a solution building approach very attractive because most of the time individuals can not know all of the information needed to effectively problem solve.

One's solutions do not need to be directly connected to one's problems (de Shazer, 1988a). For example, if a client presents a problem with alcohol, their solution may include getting a hobby, spending more time with their family, or exercising more often. The solution can, but does not necessarily, include other behaviors that may result in drinking less. If an individual spends more time with their family they may drink less. This solution is not directly related to the stated problem.

The tactics needed for solution building differ greatly from problem-solving (DeJong and Berg, 1998). Although both seem to be cognitively similar, the specific thought processes differ. Instead of concentrating on the components of the problem, 
SFBT encourages clients to focus on the future by describing how they would like their life to be. In addition, solution building requires searching for evidence when pieces of a client's desired life have already occurred. This is called focusing on an exception. Berg (1994) states that "It is also easier to repeat already successful behavior patterns than it is to try and stop or change existing problematic behavior."'(p.10) Berg goes on to say that teaching a new skill is more difficult than repeating a successful method. Thus, highlighting exceptions allows an individual to feel confident about future change because they have already made steps towards their goal. Gingerich and de Shazer (1991) state that constructing solutions "automatically" decreases the presence of the problem without using problem-solving techniques. Solutions are constructed by aiding the client in increasing the amount of times they do something that is an exception to the problem. For example, if a client states that they always fight with their spouse a therapist can help the client create solutions by having them increase the amount of times that they have meaningful conversations with their partner. This is a shift from problem-solving because the focus is on what the client is currently doing well instead of developing a new way to deal with the current problem. Thus, solution building allows the client to build on the effective things they are already doing where problem-solving merely attempts to answer a particular question.

Key components. Throughout the problem-solving literature, an attempt has been made to define the factors of problem-solving. Problem-solving appraisal has been identified as problem-solving confidence, approach-avoidance style, and personal control (Heppner \& Petersen, 1982). These factors emerged when the Problem-solving Inventory was developed. By identifying the clear components of problem-solving, scholars have been able to use these in defining the term problem-solving. In an effort to clearly define and articulate the concept of solution building, discovering its factors seems essential. Prior to statistical analyses, a theoretical framework of the components has been developed by the researcher. The following are theoretical factors of solution building derived from the solution building literature.

Identifying the solution. One main factor of solution building seems to be individuals' awareness of what they want their lives to look like. This component is identifying the solution. One must begin my stating how they would like their lives to be 
different. Solution building begins with individuals describing how they would like their lives to be different (DeJong \& Berg, 1998). This is different than identifying a solution in problem-solving. In problem-solving, a solution is an answer or a means to eliminate a problem. Identifying a solution in solution building is having a person state how their life can be better even despite the existence of a problem. For example, a person may state that their problem is that they have cancer. Taking a problem-solving approach may mean taking steps to fight the cancer. This can be a helpful approach unless the cancer is terminal. By using a solution building approach, the individual will first be asked how things might be better despite having cancer. The individual may state that if they had a better relationship with their sister things might be better. By identifying the solution, an individual is asked to imagine how things might be better even in the midst of dying.

This component of identifying the solution usually occurs by asking the miracle question. As previously described, the miracle question allows individuals to recognize what they want their life to look like if a miracle occurred. For example, asking an individual with cancer how things might look different is used in solution focused brief therapy to identifying the client's solution. The miracle question is a therapeutic technique that allows the therapist to aid the client in identifying the solution.

Awareness of exceptions. The next factor of solution building seems to be one's present awareness of exceptions. DeJong and Berg (1998) state that the second step in solution building involves looking for evidence when individuals have already experienced pieces of their desired life. This is called looking for exceptions. Although DeJong and Berg do not lay out the components of solution building they do identify awareness of exceptions as an essential piece. de Shazer (1991) states that exceptions are an antecedent to solutions. In essence, a solution is comprised of exceptions. Thus, exceptions are at the core of solution building because solutions emerge when the exceptions become the rule (de Shazer, 1988b). For example, if an individual becomes aware of the fact that they exercise and spend time with their family instead of using substances on the weekend, they can use these "weekend exceptions" throughout the week. If an individual's goal is to not use substances during the week they can use their weekend behavior during the week to obtain their solution. When exceptions become the focus, instead of problems, solution building can occur (de Shazer, 1991). Being able to 
recognize that there are times when things are a little better (an exception) is an important component of solution building.

Hope in the future. Finally, it seems as though possessing a hope in the future is an essential factor in solution building. Berg and Dolan (2001) state that the one phrase that captures the essence of the SFBT approach it would be "the pragmatics of hope and respect."(p.1) In addition, they emphasize that SFBT believes that the future is both negotiable and created. For example, since the future is the only period of time that has not occurred, its course is negotiable. An individual can change the future, not the past. By simply asking the miracle question implies that tomorrow exists. It also implies that an individual can have a different future based upon the changes that they want to make. This preliminary outline of the components of solution building will serve to inform the research completed in this study.

\section{Solution-Focused Brief Therapy Research}

de Shazer (1985) conducted the first official study on SFBT by asking clients after treatment to measure whether they had met their goals for therapy or whether significant progress occurred. Clients were given a survey at 6-18 months following treatment. Twenty eight clients responded with an 82\% success report. In his 1986 study, de Shazer et al. had 400 clients respond with a 72\% success rate. Several clinicians outside of the original group of SFBT developers have also done follow-up studies on SFBT (Lee, 1997; Macdonald, 1997; Morrison, Olivos, Dominguez, Gomez, \& Lena, 1993; Schorr, 1997). In addition, Schorr used a pre-post test design using the State-Trait Anger Inventory as an outcome measure and found that, after 8 sessions, the percentage of clients in the clinical range dropped from $67 \%$ to $40 \%$. Despite the fact that these initial follow-up studies showed promise for SFBT, their lack of experimental control prohibits making causal inferences about treatment.

Gingerich and Eisengart (2000) wrote an article overviewing all SFBT controlled studies completed through 1999. The criteria that they used for their review included the following: studies had to have some degree of experimental control and had to include one or more of the 7 SFBT tenets. Their results found 15 controlled studies on SFBT. A review of these studies will be explored. The review will be broken down into three categories: well-controlled, moderately controlled, and poorly-controlled. 
Well-controlled studies. Sundstrom (1993) compared a single session of SFBT to a single session of Interpersonal Psychotherapy for Depression (IPT). Both treatment conditions had significant positive change in depression but one was not significantly better than the other. One possible problem with this study was that the sample size was only 20 clients per group. This small sample made it difficult to conclude that the treatments were uniquely different. Sundstrom's study did find that SFBT was effective in significantly reducing depression, but was unable to suggest that SFBT faired better than the control group.

A similar study done by Zimmerman, Jacobsen, MacIntyre, and Watson (1996) compared SFBT in a parenting group to a control group. Pre and post-test data were collected on the Parenting Skills Inventory and the Family Strengths Assessments. The SFBT group did significantly better on the Parenting Skills Inventory compared to the control group but did not do significantly better than the control group on the Family Strengths Assessments. Post-test scores on the Family Strengths Assessments were significantly different than the pre-test scores in the SFBT group but were not significantly different from the control group's post-test scores.

Another well-controlled study was done by Cockburn, Thomas, and Cockburn (1997). This study compared the use of SFBT and the standard rehabilitation program treatment for patients with orthopedic injuries. The experimental group received SFBT plus the standard rehab program. The control group only received the standard rehab program. Subjects were given 3 outcome measures and the participants' return to work data were also collected. The results showed a significant difference between groups on 2 out of the 3 outcome measures, showing that SFBT was better than the standard rehab program. By 30 days post-treatment, $92 \%$ of the SFBT individuals returned to work compared to only $47 \%$ of the control group's members which was statistically significant.

A studied completed on recidivism in the prison population was completed by Lindforss and Magnusson (1997). At twelve months after treatment, the SFBT group had a 53\% recidivism rate compared to the control group which had a 76\% recidivism rate. An additional finding was that the SFBT group also had less severe offenses and a shorter length of punishment than the control group. 
Seagram's (1997) study was done looking at SFBT's effects on adolescent offenders. This study found at a 6 -month follow-up $20 \%$ of the SFBT group and $42 \%$ of the control group had re-offended. However, overall the SFBT outcomes appeared modest.

Moderately-controlled studies. A post-test only design by Littrell, Malia, and Vanderwood (1995) conducted a study looking at how a single session of SFBT can aid in alleviating academic and personal concerns in high school students. Two control groups and the treatment group were used. Results showed that all 3 groups had statistically significant improvements in their post test but no significant differences between treatment effects were found.

LaFountain and Garner (1996) used SF groups to treat school age children and counselors. The treatment group used SFBT for 8 weekly group sessions. The control group did not receive counseling; they were only administered pre and post tests. Moderately significant results showed that students in the experimental group had the following traits compared to the control group: more positive attitudes about themselves, higher self-esteem, and more appropriate ways to cope with emotions. Despite the reporting that SFBT was helpful, it is hard to say whether the findings were a result of the intervention or not.

A pilot study examined how SF training for mental health supervisors impacted client outcomes (Triantafillou, 1997). The experimental group consisted of 5 children in a residential facility who were treated by a team that had been trained in SFBT. The control group consisted of 7 residential children and a team of supervisors that were not trained in SFBT. Random assignment was not used in this study. The outcome measures were frequency of serious incidents and clients' use of psychotropic drugs. After treatment, both groups of children showed equilivant outcomes. However, at a 16 week follow-up, the SFBT group decreased their number of serious incidences by $65.5 \%$ where as the control group decreased by $10 \%$.

SFBT has also been studied to determine its effectiveness with couples. Zimmerman, Prest, and Wetzel (1997) tested the effectiveness of SFBT on improving marital satisfaction for couples. The experiment consisted of 10 couples with marital discord. The control group consisted of 13 couples who did not classify themselves as 
dissatisfied with their marriage. Both groups were given the Dyadic Adjustment Scale (DAS) and the Marital Status Inventory (MSI) at pretest. At the end of treatment, the experimental groups' posttest scores on the DAS were in the same range as the control groups' pretest scores on the DAS. This type of comparison still leaves room for confounding error.

Poorly-controlled studies. Gingerich and Eisengart (2000) list six studies that are poorly controlled. All six studies (Eakes, Walsh, Markowksi, Cain, \& Swanson, 1997; Franklin, Corcoran, Nowicki, \& Streeter, 1997; Geil, 1998; Lambert, Okiishi, Finch, \& Johnson, 1998; Polk, 1996; Sundman, 1997) found that SFBT is helpful but due to the fact that they were poorly controlled it is hard to postulate that the findings were valid.

Additional research. A few additional studies have been completed since 1999 on SFBT (Guterman, Mecias, \& Ainbinder, 2005; Franklin, Biever, Moore, Clemons, \& Scamardo, 2001; Lee, Uken, \& Sebold, 2004; Nelson \& Kelley, 2001). In addition, a pilot study comparing SFBT with psychoeducational group treatment for level-one substance abusers found that the SFBT group did statistically significantly better from pretest to posttest on the Outcome Questionnaire and the Beck Depression Inventory where the control group did not do significantly better on either measure when looking at pretest and posttest scores (Smock, Trepper, Wetchler, Ray, Pierce, \& McCollum, 2005). Smock (2004) also found that, when clients are given problem focused intake forms, they list more problems then when they are given solution-focused intake forms. These are just a few examples of recent research conducted on SFBT. It is evident that the desire to increase the amount of research on SFBT is prevalent in the literature. However, no published study has identified the key components of solution building.

\section{Additional Measures of Solution Building Concepts}

Hope. Although not a great deal of research has been completed on SFBT, concepts within the SF approach have been studied. Hope has been stated as an essential piece of SFBT (Berg \& Dolan, 2001). Lopez, Snyderk, and Teramoto-Pedrotti define hope as "goal directed thinking in which people perceive that they can produce routes to desired goals (pathway thinking) and the requisite motivation to use those routes (agency thinking) (2003, p. 94). Pathway thinking involves being able to generate effective and workable avenues to reach one's goals. Agency thinking refers to one's perception of 
their ability to follow the course leading to their goal (Snyder, Harris, Anderson, Holleran, Irving, et al., 1991; Snyder \& Taylor, 2000). These factors of hope illustrate key pieces to solution building. Thus, there is an important place for comparing research on hope to SFBT.

Several scales exist measuring the concept of hope (Erickson, Post, \& Paige, 1975; Herth, 1991; Snyder et al., 1991; Staats \& Stassen, 1985). For the current study, the Dispositional Hope Scale (DHS) was selected to measure the concept of hope due to its internal reliability and its construct validity. The DHS will be compared to the SBI because hope is an essential part of solution building.

Future. Another important concept of solution building is its future focus. Pichot and Dolan (2003) state that the most important tenet in SFBT is "The future is both created and negotiable" (p.13). The future focus of SFBT makes it uniquely different from cognitive behavioral tasks like problem-solving.

In an effort to explore the future focus in solution building, the Life Orientation Test Revised (LOT-R) was used in the present study. The LOT-R measures individual's expectations concerning the favorability of future effects (Carver \& Scheier, 2003). This instrument looks at the following domains: a) an individual's pursuit of a goal and b) an individual's confidence in reaching their desired goal. The LOT-R focuses on measuring the degree of optimism, or pessimism, one possesses about the future. Thus, the LOT-R was used in the present study to ensure validity of the SBI.

Scale development remains a growing area within psychology and other related disciplines. From 1989 to 1994 1,726 articles were published containing the key words "test construction" or "scale development" in the PsycLIT database (Clark \& Watson, 1995). As of December 2005, 14,117 published articles were displayed in the PsycINFO database with "test construction" or "scale development" as key words. Thus, developing inventories is a major area of research.

\section{General Scale Development}

Clark and Watson (1995) provide a comprehensive outline for quality scale construction taken from Loevinger's (1957) work. Loevinger's work remains the most thorough discussion of theoretically-based scale development. The present study was informed by Loevinger's monograph. 
Clark and Watson (1995) summarize the following areas of scale development: creating substantive validity, structural validity, and external validity. Substantive validity involves developing a theoretical context for the construct being measured by defining the construct as well as basing it in the literature. Structural validity involves conducting some type of internal consistency analysis. External validity involves continuous refinement of the developed scale. A further discussion of these areas of scale development will be covered below.

Substantive validity. Clark and Watson (1995) define substantive validity as the conceptualization and development of an initial item pool. Developing a detailed description of the construct being measured is the first step in item pool creation. The researcher must clearly outline the theoretical context at this stage. Clark and Watson recommend writing a brief outline of the construct being measured, and state that it is important to explore the theoretical issues prior to scale construction to increase the likelihood of the scale's contribution to the literature. To this end, chapter one of the current study outlines the components of solution building. A table is also provided for clarification (see Table 1).

A thorough review of the literature ensures that the researcher is not developing a measure that already exists. For example, creating a measure on hope would not be useful if several reliable hope inventories exist. The researcher reviewed the literature on solution focused theory and research. A summary of the literature on SFBT included in chapter two of this study shows that a solution building measure does not currently exist.

The creation of an item pool is another step in the process of scale development. Items must carefully and clearly be written to ensure content validity (Clark \& Watson, 1995). Loevinger (1957) states "The items of the pool should be chosen so as to sample all possible contents which might comprise the putative trait according to all known alternative theories of the trait" (p.659). The researcher used a group of experts on SFBT to aid in the development of the items. This rating occurred to assure that various perspectives of solution building would be included in the initial item pool.

Clark and Watson also emphasize the importance of writing clear items for the item pool. As previously mentioned, the present study used a group of experts in SFBT to provide input for the initial item pool. Experts were asked to rate the initial pool of items 
in two separate waves of data analyses described below. This was done to ensure that the items used in the pilot test of the SBI were as theoretically sound as possible.

Choosing a format (Likert, true-false, etc.) is another step in the process of scale development. Comrey (1988) discourages the use of dichotomous responses and states that multiple-response formats are more reliable and stable and generate better scales. On the other hand, allowing too many options for each item can reduce the validity for that item (Clark \& Watson, 1995). The current study used a Likert format because the SBI attempts to measure the degree of solution building.

Structural validity. Structural validity is defined as item selection and psychometric evaluation of an instrument (Clark \& Watson, 1995). While several methods are used to select items in scale development, the most widely used is some form of internal consistency analysis. Factor analysis is used mainly when a concept is multidimensionally defined. Although subscales are general created in these cases, factor analysis is not always the method for determining factors. A combination of rational and internal consistency analyses can be used to develop factors (Clark \& Watson). The current study used factor analysis to examine the items in the SBI to determine the components of solution building. In addition, a theoretical rationale modified the identified factors.

An initial pilot sample of 100-200 participants is adequate for scale development (Clark \& Watson). After the initial pilot data are collected, the instrument should be tested with at least 300 participants due to issues of stability and replicability of structural analyses (Guadagnoli \& Velicer, 1988). The present study had 97 participants in the initial wave of data collection and 302 participants in the second wave.

While internal consistency is an important aspect of a good measure, Clark and Watson (1995) argue that possessing a strong alpha does not ensure that a scale is unidimensional. Several scale developers state that conducting a factor analysis of the items is a must (Briggs \& Cheek, 1986; Comrey, 1988; Cortina, 1993; Floyd \& Widaman, 1995). Since factor analysis requires a minimum of 200-300 participants (Comrey, 1988; Cuadagnoli \& Velicer, 1988), many test developers are hesitant to use this analysis. As previously mentioned, the present study had 302 participants in the second wave of data collection alone and conducted factor analytic analyses of the SBI. 
External validity. Clark and Watson (1995) describe establishing external validity as an ongoing process. The role of external validity in scale development is how a scale can be generalized to a larger population. If the SBI can be tested in various populations then it possesses good external validity. As a developer refines their scale the measure becomes stronger. Through the refinement and retesting an instrument in various populations, the external validity can improve. The present study is an initial attempt to define and measure the concept of solution building. 


\section{CHAPTER III}

\section{Methodology}

\section{Scale Format}

Prior to data collection, the researcher developed a list of questions loosely following the problem-solving inventory (PSI), modified based on the solution-oriented framework (see table 2). Then, the researcher asked experts of the solution-focused brief therapy association (SFBTA) to participate in rating the items. Experts are considered to be individuals who have been trained directly by the founders of SFBT (Steve de Shazer and Insoo Kim Berg) and who are members of the SFBTA founder's group. These experts were academicians and/or clinical trainers of SFBT. Eight experts agreed and rated the items provided by the researcher. The experts rated 61 items on a Likert scale from 1 to $5(1=$ strongly does not measure solution building, $3=$ neutral, and $5=$ strongly measures solution building) to measure content validity. Experts were also asked to revise or add items.

The researcher examined the ratings for each item. Twenty two items were retained and thirty nine were deleted. The researcher evaluated the mean score for each item. Items with a mean of 4.43 or greater containing no ratings lower than a 3 were kept (22 items). This cutoff was determined by the researcher to be a natural breaking point. Since the experts provided a list of 18 additional items to add to the second rating, the researcher did not want to retain a large number of the original items to be reconsidered. The researcher did not want to retain items that received any ratings lower than a 3 (neutral) so items with ratings of 3 or above were considered in the cutoff. The researcher did not think that items receiving a "neutral" rating would be strong measures of solution building. The researcher also used the 4.43 mean cutoff because there were enough, but not too many, items that also met this criteria. So, retaining items with a mean score of 4.43 or greater containing no ratings lower than a 3 provided enough items, but not too many items, to be included with the new suggested items for the second rating.

The compiled questions were then given back to the experts for a final rating, with 40 items in all. This time the experts were asked to rate all of the items on a scale from 1 to 7 ( 1 = strongly does not measure the concept of solution building, $4=$ neutral, and $7=$ strongly measures solution building) and were not given the opportunity to 
add/change any items. The rationale for using a 7 point Likert scale for round two was to allow for more variance in the item ratings. Seven out of the eight original raters completed the second rating. The researcher computed means for each item and found that there was not a clear cutoff in mean scores (not a great deal of variability). Means ranged from 5.0 to 6.67 with no clear division. Thus, the researcher decided to use items that received scores of 5 or above and excluded any items that received ratings of neutral or below. The rationale for only using items that did not receive ratings of neutral or below was because the researcher wanted the SBI to be approximately 20 items in length (not 40 items). Twenty two of the forty items met this criteria. This concluded the rating of items that occurred prior to data collection.

\section{Sample Recruitment}

To test the preliminary version of the solution-building inventory (SBI), a sample was obtained from the undergraduate student body from Virginia Polytechnic Institute and State University. After IRB approval was obtained, the researcher invited instructors to allow their students to participate in an online survey (see Appendix A). The researcher sent emails to all Department of Human Development instructors inviting them to allow their students to participate (see Appendix B). As a result, the researcher was invited to visit several classes to recruit students. In addition, the researcher contacted the Psychology Department at Virginia Tech and uploaded a link to the survey on the SONA research system. SONA is Virginia Tech's psychology department's experiment management system. Psychology students can log into this system and participate in various research experiments for extra credit points.

Participants were undergraduate students attending Virginia Tech during the fall of 2005. Participants consisted of males and females and were not limited to any specific demographic criteria. The sample size for the pilot test of the SBI was 97 participants. An additional 302 participants were used for the second wave of data collection. These sample sizes were recommended from Clark and Watson (1995). Students participating in the first wave of data were not allowed to participate in the second round of data collection. In addition, the online survey prevented participants from taking the survey more than once. 
The use of undergraduates seems to be an acceptable population for developing the SBI. Several problem-focused inventories were developed by using the general population for their sample (D'Zurilla \& Nezu, 1990; Heppner, Cook, Wright \& Johnson, 1995; Heppner, Cooper, Mulholland, \& Wei, 2001). Outcome measures like the Outcome Questionnaire used both the general population and a clinical population in its development (Lambert, Burlingame, Umphress, Hansen, Vermeersch, Clouse, et al., 1998). Other psychological measures like the Beck Depression Inventory (Beck, Ward, Mendelson, Mock, \& Erbaugh, 1961) are used to diagnose individuals in a clinical population and use a clinical sample. However, since the solution-building inventory, similar to the PSI, was developed to measure non-clinical issues (i.e. how to build solutions), it seems reasonable that for the purposes of scale development a non-clinical sample is appropriate.

\section{Data Collection}

The survey was administered via Virginia Tech's web-based survey tool. Seven willing instructors, teaching classes ranging from 30-250 students, gave their students the URL for the survey. In addition, hundreds students in the Psychology Department had access to the survey through the SONA research system. Once participants logged on to the website survey.vt.edu, they were asked to check a box agreeing to the conditions of the study. This served as their electronic signature for informed consent. The survey then asked participants who wanted extra credit from their instructors to provide their name and their instructor's name (the majority of the instructors allowed their students to receive extra credit points). The researcher received a list of participant names and instructor's names once the survey was closed for data collection. The researcher emailed instructors once both waves of data were completed with a list of participant names in their class. The instructor did not receive the participants' scores and the participants' names were not saved in the data set. The online survey tracked participants by their Virginia Tech personal identification username (PID) and did not allow the same individuals to participate more than once. In addition, the researcher and her committee members had access to the data but participants' names were not listed in the data set.

After electronically signing the informed consent, the participants were asked to rate each item. The first questionnaire consisted of demographic questions and the SBI. 
The SBI consisted of twenty two items. Participants were given instructions to respond to each item on a Likert scale ( $5=$ strongly agree, $4=$ agree, $3=$ neutral, $2=$ disagree, $1=$ strongly disagree). In addition to the items for the solution building inventory, a few demographic questions were asked (see table 3). These items were used to further understand how demographic factors relate to solution building skills.

Ninety seven participants completed the initial wave of data collection. Reliabilities were run and a factor analysis was preformed after the initial wave of data was collected and it was determined to maintain the original twenty two items for the second round of data collection. The results will be provided in chapter 4 .

After the initial wave of data were collected, additional undergraduate students were invited in the same manner to complete another online questionnaire (the same students did not take the survey during wave two of collection). Items on the second questionnaire consisted of items from the first survey as well as the Dispositional Hope Scale and the Life Orientation Test Revised. An additional wave of data was collected in order to increase the stability and replicability of structural analyses (see Guadagnoli \& Velicer, 1988). Additional measures were added to test the validity of the SBI items.

\section{Additional Measures}

Dispositional hope scale. In order to compare the SBI to hope, the Dispositional Hope Scale (DHS) was chosen because solution building seems to possess an aspect of hope. This self report measure contains 12-items and allows participants to rate each item on a four point Likert scale ( $1=$ definitely false and $4=$ definitely true) (Snyder, Harris, Anderson, Holleran, Irving, Sigmon, et al., 1991). Agency and pathways are the two factors reflected in the DHS (see chapter two for more details on the DHS). There are four items that measure each component along with four distracters. Items one, four, six, and eight measure the concept of pathway where items two, nine, ten, and twelve measure agency. Scores on the DHS range from 8 to 32 . Higher scores indicate greater dispositional hope.

Cronbach's alpha for the DHS ranges from .74 to .84 (Lopez, Snyder, \& Teramoto-Pedrotti, 2003). Test re-test reliability ranges .80 and greater for time periods of 3 to 10 weeks (Snyder, 1995). 
Life orientation test revised (LOT-R). In addition to comparing the SBI to a hope scale, the Life Orientation Test Revised (LOT-R) was used to assess individual's expectations concerning the probability of future outcomes (Carver \& Scheier, 2003). The two domains of the LOT-R are an individual's goal pursuit and their confidence or doubt concerning reaching a desirable goal. The LOT-R was chosen to compare to the SBI because solution building correlates with goal setting and the confidence to attain goals. The LOT-R is a 10 item self report measure. Four of the ten items are distracters and three of the six scored items should be reverse-coded. Items are answered on a 5point Likert score $(1=\mathrm{I}$ agree a lot to $5=\mathrm{I}$ disagree a lot). There are no subscales for the LOT-R. The Cronbach's alpha ranges from high .70s to low .80s (Carver \& Scheier, 2003).

\section{Statistical Analysis}

An exploratory factor analysis was conducted on the first wave of data to explore the factors reflected by the inventory. The principle component extraction method in exploratory factor analysis was used due to the assumption that no unique variance exists, resulting in the error part of the factor model disappearing (Maruyama, 1998). In addition, a varimax rotation was specified in order to sum the variances of the loadings to create the maximum possible solution. This rotation yields results making it as easy as possible to identify each variable with a single factor. A varimax rotation is the most common option in exploratory factor analysis. Since many factors were found (8), theoretical judgement was used to reduce the number of factors to 3 . The theoretical constructs developed in table 1 were used as a rationale for which items fell within a certain factor. A factor analysis was conducted collapsing the 8 factors into the 3 theoretical ones. In addition, a reliability analysis of the sub-scales was conducted using SPSS software.

Then, a confirmatory factor analysis was run in LISREL on the data driven model as well as on the theoretical model. Since the reliability of the entire measure was sufficient (.839) the original twenty two items comprised the SBI for wave two.

The same analyses were preformed on the second wave of data for the SBI. Additional analyses examined the relationship of the SBI to the DHS and the LOT-R. 


\title{
CHAPTER IV
}

\author{
Results
}

\section{Scale Development}

As described in chapter three, scale development is widely practiced in the field of psychotherapy. The use of theory in scale development is paramount. Identifying distinctions, dependencies, and relations of the target term is an essential part of scale development (Dawis, 1987). This chapter describes the steps and results of constructing the SBI.

Prior to data collection, the researcher developed a list of questions loosely following the problem-solving inventory (see Heppner \& Petersen, 1982), modified based on the solution-oriented framework (Appendix C). Then, the researcher asked experts of the solution-focused brief therapy to participate in rating the items. Seven of 18 experts agreed to rate the items provided by the researcher. The experts rated 61 items on a Likert scale from 1 to 5 ( $1=$ strongly does not measure solution building, $3=$ neutral, and $5=$ strongly measures solution building) to measure content validity. Experts were also asked to revise or add items based on their clinical and theoretical expertise.

The researcher examined the ratings for each item. Twenty two items were retained, all eighteen of the new items were added from the raters' suggestions, and thirty nine were deleted after evaluating the mean rating scores. The means of all of the items ranged from 2.71 to 4.86 (Table 2). Items with a mean of 4.43 or greater containing no ratings lower than a 3 were retained ( 22 items). This cutoff was determined by the researcher to be a natural breaking point. The researcher wanted to keep a manageable amount of items so items with ratings of 3 or above were considered in the cutoff. The researcher also used the 4.43 mean cutoff because there were enough, but not too many, items meeting this criteria. 
Table 2

Original Items Evaluated for the SBI

\begin{tabular}{|c|c|c|}
\hline & $M$ & Range \\
\hline I am able to cope well with difficult life circumstances & 4.57 & 1 \\
\hline I am able to generate solutions & 4.57 & 1 \\
\hline I am confident in my ability to generate solutions & 4.57 & 1 \\
\hline I am able to make good choices & 4.29 & 2 \\
\hline I am able to create solutions & 4.14 & 4 \\
\hline There are times when problems are absent from my life & 4.0 & 4 \\
\hline I have the ability to focus on what I want to occur in my life & 4.71 & 1 \\
\hline $\begin{array}{l}\text { There are times in my life where I am able to handle } \\
\text { difficulties well }\end{array}$ & 4.71 & 1 \\
\hline I have hope for the future & 4.28 & 1 \\
\hline I know where I would like to see myself 1 year from now & 4.0 & 2 \\
\hline I am able to set goals & 4.0 & 2 \\
\hline I am able to accomplish goals & 4.71 & 1 \\
\hline It is helpful to focus on my future & 4.71 & 1 \\
\hline The future is important to me & 4.57 & 1 \\
\hline It is important to focus on solutions & 4.57 & 1 \\
\hline $\begin{array}{l}\text { I believe that it is more important to focus on solutions rather } \\
\text { than problems }\end{array}$ & 4.71 & 1 \\
\hline $\begin{array}{l}\text { In difficult life situations I have a hard time focusing on } \\
\text { solutions }\end{array}$ & 2.71 & 3 \\
\hline I am better than most at knowing what would make life better & 3.86 & 2 \\
\hline Things are going fairly well right now & 3.29 & 3 \\
\hline $\begin{array}{l}\text { If I woke up tomorrow and a miracle happened in my life I } \\
\text { would be able to notice differences in myself and others }\end{array}$ & 4.71 & 1 \\
\hline $\begin{array}{l}\text { I would know things had improved in my life if my } \\
\text { friends/family noticed the changes }\end{array}$ & 4.57 & 1 \\
\hline There are times when my problems are not as obvious & 3.14 & 4 \\
\hline
\end{tabular}


There have been times this week when I expected a problem

to exist and it didn't (even a small absence)

I often make plans for the future

I believe I will enjoy my future

better

Hope is important

Even in hard times, I have hope that things can improve

I am aware of small positive changes that I make

\section{different}

There are times when I am really proud of how I am able to

handle difficult situations

I am better than most people at feeling hopeful about the

future

I am confident in the future

I am confident in my ability to overcome everyday challenges

I am a hopeful person

I have successfully overcome challenges in the past

I have been able to cope with life's challenges

My life can improve

I am able to acknowledge my accomplishments

I have made many accomplishments in my life

I am confident that I can overcome future obstacles in my life

I know how to make difficult situations better

I know what my life would look like if it were better 


\begin{tabular}{lcc}
\hline The future looks bright & 3.0 & 3 \\
I know what I want in life & 4.43 & 2 \\
I know how to get what I want in life & 4.29 & 1 \\
I have been able to get what I want in life & 4.0 & 3 \\
I believe that in the future I will know what I want from life & 3.89 & 3 \\
Life can be great despite problems & 3.89 & 3 \\
I have the ability to make my future better & 4.0 & 3 \\
I am able to deal with challenges & 4.14 & 3 \\
My life is better today than it has been in the past & 3.57 & 2 \\
I know when my life is better & 3.71 & 3 \\
I have made steps towards improving my life & 4.43 & 2 \\
I know what makes me happy & 4.0 & 2 \\
I have overcome many life challenges & 4.43 & 2 \\
\hline
\end{tabular}

The compiled questions were returned to the experts for a final rating. Forty items included the eighteen new items from the raters (Appendix D). During this phase the experts were asked to rate all of the items on a Likert scale from 1 to 7 (1= strongly does not measure the concept of solution building, $4=$ neutral, and $7=$ strongly measures solution building). They were not given the opportunity to add/change any items. To allow for more variance in item ratings, a 7 point Likert scale was used. Six out of the seven original raters completed the second rating. The researcher computed means for each item and found that there was not a clear cutoff in mean scores. Means ranged from 5.0 to 6.67 with no clear division (Table 3). Thus, the researcher decided to use items that received ratings of 5 or above and excluded any items that received ratings of neutral (4) or below. The researcher desires the SBI to be approximately 20 items in length (not 40 items). This length is more suitable in clinical settings. Twenty two of the forty items met this criterion (Appendix E). This concluded the rating of items that occurred prior to data collection. 
Table 3

Second Group of Items Rated for the SBI

\begin{tabular}{|c|c|c|}
\hline Items & $M$ & Range \\
\hline I am able to cope well with difficult life circumstances & 6.33 & 2 \\
\hline I am able to generate solutions & 6.33 & 1 \\
\hline I am confident in my ability to generate solutions & 6.0 & 3 \\
\hline I have the ability to focus on what I want to occur in my life & 6.33 & 1 \\
\hline $\begin{array}{l}\text { There are times in my life where I am able to handle } \\
\text { difficulties well }\end{array}$ & 6.17 & 2 \\
\hline I am able to accomplish goals & 5.67 & 3 \\
\hline It is helpful to focus on my future & 6.17 & 3 \\
\hline The future is important to me & 5.83 & 3 \\
\hline It is important to focus on solutions & 6.33 & 2 \\
\hline I believe that it is more important to focus & 6.17 & 2 \\
\hline If I woke up tomorrow and a miracle happened in my life & 6.67 & 2 \\
\hline $\begin{array}{l}\text { I would know things had improved in my life if my } \\
\text { friends/family noticed the changes }\end{array}$ & 6.33 & 3 \\
\hline I am aware of small positive changes that I make & 5.83 & 2 \\
\hline $\begin{array}{l}\text { I have a clear picture of how I would like my life to be } \\
\text { different }\end{array}$ & 5.5 & 3 \\
\hline $\begin{array}{l}\text { There are times when I am really proud of how I am able to } \\
\text { handle difficult situations }\end{array}$ & 5.5 & 1 \\
\hline I am a hopeful person & 5.5 & 3 \\
\hline I have successfully overcome challenges in the past & 6.67 & 1 \\
\hline I have been able to cope with life's challenges & 6.0 & 2 \\
\hline I know what my life would look like if it were better & 5.67 & 3 \\
\hline I know what I want in life & 5.0 & 2 \\
\hline I have made steps towards improving my life & 6.33 & 2 \\
\hline I have overcome many life challenges & 5.83 & 3 \\
\hline I am able to break goals into smaller steps & 5.0 & 4 \\
\hline I have confidence in my ability to take steps toward goals & 5.5 & 3 \\
\hline
\end{tabular}


I can think of times when my problems are less

5.83

5

overwhelming

I can recognize in others when things may be going better for

5.67

2

me

I can think of times when I have been able to solve problems

5.0

5

I can think about things that have made a positive difference

6.17

2

for me

I can recognize small steps as important even though they are

6.33

2 small

I can recognize things that I can do, even though it seems that

5.67

2

the problem is someone else

I have confidence in my ability to make small changes

$5.5 \quad 3$

I am able to notice good things in myself, others, and my

6.172

situation

I am able to focus on times when my situation is not so

6.17

2

overwhelming, even a little bit

I am able to see good thing in my situation, even though parts

5.83

2

of it seem very difficult

I am able to give myself pats on the back sometimes

$5.5 \quad 3$

I am able to take compliments in a positive way

$5.33 \quad 3$

I am willing to try new things or old things in a different way

6.02

I know that solutions to my problems may not be the same as

5.5

3

others'

I know that some solutions that work for others may not work

5.5

3

for me

Dwelling on my problems may not be the best way to find

6.33

2 solutions 


\section{Scale Pilot Testing - Wave One}

As previously discussed in chapter three, the SBI used an undergraduate sample during both waves of data collection. This section describes the first wave of data collected.

Sample. Frequencies determined the sample characteristics of the ninety seven participants (Appendix F). As shown in Table 4, thirty five percent of the participants were between 18 and 19 years old, while the majority of the participants were between 20 and 21 years old (53.6\%). Ten percent of the participants were between 22 and 23 years of age and one percent were either 24 or 25 years of age.

Table 4

Sample Characteristics

$n \quad \%$

\begin{tabular}{lcc}
\hline Age & 34 & 35.1 \\
18-19 years old & 52 & 53.6 \\
$20-21$ years old & 10 & 10.3 \\
$22-23$ years old & 1 & 1.0 \\
$24-25$ years old & & \\
Ethnicity & 9 & 9.3 \\
African American & 8 & 8.2 \\
Asian & 76 & 78.4 \\
Caucasian & 3 & 3.1 \\
Hispanic & 1 & 1.0 \\
Other & & \\
Marital Status & 51 & 62.6 \\
Single & 38 & 39.2 \\
Boyfriend/Girlfriend & 4 & 4.1 \\
Lives with partner & & 2.1 \\
but not engaged & 2 & 0 \\
Engaged & 0 & \\
Married & & \\
Divorced & & \\
\hline
\end{tabular}


Widowed

Religious Affiliation

Not religious

Somewhat religious

Religious

Very Religious

Spirituality

Not spiritual

Somewhat spiritual

Spiritual

Very Spiritual
21

32

37

7

18

42

26

11
21.6

33.0

38.0

7.2

18.6

26.8

11.3

The majority of the sample categorized themselves as Caucasian $(78.4 \%), 9.3 \%$ as African American, and 8,2\% as Asian. While 3.1\% stated that they were Hispanic, one percent selected the "other" category.

The majority of the sample stated that they were single (62.6\%) (Table 4).

Individuals with a girlfriend or boyfriend ranked in the next highest category (39.2\%). An equal amount or married and engaged participants existed. A little over four percent $(4.1 \%)$ lived with a partner but were not engaged. None reported a previous divorce or loss of spouse.

Table 4 states that thirty eight percent of the individuals were religious where thirty three percent stated that they were somewhat religious. "Not religious" individuals made up $21.6 \%$ of the population. Very religious participants ranked in the lowest category $(7.2 \%)$

The greatest number of participants categorized themselves as somewhat spiritual $(43.3 \%)$ (Table 4). The next group stated that they were spiritual (26.8\%). Not spiritual $(18.6 \%)$ and very spiritual (11.3\%) also participated. 
SBI. Frequencies were also run on the items of the SBI to investigate item distribution (Table 5). Means ranged from 3.72 to 4.34 and the standard deviations ranged from .567 to .864 .

Table 5

Frequencies of the items from the SBI

\begin{tabular}{|c|c|c|c|}
\hline & $M$ & Med. & $S D$ \\
\hline I am able to cope well & 3.74 & 4.0 & .845 \\
\hline I can recognize small steps & 4.01 & 4.0 & .604 \\
\hline I am able to generate solutions & 4.03 & 4.0 & .567 \\
\hline I have the ability to focus & 4.07 & 4.0 & .807 \\
\hline I can think about things that have made & 4.24 & 4.0 & .594 \\
\hline I am able to focus on times when & 3.91 & 4.0 & .682 \\
\hline There are times in my life & 4.19 & 4.0 & .654 \\
\hline It is important to focus on solutions & 4.07 & 4.0 & .700 \\
\hline I believe that it is more important & 3.94 & 4.0 & .864 \\
\hline I am able to notice good things & 4.15 & 4.0 & .781 \\
\hline I have been able to cope with life's challenges & 4.08 & 4.0 & .589 \\
\hline If I woke up tomorrow and a miracle happened & 4.21 & 4.0 & .790 \\
\hline I am aware of small positive & 3.97 & 4.0 & .620 \\
\hline There are times when I am really proud & 4.19 & 4.0 & .755 \\
\hline I have successfully overcome & 4.18 & 4.0 & .613 \\
\hline I have make steps towards & 4.17 & 4.0 & .610 \\
\hline I can think of times when my problems & 4.04 & 4.0 & .720 \\
\hline I can recognize in others when & 3.72 & 4.0 & .736 \\
\hline I am able to see good things in my situation & 3.92 & 4.0 & .702 \\
\hline I am willing to try new things & 4.13 & 4.0 & .772 \\
\hline Dwelling on my problems may not & 4.34 & 4.0 & .665 \\
\hline I can recognize things that I can do & 3.96 & 4.0 & .611 \\
\hline
\end{tabular}


Exploratory factor analysis. An exploratory factor analysis was run in SPSS on the SBI. The principle component extraction method was used due to the assumption that no unique variance exists, resulting in the error part of the factor model disappearing (Maruyama, 1998). In addition, a varimax rotation was specified in order to sum the variances of the loadings to create the maximum possible solution. This rotation yields results making it as easy as possible to identify each variable with a single factor. A varimax rotation is the most common option in exploratory factor analysis. This was done to see how many factors existed in the SBI. Also, the factor analysis was completed to determine the factor structure. Twenty two items loaded on eight factors (Table 6). Items $1,7,10$, and 11 loaded on factor one. Items 4, 5, 15, and 16 loaded on factor two. Items 13, 14, 21, and 22 loaded on factor three. Factor four consisted of items 8, 9, and 19. Items 6, 12, and 18 loaded on factor five. Factor six consisted of items 17 and 20. Finally, the eighth factor consisted of item 2 . These factors make up the data driven model that was tested later in a confirmatory factor analysis.

Table 6

Exploratory Factor Analysis Factor Loadings

\begin{tabular}{lcccccccc}
\hline & Factor & Factor & Factor & Factor & Factor & Factor & Factor & Factor \\
& 1 & 2 & 3 & 4 & 5 & 6 & 7 & 8 \\
\hline I am able to cope well & $\mathrm{X}$ & & & & & & & \\
There are times in my life & $\mathrm{X}$ & & & & & & \\
I am able to notice good & $\mathrm{X}$ & & & & & & \\
things & & & & & & & \\
I have been able to cope & $\mathrm{X}$ & & & & & & \\
with life's challenges & & $\mathrm{X}$ & & & & \\
I have the ability to focus & & $\mathrm{X}$ & & & & \\
I can think about things & & & & & \\
that have made & & $\mathrm{X}$ & & & \\
I have successfully & & $\mathrm{X}$ & & & \\
overcome & & & & & \\
I have make steps & & & & & \\
towards & & & & & & \\
\hline
\end{tabular}


I am aware of small

positive

There are times when I

am really proud

Dwelling on my

problems may not

I can recognize things

that I can do

It is important to focus on

solutions

I believe that it is more

important

I am able to see good

things in my situation

I am able to focus on

times when

If I woke up tomorrow

and a miracle happened

I can recognize in others

when

I can think of times when

my problems

I am willing to try new

things

I am able to generate

solutions

I can recognize small

steps

\section{X}

X

$\mathrm{X}$

X

X

X

X

X

X

X

X

X 
Reliability analysis. A reliability analysis on the SBI measured the internal consistently of the scale. The total reliability for all items of the SBI was $\alpha=.839$. Reliabilities of each factor are shown in Table 7. During the analysis of the total SBI the researcher chose "if item is deleted" to see if the reliability changed if any items were deleted. The reliability did not change significantly if any of the items were deleted. Since the reliability did not change if any items were deleted, the researcher retained all 22 items of the SBI for the second wave of data collection. The reliabilities of each factor were also calculated (Table 7). They ranged from .300 to .767.

Table 7

Reliabilities of Factors

\begin{tabular}{lc}
\hline \multicolumn{1}{c}{ Factors } & $\alpha$ \\
\hline Factor 1 & .767 \\
I am able to cope well & \\
There are times in my life & \\
I am able to notice good things & \\
\hline
\end{tabular}

I have been able to cope with life's challenges

Factor 2

I have the ability to focus

I can think about things that have made

I have successfully overcome

I have make steps towards

Factor 3

I am aware of small positive

There are times when I am really proud

Dwelling on my problems may not

I can recognize things that I can do

Factor 4 .604

It is important to focus on solutions

I believe that it is more important

I am able to see good things in my situation 
Factor 5

.498

I am able to focus on times when

If I woke up tomorrow and a miracle happened

I can recognize in others when

Factor 6

.300

I can think of times when my problems

I am willing to try new things

Factor 7

Only 1 item

I am able to generate solutions

Factor 8

Only 1 item

I can recognize small steps

The researcher collapsed the 8 factors into 3 conceptual factors according to the conceptual table in chapter one to prepare the theoretical model for a confirmatory factor analysis (Table 1). Each of the eight factors were labeled by the researcher according to theoretical rationale. Labels were given to the eight factors to aid in collapsing the model into three theoretical factors. The researcher used the created labels to decide where each data driven factor would fit. Two of the eight factors "implemented positive change" and "miracle question" fit theoretically under the conceptual title "identifying the solution". Factors "serenity", "solution focused", "exceptions", and "small exceptions" fit under the conceptual title "awareness of exceptions". Factors "confidence in coping and "solution generation" fit under the conceptual title "hope in the future".

Table 8 .

Collapsed Factors According to Conceptual Table Identifying the Solution Awareness of Exceptions Hope in the Future

Factor 2 and Factor 5 Items

I have the ability to focus
Factor 3, Factor 4, Factor 6, and

Factor 8

Items 


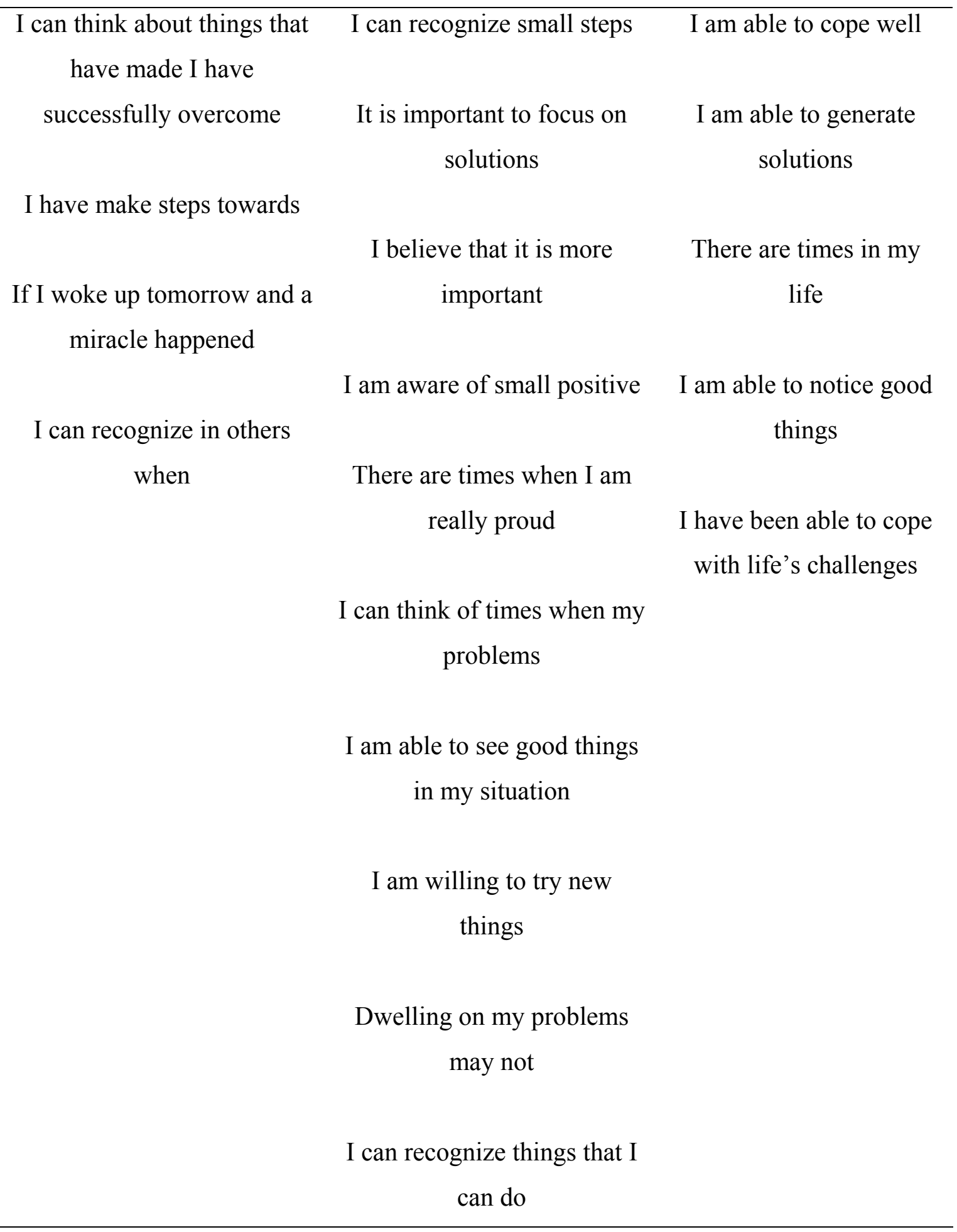

The reliabilities of the collapsed factors are given in Table 9. The reliability for the proposed fact "hope in the future" was .757. The reliability of the factor "awareness of exceptions" was .694. The reliability of the factor "identifying the solution" was .634. 
These reliabilities show that the collapsed factors fall within an acceptable range to be considered reliable (Cronbach, 1951).

Table 9

Reliabilities for the Collapsed Factors

\begin{tabular}{cc}
\hline Collapsed Factor & $\alpha$ \\
\hline Identifying the Solution & .634 \\
Awareness of Exceptions & .694 \\
Hope in the Future & .757 \\
\hline
\end{tabular}

Confirmatory factor analysis. A confirmatory factor analysis was first run on the data driven factors using LISREL software. The purpose of a confirmatory factor analysis is to confirm the data driven factors, which make up the data driven model, from the exploratory factor analysis. A covariance matrix was used in the syntax (Appendix G).

First, model fit was examined using the $\chi^{2}$ statistic. It is desirable for $\chi^{2}$ to be nonsignificant. The $\chi^{2}$ for this model was significant suggesting that the data did not fit the model. A poor model fit means that the suggested factor structure did not work. Additional fit indices also suggested the model was not a good fit for the data, NFI $=.78$ $(>.9)$; $\mathrm{RMR}=.078(<.05) ; \mathrm{RMSEA}=0.059(<.05)$, though RMSEA indices were reasonably acceptable (Raykov \& Marcoulides, 2000).

Since the data did not fit the data driven model, the researcher conducted a second confirmatory factor analysis on the theoretical model (Appendix H). The theoretical model used the collapsed factors given in table 9 to construct the theoretical model. The covariance matrix computed by SPSS appeared in the revised syntax.

The results from the theoretical model suggested a marginal fit, $\chi^{2}=307.16, \mathrm{p}<$ $.00 ; \mathrm{NFI}=.75(>.9) ; \mathrm{RMR}=.04(<.05) ; \mathrm{RMSEA}=.058(<.05)$. Although this model only possessed a marginal fit, it fit better than the original model. Item two was the only item that did not have a significant $t$ value meaning that it did not have a significant correlation with factor two. The researcher removed item two but the model did not improve. Thus, item two was retained and included in the SBI for the second wave of data collection. Scale Verification with Second Sample 
Sample characteristics. Wave two of data was collected in order to increase the stability and replicability of structural analyses (see Guadagnoli \& Velicer, 1988). Three hundred and two subjects participated in the second wave of data collection. Forty three percent of the participants were between 18 and 19 years old (Table 10). The greatest number of participants were between 20 and 21 years old (45\%). Over eight percent of the participants were between 22 and 23 years of age. More than one percent were either 24 or 25 years of age. Wave two of data collection included individuals between 26 and 27 years of age (.3\%) as well as participants 28 years old or older $(1 \%)$. A chi-square test comparing wave one and wave two age demographics found no significant differences in the distributions of participants (see Table 10).

Table 10

Age

\begin{tabular}{lccc}
\hline & Wave 1 & Wave 2 & $\chi^{2}$ \\
& $\%$ & $\%$ & .240 \\
\hline 18-19 years old & 35.1 & 43 & \\
20-21 years old & 53.6 & 45 & \\
22-23 years old & 10.3 & 8.6 & \\
24-25 years old & 1.0 & 1.7 & \\
26-27 years old & 0 & .3 & \\
28 years or more & 0 & 1.0 & \\
\hline
\end{tabular}

The majority of the sample categorized themselves as Caucasian (80.8\%) (Table 11). Six percent of participants identified themselves as African American and four percent were Asian. While over four percent stated being Hispanic, over three percent checked the "other" category. A chi-square comparing wave one and wave two ethnicity demographics found no significant differences (see Table 11). 
Table 11

Ethnicity

\begin{tabular}{lccc}
\hline & Wave 1 & Wave 2 & $\chi^{2}$ \\
& $\%$ & $\%$ & .988 \\
\hline African American & 9.3 & 6.3 & \\
Asian & 8.2 & 4.0 & \\
Caucasian & 78.4 & 80.8 & \\
Hispanic & 3.1 & 4.3 & \\
Other & 1.0 & 3.6 & \\
\hline
\end{tabular}

The majority of the sample stated that they were single (50.5\%) (Table 12). Those that had a girlfriend or boyfriend ranked in the next highest category (44.5\%). Two percent said they were married and one percent were engaged. Less than one percent $(.7 \%)$ lived with a partner but were not engaged or were divorced. None were widowed. A chi-square comparing wave one and wave two marital status demographics found no significant differences in the variable's distribution (Table 12).

Table 12

Marital Status

\begin{tabular}{lccc}
\hline & Wave 1 & Wave 2 & $\chi^{2}$ \\
& $\%$ & $\%$ & .871 \\
\hline Single & 62.6 & 50.5 & \\
Boyfriend/Girlfriend & 39.2 & 44.5 & \\
Lives with partner & 4.1 & .7 & \\
but not engaged & & & \\
Engaged & 2.1 & 2.3 & \\
Married & 2.1 & 1.3 & \\
Divorced & & .7 & \\
Widowed & & & \\
\hline
\end{tabular}

Very religious participants ranked in the lowest category (7.4\%) (Table 13). Almost thirty five percent of the individuals were religious and over forty four percent 
stated that they were somewhat religious. Non religious individuals made up the rest of the population (13.1\%). A chi-square comparing wave one and wave two religious demographics found no significant differences in the variable's distribution (Table 13).

Table 13

Religiosity

\begin{tabular}{lccc}
\hline & Wave 1 & Wave 2 & $\chi^{2}$ \\
& $\%$ & $\%$ & \\
\hline Not religious & 21.6 & 13.1 & .158 \\
Somewhat religious & 33.0 & 44.6 & \\
Religious & 38.0 & 34.9 & \\
Very Religious & 7.2 & 7.4 & \\
\hline
\end{tabular}

The greatest number of participants categorized themselves as somewhat spiritual (43.2\%) (Table 14). The next group stated that they were spiritual (33.9\%). Non spiritual individuals made up thirteen percent and very spiritual participants made up ten percent of the sample. A chi-square comparing wave one and wave two spirituality demographics found no significant differences between the two groups (Table 14).

Table 14

Spirituality

\begin{tabular}{lccc}
\hline & Wave 1 & Wave 2 & $\chi^{2}$ \\
& $\%$ & $\%$ & .333 \\
\hline Not spiritual & 18.6 & 13.0 & \\
Somewhat spiritual & 43.3 & 43.2 & \\
Spiritual & 26.8 & 33.9 & \\
Very Spiritual & 11.3 & 10.0 & \\
\hline
\end{tabular}

Overall, among all of the demographic variables no significant differences existed in category distribution. Thus, it can be concluded that the demographics for the samples were comparable. 
Frequencies. The second wave of data included the SBI as well as the Dispositional Hope Scale and the Life Orientation Test Revised. The SBI was tested in two waves to increase the stability and replicability of structural analyses (see Guadagnoli \& Velicer, 1988). Additional measures were added to test the convergent validity of the SBI items.

Frequencies were run on the items of the SBI from the second wave of data collection (Table 15). This analysis was done to see the distribution of each item. Items' means ranged from 3.64 to 4.31 . The standard deviation of items ranged from .494 to .882 .

Table 15

Frequencies of the SBI for the Second Wave of Data

\begin{tabular}{|c|c|c|c|c|}
\hline & $M$ & Med. & $S D$ & Range \\
\hline I am able to cope well & 3.83 & 4 & .848 & 4 \\
\hline I can recognize small steps & 3.94 & 4 & .779 & 3 \\
\hline $\begin{array}{c}\text { I am able to generate } \\
\text { solutions }\end{array}$ & 3.95 & 4 & .646 & 4 \\
\hline I have the ability to focus & 3.98 & 4 & .780 & 4 \\
\hline $\begin{array}{l}\text { I can think about things } \\
\text { that have made }\end{array}$ & 4.18 & 4 & .725 & 4 \\
\hline $\begin{array}{l}\text { I am able to focus on } \\
\text { times when }\end{array}$ & 3.64 & 4 & .827 & 4 \\
\hline There are times in my life & 4.07 & 4 & .731 & 4 \\
\hline $\begin{array}{c}\text { It is important to focus on } \\
\text { solutions }\end{array}$ & 4.04 & 4 & .764 & 3 \\
\hline $\begin{array}{l}\text { I believe that it is more } \\
\text { important }\end{array}$ & 3.80 & 4 & .965 & 4 \\
\hline $\begin{array}{l}\text { I am able to notice good } \\
\text { things }\end{array}$ & 4.12 & 4 & .783 & 3 \\
\hline $\begin{array}{l}\text { I have been able to cope } \\
\text { with life's challenges }\end{array}$ & 4.07 & 4 & .785 & 4 \\
\hline
\end{tabular}




\begin{tabular}{|c|c|c|c|c|}
\hline $\begin{array}{l}\text { If I woke up tomorrow } \\
\text { and a miracle happened }\end{array}$ & 4.22 & 4 & .755 & 4 \\
\hline $\begin{array}{c}\text { I am aware of small } \\
\text { positive }\end{array}$ & 3.88 & 4 & .779 & 4 \\
\hline $\begin{array}{c}\text { There are times when I am } \\
\text { really proud }\end{array}$ & 4.11 & 4 & .770 & 3 \\
\hline $\begin{array}{l}\text { I have successfully } \\
\text { overcome }\end{array}$ & 4.31 & 4 & .664 & 3 \\
\hline I have make steps towards & 4.16 & 4 & .700 & 4 \\
\hline $\begin{array}{l}\text { I can think of times when } \\
\text { my problems }\end{array}$ & 3.96 & 4 & .741 & 4 \\
\hline $\begin{array}{l}\text { I can recognize in others } \\
\text { when }\end{array}$ & 3.77 & 4 & .760 & 3 \\
\hline $\begin{array}{l}\text { I am able to see good } \\
\text { things in my situation }\end{array}$ & 3.81 & 4 & .829 & 4 \\
\hline $\begin{array}{l}\text { I am willing to try new } \\
\text { things }\end{array}$ & 4.00 & 4 & .858 & 4 \\
\hline $\begin{array}{l}\text { Dwelling on my problems } \\
\text { may not }\end{array}$ & 4.26 & 4 & .764 & 4 \\
\hline $\begin{array}{l}\text { I can recognize things that } \\
\text { I can do }\end{array}$ & 3.85 & 4 & .745 & 4 \\
\hline
\end{tabular}

Frequencies were also run on the Dispositional Hope Scale (DHS; Table 16). Items 3, 5, 7, and 11 are filler items for the DHS. The means ranged from 2.34 to 3.36. The standard deviations ranged from .494 to .882 . 
Table 16

Items in the Dispositional Hope Scale

\begin{tabular}{|c|c|c|c|c|}
\hline & $M$ & Med. & $S D$ & Range \\
\hline $\begin{array}{l}\text { I can think of many ways to get out of a } \\
\text { jam. }\end{array}$ & 3.08 & 3 & .563 & 3 \\
\hline I energetically pursue my goals. & 3.24 & 3 & .607 & 2 \\
\hline I feel tired most of the time. & 2.34 & 2 & .813 & 3 \\
\hline $\begin{array}{l}\text { There are lots of ways around any } \\
\text { problem }\end{array}$ & 3.04 & 3 & .674 & 3 \\
\hline I am easily downed in an argument. & 1.97 & 2 & .823 & 3 \\
\hline $\begin{array}{l}\text { I can think of many ways to get the } \\
\text { things }\end{array}$ & 3.21 & 3 & .652 & 3 \\
\hline I worry about my health. & 2.52 & 3 & .878 & 3 \\
\hline Even when others get discouraged, & 2.98 & 3 & .573 & 3 \\
\hline My past experiences have prepared & 3.36 & 3 & .631 & 3 \\
\hline I've been pretty successful in life. & 3.36 & 3 & .570 & 2 \\
\hline $\begin{array}{l}\text { I usually find myself worrying about } \\
\text { something. }\end{array}$ & 2.81 & 3 & .882 & 3 \\
\hline I meet the goals that I set for myself. & 3.06 & 3 & .494 & 2 \\
\hline
\end{tabular}

Frequencies were also completed on the LOT-R (Table 17). Items 2, 5, 6, and 8 are filler items. Items 3, 7, and 9 are reverse coded. The means ranged from 1.36 to 2.92. The standard deviations ranged from .759 to 1.261 .

Table 17

Items in the Life Orientation Test-Revised

\begin{tabular}{lcccc}
\hline & $M$ & Med. & $S D$ & Range \\
\hline In uncertain times, I usually expect the & 2.71 & 3 & 1.164 & 4 \\
best. & & & & \\
It's easy for me to relax. & 2.75 & 3 & 1.261 & 4 \\
If something can go wrong for me, it & 2.87 & 3 & 1.159 & 4 \\
will. & & & & \\
\hline
\end{tabular}




\begin{tabular}{|c|c|c|c|c|}
\hline I'm always optimistic about my future. & 2.37 & 2 & 1.002 & 4 \\
\hline I enjoy my friends a lot. & 1.36 & 1 & .759 & 4 \\
\hline It's important for me to keep busy. & 2.16 & 2 & 1.041 & 4 \\
\hline I hardly ever expect things to go my & 2.57 & 2 & 1.125 & 4 \\
\hline \multicolumn{5}{|l|}{ way. } \\
\hline I don't get upset too easily. & 2.92 & 3 & 1.259 & 4 \\
\hline $\begin{array}{l}\text { I rarely count on good things happening } \\
\text { to me. }\end{array}$ & 2.4 & 2 & 1.157 & 4 \\
\hline $\begin{array}{l}\text { Overall, I expect more good things to } \\
\text { happen to me than bad. }\end{array}$ & 2.14 & 2 & .995 & 4 \\
\hline
\end{tabular}

Exploratory factor analysis. An exploratory factor analysis was run in SPSS on the SBI for the second wave of data for the purpose of determining the number of existing factors. The principle component extraction method in exploratory factor analysis was used based on the assumption that no unique variance exists, resulting in the error part of the factor model disappearing (Maruyama, 1998). In addition, a varimax rotation was specified in order to sum the variances of the loadings to create the maximum possible solution. This rotation yields results making it as easy as possible to identify each variable with a single factor. A varimax rotation is the most common option in exploratory factor analysis. This analysis was repeated with the second wave of data to see how many factors existed in the SBI with a larger sample. Also, the exploratory factor analysis was completed to find factor loadings. The researcher recruited a larger sample size during the second wave of data collection, as suggested by Clark and David (1995), because sample sizes of 300 are preferred during this stage of scale development. Twenty two items loaded on six factors (Table 18). Although the number of factors reduced from eight to six, six factors was still a large number of factors. An unexpected finding was that the item loadings were inconsistent between waves one and two. In other words, items loaded on different factors during the second wave of data collection. 
Table 18

Exploratory Factor Analysis Factor Loadings for Wave Two

\begin{tabular}{|c|c|c|c|c|c|c|}
\hline & $\begin{array}{c}\text { Factor } \\
1\end{array}$ & $\begin{array}{c}\text { Factor } \\
2\end{array}$ & $\begin{array}{c}\text { Factor } \\
3\end{array}$ & $\begin{array}{c}\text { Factor } \\
4\end{array}$ & $\begin{array}{c}\text { Factor } \\
5\end{array}$ & $\begin{array}{c}\text { Factor } \\
6\end{array}$ \\
\hline I am able to cope well & $\mathrm{X}$ & & & & & \\
\hline I have successfully overcome & $\mathrm{X}$ & & & & & \\
\hline There are times in my life & $\mathrm{X}$ & & & & & \\
\hline $\begin{array}{l}\text { I have been able to cope with } \\
\text { life's challenges }\end{array}$ & $\mathrm{X}$ & & & & & \\
\hline I can recognize small steps & & $\mathrm{X}$ & & & & \\
\hline $\begin{array}{l}\text { I am able to notice good } \\
\text { things }\end{array}$ & & $\mathrm{X}$ & & & & \\
\hline $\begin{array}{l}\text { I can recognize in others } \\
\text { when }\end{array}$ & & $\mathrm{X}$ & & & & \\
\hline $\begin{array}{l}\text { I am able to see good things } \\
\text { in my situation }\end{array}$ & & $\mathrm{X}$ & & & & \\
\hline $\begin{array}{l}\text { I can recognize things that I } \\
\text { can do }\end{array}$ & & $\mathrm{X}$ & & & & \\
\hline I am aware of small positive & & & $\mathrm{X}$ & & & \\
\hline $\begin{array}{l}\text { There are times when I am } \\
\text { really proud }\end{array}$ & & & $\mathrm{X}$ & & & \\
\hline I have make steps towards & & & $\mathrm{X}$ & & & \\
\hline I am willing to try new things & & & $\mathrm{X}$ & & & \\
\hline $\begin{array}{l}\text { Dwelling on my problems } \\
\text { may not }\end{array}$ & & & $\mathrm{X}$ & & & \\
\hline $\begin{array}{l}\text { I am able to generate } \\
\text { solutions }\end{array}$ & & & & $\mathrm{X}$ & & \\
\hline I have the ability to focus & & & & $\mathrm{X}$ & & \\
\hline I can think about things that & & & & $\mathrm{X}$ & & \\
\hline have made & & & & & & \\
\hline
\end{tabular}


I am able to focus on times

when

If I woke up tomorrow and a

miracle happened

I can think of times when my

problems

It is important to focus on

solutions

I believe that it is more

important

\section{$\mathrm{X}$}

\section{X}

$\mathrm{X}$

$\mathrm{X}$

$\mathrm{X}$

$\mathrm{X}$

Reliability analysis. A reliability analysis was conducted on the SBI in SPSS with the second wave of data. The total reliability for the SBI was $\alpha=.886$. This was an increase from the first wave of data $(\alpha=.839)$. During the analysis the researcher chose "if item is deleted" to see if the reliability changed for the scale if any items were deleted. The reliability did not change significantly if any of the items were deleted. This result indicated that all of the 22 items of the SBI should be retained. The reliabilities of each factor were also calculated (Table 19). They ranged from .342 to .810 . Overall, the reliabilities for the entire SBI, as well as for each factor, increased in the second wave of data collection.

Table 19

Reliabilities of Factors for Wave Two

\begin{tabular}{lc}
\multicolumn{1}{c}{ Factors } & $\alpha$ \\
\hline Factor 1 & .810 \\
There are times in my life & \\
I have been able to cope with life's challenges & .717 \\
I have successfully overcome & \\
Factor 2 & \\
I am able to notice good things & \\
I can recognize in others when & \\
I am able to see good things in my situation &
\end{tabular}


I can recognize things that I can do

Factor 3

There are times when I am really proud

I have make steps towards

I am willing to try new things

Dwelling on my problems may not

Factor 4

I have the ability to focus

I can think about things that have made

I am able to focus on times when

Factor 5

I can think of times when my problems

Factor 6

.545

I believe that it is more important

The researcher collapsed the 6 factors into 3 factors according to the conceptual table in chapter one. The researcher used the same factor loadings of the theoretical model from the first wave of data for the confirmatory factor analysis.

In addition, the researcher revised the theoretical model due to the fact that factor loadings from the second exploratory factor analysis differed from those of the first analysis. The researcher used the factor loadings from the initial exploratory factor analysis to inform the new three factor model for a confirmatory factor analysis (Table 20). 
Table 20

Rationale for Item Loadings

\begin{tabular}{|c|c|c|}
\hline $\begin{array}{c}\text { Data driven factor loadings } \\
\text { for wave two }\end{array}$ & SBI Item & $\begin{array}{c}\text { Factor loadings on wave 1's } \\
\text { theoretical model }\end{array}$ \\
\hline 1 & 1 & 3 \\
\hline 1 & 7 & 3 \\
\hline 1 & 11 & 3 \\
\hline 1 & 15 & 1 \\
\hline 2 & 2 & 3 \\
\hline 2 & 10 & 3 \\
\hline 2 & 18 & 1 \\
\hline 2 & 19 & 2 \\
\hline 2 & 22 & 2 \\
\hline 3 & 13 & 2 \\
\hline 3 & 14 & 2 \\
\hline 3 & 16 & 1 \\
\hline 3 & 20 & 2 \\
\hline 3 & 21 & 2 \\
\hline 4 & 3 & 1 \\
\hline 4 & 4 & 1 \\
\hline 4 & 5 & 1 \\
\hline 4 & 6 & 1 \\
\hline 5 & 12 & 1 \\
\hline 5 & 17 & 2 \\
\hline 6 & 8 & 2 \\
\hline 6 & 9 & 2 \\
\hline
\end{tabular}

Table 20 illustrates each item loading from the exploratory factor analysis. In addition, the right hand column shows the factor loadings of the theoretical factor from the first wave of data. The researcher used the factor loadings of the theoretical model to inform which data driven factors would be collapsed into the three theoretical factors. For 
example, items one, seven, eleven, and fifteen of the SBI loaded on factor one during the exploratory factor analysis. Out of these items, seven, eleven, and fifteen loaded on theoretical factor three "hope in the future". Thus, since the majority of items loaded on theoretical factor three the first data driven factor was collapsed into the third theoretical factor. This process was repeated for each data driven factors. The second and fifth data driven factors did not fit neatly into one of the three theoretical factors. In these cases, the researcher looked at each item of the SBI to determine how to collapse these factors into the theoretical model.

Table 21 displays how the six data driven factors were collapsed into the three theoretical factors for the confirmatory factor analysis. Factors four and five fit theoretically under the title "identifying the solution". Factors three and six fit under "awareness of exceptions". Factors one and two fit under "hope in the future". When the factor loadings were split, the researcher used theoretical rationale for deciding how each of the 6 factors would be combined into the 3 theoretical factors.

Table 21

Collapsed Data Driven Factors into Theoretical Factors Table

\begin{tabular}{ccc}
\hline Identifying the Solution & Awareness of Exceptions & Hope in the Future \\
\hline Factors $4 \& 5$ & Factors $3 \& 6$ & Factors $1 \& 2$ \\
Items & Items & Items \\
I am able to generate & It is important to focus on & I am able to cope well \\
solutions & solutions & \\
I have the ability to & It is important to focus on & I can recognize small steps \\
focus & solutions
\end{tabular}

I can think about things I am aware of small positive There are times in my life that have made
I am able to focus on There are times when I am I am able to notice good times when really proud things

If I woke up tomorrow I have made steps towards I have been able to cope with and a miracle happened life's challenges 


$\begin{array}{lcc}\text { I can think of times } & \text { I am willing to try new } & \text { I have successfully overcome } \\ \text { when my problems } & \text { things }\end{array}$

$\begin{gathered}\text { I can recognize in others } \\ \text { when }\end{gathered}$
I am able to see good things
in my situation
I can recognize things that I
can do

The reliabilities of the collapsed factors were calculated (Table 22). The reliability for the proposed fact or "hope in the future" was .825 (an increase from .757 at wave one). The reliability of the factor "awareness of exceptions" was .708 (an increase from .694 at wave one). The reliability of the factor "identifying the solution" was .682 (an increase from .634 at wave one). All of the reliabilities for the collapsed factors improved in the second wave of data despite the fact that different items loaded on different factors.

Table 22

Reliabilities for the Collapsed Factors

\begin{tabular}{lc}
\hline \multicolumn{1}{c}{ Collapsed Factor } & $\alpha$ \\
\hline Identifying the Solution & .682 \\
Awareness of Exceptions & .708 \\
Hope in the Future & .825 \\
\hline
\end{tabular}

Confirmatory factor analysis. A confirmatory factor analysis was conducted on the data driven model using LISREL software. This analysis was done to confirm the data driven model based on the exploratory factor analysis in SPSS. A covariance matrix was used in the syntax (Appendix I).

First, model fit was examined using the $\chi^{2}$ statistic. It is desirable for $\chi^{2}$ to be nonsignificant. The $\chi^{2}$ for this model was significant $\left(\chi^{2}=886.84 \mathrm{p}=0.0\right)$ which suggests that the model was not a good fit for the data. Additional fit indices suggested that the 
model was not a good fit for the data, NFI $=.86(>.9) ; \mathrm{RMR}=.036(<.05)$; RMSEA $=$ $0.087(<.05)$.

Since the model was not a good fit for the data, the researcher conducted a second confirmatory factor analysis on the theoretical model (Appendix J). This was done first using the initial theoretical model developed during wave one of data collection along with the covariance matrix from the second wave of data.

The results from the theoretical model using the second wave of data did not fit as well as the data driven model, $\chi^{2}=1002.17, \mathrm{p}<.00 ; \mathrm{NFI}=.84(<.9)$; $\mathrm{RMR}=.042(<.05)$; RMSEA $=.094(<.05)$. These results suggest that the original theoretical model does not work well with the data from wave two.

Since the model was not a good fit for the data, the researcher revised the theoretical model (Appendix K) based on the new factor loadings from the second wave of data. The results indicate that the revised proposed model is actually a worse fit for the data than the original proposed model, $\chi^{2}=1016.56, \mathrm{p}<.00 ; \mathrm{NFI}=.83(>.9) ; \mathrm{RMR}=$ $.070(<.05)$; RMSEA $=.097(<.05)$. These findings suggest that the items crossloaded too much with other factors (errors ranging from .42 to .94 ).

In order to further explore why the revised hypothetical model fit the data worse, another exploratory factor analysis with the second wave of data occurred restricting the analysis to three factors. This revision compared the expected loading of items with specific factors with actual item relationships. Although the data were restricted to three factors, the items failed to load on three factors. Revisions were made by using the results from the factor analysis to drop items failing to load strongly. Items with a loading of .4 or greater were retained (Tabachnick \& Fidell, 2001). The following items were retained based on the results of the exploratory factor analysis to conduct a confirmatory factor analysis: I am able to cope well, I am able to generate solutions, There are times in my life, It is important to focus on solutions, I believe that it is more important, I have been able to cope with life's challenges, If I woke up tomorrow and a miracle happened, I am aware of small positive, I have successfully overcome, I can recognize in others when, I am able to see good things in my situation, and I can recognize things that I can do. 
A confirmatory factor analysis was conducted on the data driven model using the twelve retained items from the SBI. The results indicated that the data driven twelve item model produced a better fit to the data although it still failed to meet the criteria for a good model fit, $\chi^{2}=267.56 \mathrm{p}<.00 ; \mathrm{NFI}=.86(>.9) ; \mathrm{RMR}=.071(<.05) ; \mathrm{RMSEA}=.11$ $(<.05)$. Another confirmatory factor analysis was run on the proposed model excluding items 8, 9, and 22 from the SBI. These items were taken out due to their weak loadings and theoretical consideration. Items eight and nine were general items measuring the concept of solution building. Item twenty two theoretically could have fit on more than one factor. Other items possessed marginal loadings but were not removed due to their theoretical significance (items 12, 17, and 22). The results indicated that the hypothetical nineteen item model still is not a good fit for the data, $\chi^{2}=832.51 \mathrm{p}<.00$; NFI $=$ $.84(>.9) ; \mathrm{RMR}=.071(<.05) ; \mathrm{RMSEA}=.11(<.05)$. Overall, the results from both models with reduced items did not suggest a good fit. The error terms (ranging from .47 to .90) suggest that in general there are too many cross loadings. This can be evidenced by the fact that items loaded differently than the researcher hypothesized as well as different factors loadings during wave one and wave two of data collection. Overlaying theory on the data was not successful because the data driven models seemed to fit better overall then the theory driven models. In addition, asking LISREL to confirm three factors was not successful.

At this point the researcher made a decision to evaluate the correlations of each item since a great deal of crossloading occurred during various factor analyses. Since the hypothesized and data driven models did not fit the data the researcher wanted to see if any items needed to be eliminated to produce a better fit. Items with more than one nonsignificant correlation and correlations less than .10 were dropped from the SBI. Ten items met this criteria (I am able to cope well, I can recognize small steps, I have the ability to focus, It is important to focus on solutions, I believe that it is more important, If I woke up tomorrow and a miracle happened, I can think of times when my problems, I can recognize in others when, I am willing to try new things, and I can recognize things that I can do). Out of these items, two did not make theoretical sense to exclude. Items four and twelve measured key components of solution building. Thus, items four and twelve were retained. Eight items were trimmed from the SBI. The items included in the 
final version of the SBI are in Table 23 (also see Appendix L). The reliability of these items is .866 which is an increase from wave one $(\alpha=.839)$ and almost as high as wave two's reliability $(\alpha=.886)$.

Table 23

SBI Revised

Item 3 I am able to generate solutions.

Item 4 I have the ability to focus on what I want to occur in my life.

Item 5 I can think about things that have made a positive difference for me.

Item 6 I am able to focus on times when my situation is not so overwhelming, even a little bit.

Item 7 There are times in my life where I am able to handle difficulties well.

Item 10 I am able to notice good things in myself, others, and my situation.

Item 11 I have been able to cope with life's challenges.

Item 12 If I woke up tomorrow and a miracle happened in my life I would be able to notice differences in myself and others.

Item 13 I am aware of small positive changes that I make.

Item 14 There are times when I am really proud of how I am able to handle difficult situations.

Item 15 I have successfully overcome challenges in the past.

Item 16 I have make steps towards improving my life.

Item 19 I am able to see good things in my situation, even though parts of it seem very difficult.

Item 21 Dwelling on my problems may not be the best way to find solutions.

Several reasons exist why the researcher trimmed items from the SBI. First, since a reasonable number of factors were not discovered through statistical analyses, the SBI seems to consist of one main factor. Secondly, since the SBI was developed to be used in clinical settings it seemed wise to keep the measure brief enough to be used by clients on a regular basis without jeopardizing its reliability. An additional reason lies in the 
potential for the SBI to be used in outcome research. Shorter measures are adapted more often in clinical research, enabling the use of multiple scales in a limited timeframe.

Factor analysis of final SBI items. In a last attempt to evaluate whether the SBI was a multidimensional scale the researcher conducted another factor analysis on the remaining items. Results of this analysis found 3 factors of the SBI (Table 24). This is the first factor analysis finding three factors. Although three factors were found, not all of the loadings were strong. Factor loadings ranged from .471 to .759. In addition, the factor loadings of the items failed to fit the theoretical components from chapter one. Thus, no further exploration of factors were conducted.

Table 24

Final SBI Factor Loadings

\begin{tabular}{|c|c|c|}
\hline Factor 1 & Factor 2 & Factor 3 \\
\hline $\begin{array}{l}\text { I am able to generate } \\
\text { solutions. }\end{array}$ & $\begin{array}{l}\text { There are times in my life } \\
\text { where I am able to handle } \\
\text { difficulties well. }\end{array}$ & $\begin{array}{l}\text { If I woke up tomorrow and } \\
\text { a miracle happened in my } \\
\text { life I would be able to }\end{array}$ \\
\hline $\begin{array}{l}\text { I have the ability to focus } \\
\text { on what I want to occur in } \\
\text { my life. }\end{array}$ & $\begin{array}{l}\text { I have been able to cope } \\
\text { with life's challenges. }\end{array}$ & $\begin{array}{l}\text { notice differences in myself } \\
\text { and others. }\end{array}$ \\
\hline $\begin{array}{l}\text { I can think about things that } \\
\text { have made a positive } \\
\text { difference for me. }\end{array}$ & $\begin{array}{l}\text { There are times when I am } \\
\text { really proud of how I am } \\
\text { able to handle difficult } \\
\text { situations. }\end{array}$ & $\begin{array}{l}\text { I am aware of small positive } \\
\text { changes that I make. }\end{array}$ \\
\hline $\begin{array}{l}\text { I am able to focus on times } \\
\text { when my situation is not so } \\
\text { overwhelming, even a little } \\
\text { bit. }\end{array}$ & $\begin{array}{l}\text { I have successfully } \\
\text { overcome challenges in the } \\
\text { past. }\end{array}$ & \\
\hline $\begin{array}{l}\text { I am able to notice good } \\
\text { things in myself, others, and } \\
\text { my situation. }\end{array}$ & $\begin{array}{l}\text { I have make steps towards } \\
\text { improving my life. }\end{array}$ & \\
\hline
\end{tabular}




\section{Dwelling on my problems}

I am able to see good things may not be the best way to

in my situation, even find solutions.

though parts of it seem very

difficult.

\section{Validity of the SBI}

In order to investigate the convergent validity of the SBI, two additional measures were given during the second wave of data collection. The Dispositional Hope Scale (DHS) measures hope and the Life Orientation Test Revised (LOT-R) assessed individual's expectations concerning the probability of future outcomes. Both scales measure concepts similar to solution building. Correlations between the composite score of the revised SBI, the LOT-R, and the DHS were calculated. A correlation matrix showed that scores of the LOT-R $(r=-.526)$ and DHS $(r=.377)$ were significantly correlated with the SBI $(p=.01)$. This suggests that the SBI possesses aspects of hope and confidence in achieving goals. However, composite scores of the LOT-R and the DHS were not significantly correlated with one another (-.106). The DHS and the LOT-R measure two different concepts. While the SBI is correlated with the DHS and the LOT$\mathrm{R}$, it is a unique measure because the DHS and LOT-R measure different concepts. Thus, the $\mathrm{SBI}$ is a unique measure related to hope and confidence in goal attainment in ways predicted by theory.

The goal of this study was to define and identify the concept solution building through the development of the SBI. Although hypothesized factors emerged from the literature, results indicate that solution building is a unidimensional concept. Implications and future research will be discussed in the following chapter. 


\section{CHAPTER V}

\section{Discussion}

The purpose of this study was to systematically define and identify the components of solution building by developing the SBI. The rationale for developing the SBI was to clarify the components through factor analysis and create an instrument to measure the concept. There were several phases in the study. First, eight experts on SFBT complied and rated items in two waves. Once the researcher statistically determined the retained items the SBI was tested on an undergraduate sample. The first wave of data consisted of 97 undergraduate participants at Virginia Tech. Demographic questions were given along with the twenty two item SBI. The SBI was analyzed using exploratory factor analysis was well as a confirmatory factor analysis. All twenty two items were retained and a second wave of data consisting of 302 undergraduates was conducted. The second wave included demographic questions, the SBI, the DHS, and the LOT-R. A series of exploratory and confirmatory factor analyses were performed on the second wave of data.

The research question under investigation in this project was "What is solution building and how can it be measured?"

The objectives of this project were:

1. To ascertain if there are distinct components of solution building.

2. To create a solution building scale based on identified components

a. to create a scale that can be used in the future as an intervention in itself (to create more optimism and hope about life issues

b. to create a scale that can be used in the future as a clinical outcome measure

Solution building seems to be a unidimensional concept due to the fact that its proposed components are highly inner correlated. The concept of solution building significantly correlates with hope (DHS) and an individual's confidence in achieving goal (LOT-R) concepts related to solution building. However, data suggest that the SBI measures a unique concept. Preliminary support for the SBI suggests a fairly reliable and valid measure at this stage. The SBI shows preliminary evidence of a reliable and valid measure assessing the concept of solution building which holds promise to be an intervention in itself as well as a clinical outcome measure. 
The present investigation developed and tested a model including three theoretical factors. Although the model was not a good fit for the data, important information about the concept of solution building was gathered. The main piece of information gathered from the analyses was that the concept of solution building appears to be unimdimensional. This was concluded from the fact that the factor loadings differed between the first and second wave of data as well as cross-loadings among potential factors. Further discussion about the development of the SBI will be addressed in this chapter.

\section{Testing of the Theoretical Model}

The goal of this study was to define the key components of solution building. Literature suggests three main factors of solution building which are the following: identifying the solution, awareness of exceptions, and hope in the future (Berg \& Dolan, 2001; DeJong \& Berg, 1998). The researcher developed and tested a theoretical model of solution building based on the literature. Results of the confirmatory factor analysis revealed that the data failed to fit the theoretical model. Despite attempts to modify the factor structure of the theoretical model, the data failed to fit the model.

The data failed to fit the theoretical model because the factor loadings varied from wave one and wave two of data collection. Not only did factor loadings vary but numerous intercorrelations among items occurred. These findings suggest that the items are more similar than distinct. Although the scale development literature claims that a high Cronbach's alpha does not ensure a unidimensional scale (Clark \& Watson, 1995) results from exploratory and confirmatory factor analyses completed on the SBI suggest its unidimensionality. The results of both exploratory and confirmatory factor analyses from both waves of data suggested that the model was not a good fit for the data. Due to these findings, along with a high Cronbach's alpha, the researcher concluded that solution building is unidimensional.

What is the theoretical rationale for why the data were not a good fit? Even though the literature labels three components of solution building (Berg \& Dolan, 2001; DeJong \& Berg, 1998) the literature does not explicitly define these three factors. As the researcher examined the literature on SFBT, it was very difficult to find a consistent description of the concepts and assumptions of the theory. This inconsistency in the 
literature gives a rationale for why the model failed to fit the data. Since SFBT was developed from a pragmatic approach, a theoretical framework and rationale fails to appear in the literature. deShazer's (1994) claim to adopt Wittgenstein's rejection of theory brings light to the lack of theoretical underpinnings in the literature. SFBT is a clinical approach attempting to provide practical applications to therapy. Thus, "theoretically" it makes sense that the data failed to fit the three factor proposed model since the literature emphasizes practice not theory. Less time has been spent on the development of a theory of SFBT and more on generating descriptions of practice. Problem-Solving versus Solution Building

The purpose of the current study was not to compare the PSI to the SBI but an attempt to compare problem-solving to solution building by defining the components of solution building. The SFBT literature suggests several differences between problemsolving and solution building (DeJong and Berg, 1998). DeJong and Berg define problem-solving as 1) gathering data to understand the problem, 2) trying to understand the underlying causes of the problem, and 3) putting a plan into effect that will "resolve" the problem. In contrast, solution building encourages clients to focus on the future by describing how they would like their life to be, searching for evidence when pieces of their desired life have already occurred (DeJong \& Berg), and building hope in the future (Berg \& Dolan, 2001).

Conceptually, problem-solving and solution building differ because their goals remain incongruent. A solution-focused approach involves the client identifying a solution, becoming aware of exceptions to their problems, and possessing hope in the future. The literature suggests that SFBT's major assumptions differ from problemsolving because in SFBT the client is the expert and it is not important for the client or the therapist to understand the root of the problem (de Shazer, 1988a). In addition, solution building differs from problem-solving because it is not learning effective responses to certain challenges but focusing on a client's successful efforts towards their goals.

Problem-solving has been thought of by some as a set of skills used to diffuse a problem (DeJong \& Berg, 1998; D'Zurilla \& Goldfried, 1971). The development of the PSI used the theoretical framework that problem-solving occurs in stages (Clarke, Gelatt, 
\& Levine, 1965; Dewey, 1933; D’Zurilla \& Goldfried, 1971; Goldfried \& Goldfried, 1975; Urban \& Ford, 1971) to validate or disconfirm this assumption. Instead of validating the theory that problem-solving occurs in stages, the PSI identified three components of problem-solving appraisal that cut across stages (Heppner \& Petersen, 1982). Likewise, the SBI used the SFBT literature to hypothesize three factors of solution building. Results of the SBI failed to demonstrate any distinct factors of solution building.

Even though the current study failed to find distinct factors, the SBI maintained a fairly high level of internal consistency $(\alpha=.866)$ in its final form. This finding suggests that the items of the SBI reflect a common construct, solution building. Due to numerous intercorrelations and cross factor loadings, as well as high internal consistency, the current study suggests that solution building as it is currently measured is a unidimensional concept.

Since the current study failed to discover distinct factors of solution building it may make more sense to compare the overarching concepts of problem-solving and solution building. A revised comparison table offers a new way of comparing problemsolving and solution building. The results from the current study provide a valuable difference in problem-solving and solution building, one concept is multidimensional and the other is unidimensional. In addition, where problem-solving is composed of general principles (such as approach-avoidance style, problem-solving confidence, and personal control), future research will have to determine if solution building occurs in stages since general components did not emerge from the data.

Table 25

Problem-solving vs. Solution Building Revised

\begin{tabular}{cc}
\hline Problem-solving & Solution Building \\
Multidimensional concept & Unidimensional concept \\
General Components, not & Stages? \\
stages & (Future Research) \\
\hline
\end{tabular}




\section{Implications for the SBI as an Intervention}

Clinical. The SBI may hold clinical promise as an intervention. First, the SBI can be used by clinicians to give their clients at the beginning of treatment as an intervention. Giving the SBI before the first session could help clients shift into thinking about solutions instead of problems.

The SBI can also be used by clinicians to generate solution oriented conversations with their clients. Therapists new to the model could use items from the SBI as a guide to generate conversation. For example, a therapist could ask the client to rate themselves, like a scaling question in SFBT, on the following item "There are times in my life where I am able to handle difficulties well." The client may respond by saying that they are a 4 . The therapist could then use this information as they would when they ask clients to scale their goals. Asking the client items from the SBI would be used to help create conversations about solutions.

In addition, therapists can use items from the SBI as an opener to group therapy sessions. One solution oriented substance abuse treatment facility in Denver uses various solution oriented questions to start group therapy sessions (Pichot \& Dolan, 2003). The items can serve as opening questions or prototype questions for group therapy. A therapist could begin a group session by asking everyone "Have (you) successfully overcome challenges in the past?" Group members could share examples of times when they have overcome challenges in the past. Whether just learning SFBT, or seasoned solution oriented therapists, the SBI can provide a guide to generate solution building conversations.

Since the SBI may be a reliable and valid measure, it could be used in clinical outcome research. The SBI could be given pre and post treatment to see if a client's ability to build solutions has increased. Pairing the SBI with additional outcome measures can show whether increasing one's ability to build solutions produces other indicators of improvement (e.g. lowered depression, increased satisfaction, decreased drug use). Finding correlations between solution building and increased mental and physical health seems to be the crux for using the SBI in outcome research. 
Although the PSI is used to further explore the concept of problem-solving, the literature does not specifically state that the PSI is used as a clinical intervention. Thus, the SBI appears to be more diverse in its usage.

Supervisory. The SBI can also be used in a supervisory manner. Supervisors can give their clinical supervisees the SBI to rate the supervisee's level of solution building. The supervisor can help the supervisee track their SBI score, like with scaling, to determine their ability to build solutions. The SBI can be given periodically to help supervisees who want to become more solution-focused.

The SBI can not only be used with clinical trainees but with any supervisee. Administrators can use the SBI to help their supervisees build solutions more with students. For example, if an administrator would like their work environment to be more solution-focused he/she can given their employees the SBI as a means to measure their ability to build solutions. The SBI could not only measure employee's level of solution building but can be an intervention itself. By giving the SBI to one's employees on a regular basis the employees may begin to build solutions by just reading solution oriented questions. Any type of supervisor can use the SBI as a tool to aid supervisees in becoming more solution-focused.

Total SBI score. Many psychological instruments use a score to classify individuals into a certain category (e.g. Beck Depression Inventory, SASSI, etc.). Although the SBI gives a total score, it does not classify the score into categories. Scores on the SBI are continuous rather than categorical, like the PSI. Lower scores on the PSI indicate more functional problem-solving appraisal (Heppner \& Petersen, 1982). High scores on the SBI are considered to indicate better solution builders. The total score of the SBI can be used by researchers as an indicator of ability or progress.

In a clinical setting, clients and supervisees can interpret their total SBI score however it is meaningful. Thus, the SBI score in a clinical setting can be used like scaling questions are used in SFBT. For example, a therapist could first give their client the SBI. Then, the client could sum their score to discover their total score. The therapist could then ask the client to talk about their total score. The therapist might say "Wow, you scored a 30 on the SBI this week. How were you able to score a 30 instead of a 20 ?" The therapist and client could have a conversation about the client's SBI score similar to how 
a therapist uses scaling in SFBT. The SBI could be given weekly or monthly. This use of the SBI is congruent with the poststructural theory of SFBT which claims that meaning is negotionable (de Shazer, 1991; de Shazer, \& Berg, 1992). Meaning of the SBI score, like scaling goals in SFBT, is negotiated by the client or supervisee. The same type of example could be used with supervises wanting to assess their ability to build solutions. However, because the SBI total score is a quantitative number it can be used as a measurement tool for researchers.

\section{Strengths of the Study}

To date this is the only known investigation developing a scale to measure the concept of solution building. Since solution building is key in SFBT, a widely used clinical theory, it was essential to develop an instrument to measure the concept. Further, the study attempted to empirically investigate whether or not the concept of solution building has distinct components much like the developers of the PSI looked for components of problem-solving (Heppner \& Petersen, 1982). The findings of this study indicate that solution building is a unidimensional concept that is somewhat correlated with the concepts of hope and confidence in goal obtainment. The SBI was created not only to systematically define solution building, and to develop an intervention, but to serve as a way to discover mechanisms of change for future research.

Another strength of the study was the valuable input by experts in SFBT. The use of expert raters helped to increase the face validity of the SBI. Not only did the current study use statistical analyses to determine the reliability and validity of the SBI items but items were rated and created by experts and developers of SFBT. Instruments measuring a specific concept do not always receive input from experts and developers of the concept.

\section{Limitations of the Study}

Sample. One limitation of the study is that it was not completed on a clinical population. Although several problem-focused inventories were developed by using the general population (D’Zurilla \& Nezu, 1990; Heppner, Cook, Wright \& Johnson, 1995; Heppner, Cooper, Mulholland, \& Wei, 2001) testing the SBI on a clinical sample would have been beneficial. Future research should apply the SBI to a clinical population. Comparing clinical and non-clinical samples would also be a useful study. 
In addition, the sample used from Virginia Tech was very homogeneous. Eighty percent of the sample was Caucasian. Likewise, Heppner and Petersen's (1982) development of the PSI consisted of a ninety five percent Caucasian. Future research would benefit from a more diverse sample.

Scale location.During wave two of data collection the researcher placed the SBI in-between the DHS and the LOT-R. The rationale for placing the SBI in the middle was to create some variety in the survey. After the data were collected, the researcher realized that placing the SBI in between the DHS and the LOT-R may have affected the responses on the SBI. Since the DHS uses more "problem talk" this may have affected the participants' responses on the SBI. This might be evidenced by the fact that the items loaded differently during wave two on the factors in the exploratory factor analysis. The rationale for why the SBI was placed between the DHS and the LOT-R was to create variety to help reduce monotony in responses. Placement of the scale and its use with other, non-solution-oriented measures could be investigated in future research projects.

\section{Directions for Future Research}

While the current study provides a general difference in solution building and problem-solving (multidimensional vs. unidimensional) a systematic evaluation of the specific differences does not exist. A question that was asked initially about problemsolving appraisal was "Are there steps in problem-solving"? Early writings of the problem-solving process hypothesized several stages (Clarke, Gelatt, \& Levine, 1965; Dewey, 1933; D’Zurilla \& Goldfried, 1971; Goldfried \& Goldfried, 1975; Urban \& Ford, 1971) yet the development of the PSI found distinct components, not stages, to problemsolving appraisal (Heppner \& Petersen, 1982). It is unknown whether solution building possesses stages or not. Is solution building a process? What does it take to increase a person's ability to build solutions? Future research may answer these questions.

Another important question to ask in future research would be "Are some individuals innately better solution builders than others?" An overview of the PSI literature completed by Heppner, Witty, and Dixon (2004) give numerous examples of what types of individuals are better problem solvers. Most of the research reports that individuals who score well on the PSI tend to be better problem solvers in real life situations. The characteristics of successful problem solvers vary depending on the type 
of problem being solved. Since the current study is an initial attempt to create a measure of solution building, it is unknown which types of individuals tend to be better solution builders.

Can individuals be good problem solvers as well as solution builders? Again, since this study is an initial attempt to develop a measure of solution building this question can not be answered within this project. It will be interesting to discover which individuals are more or less successful using problem-solving skills when compared to building solutions.

One hope of the researcher is that the SBI can be used in future outcome studies to evaluate mechanisms of change. For example, by pairing the SBI with a measure like the Beck Depression Inventory, correlations between depression and solution building can be assessed. If data suggests a correlation between lower depression and solution building ability, then the concept of solution building can be viewed as one factor that aids in lowering depression.

Another research question would be "Is solution building a trait or a state?". The literature of SFBT suggests that solution building is a set of skills that can be increased through therapeutic intervention. However, this has not been empirically tested. A study comparing the SBI with other trait measurements and with other state instruments may shed light on this question.

Researchers can use SBI scores to measure progress in treatment. For example, the SBI could be administered before and after the initial session to assess change. Also, by just giving the SBI before and after the initial session could help foster change in the client. The methods of assessing change with the SBI are numerous.

Although some research has been completed on SFBT (e.g. Cockburn, Thomas, \& Cockburn, 1997; Lindforss \& Magnusson, 1997; Zimmerman, Jacobsen, MacIntyre, \& Watson, 1996) more is needed. The PSI has been used in over 120 studies to test a vast number of variables (Heppner, Witty, \& Dixon, 2004). Ineffective problem-solving has been shown to result in maladjustment (Bulter \& Meichenbaum, 1981; D’Zurilla \& Goldfried, 1971; Heppner \& Krauskopf, 1987; Heppner \& Lee, 2002; Mechanic, 1968, 1970; Spivack \& Shure, 1974). The researcher hopes that the SBI can be used to determine how solution building can improve lives. 
Some may ask why the SBI is needed to measure mechanisms of change if so many measures already exist? The SBI is unique because it attempts to measure the theoretical concept that remains essential to SFBT. Thus, how can we best measure mechanisms of change in SFBT if no scale of the concept exists? By creating and testing the SBI, the SFBT model can gain respect among clinicians. 


\section{References}

Anderson, J. R. (1983). The architecture of cognition. Hillsdale, NJ: Lawrence Erlbaum. Antonovsky, A. (1979). Health, stress, and coping. San Francisco: Jossey-Bass.

Bandura, A. (1982). Self-efficacy mechanism in human agency. American Psychologist, $37,122-147$.

Baumgardner, A. H., Heppner, P. P., \& Arkin, R. M. (1986). Role of casual attribution in personal problem-solving. Journal of Personality and Social Psychology, 50, 636643.

Berg, I. K., \& Dolan, Y. (2001). Tales of solutions: A collection of hope-inspiring stories. New York: W. W. Norton.

Beck, A. T., Ward, C. H., Mendelson, M., Mock, J., \& Erbaugh, J. (1961). An inventory for measuring depression. Archives of General Psychiatry, 4, 561-571.

Berg, I. K. (1994). Family-based services: A solution-focused approach. New York: W. W. Norton.

Berg, I. K., \& Reuss, N. (1997). Solutions step-by-step: A substance abuse treatment manual. New York: W.W. Norton.

Billings, A. G., \& Moos, R. H. (1984). Coping, stress, and social resources among adults with unipolar depression. Journal of Personality and Social Psychology, 46, 877 891.

Blankstein, K. R., Flett, G. L., \& Batten, I. (1989). Test anxiety and problem-solving selfappraisals of college students. Journal of Social Behavior and Personality, 4, 531540.

Butler, L., \& Meichenbaum, D. (1981). The assessment of interpersonal problem-solving skills. In P. C. Kendall \& S. D. Hollen (Eds.), Assessment Strategies for Cognitive Behavioral Interventions (pp. 197-225). New York: Academic Press.

Briggs, S. R., \& Cheek, J. M. (1986). The role of factor analysis in the development and evaluation of personality scales. Journal of Personality, 54, 106-148.

Carver, C. S., \& Scheier, M. (2003). Optimism. In Lopez, S. J., \& Snyder, C. R. (Eds.), Positive Psychological Assessment (pp.75-89). Washington DC: American Psychological Association. 
Carver, C. S., Scheier, M. F., \& Weintraub, J. K. (1989). Assessing coping strategies: A theoretically based approach. Journal of Personality and Social Psychology, 66, 184-195.

Chomsky, N. (1968). Language and mind. New York: Harcourt.

Chomsky, N. (1980). Rules and representations. New York: Columbia University Press.

Clark, L. A., \& Watson, D. (1995). Constructing validity: Basic issues in objective scale development. Psychological Assessment, 7, 309-319.

Clarke, R., Gelatt, H. B., \& Levine, L. (1965). A decision making paradigm for local guidance research. Personnel and Guidance Journal, 44, 40-51.

Cockburn, J. T., Thomas, F. N., \& Cockburn, O. J. (1997). Solution-focused therapy and psychosocial adjustment to orthopedic rehabilitation in a work hardening program. Journal of Occupational Rehabilitation, 7(2), 97-106.

Comrey, A. L. (1988). Factor-analytic methods of scale development in personality and clinical psychology. Journal of Consulting and Clinical Psychology, 56, 754-761.

Corcoran, C. M. (1991). Self-appraised personal problem-solving in an inmate population. Unpublished doctoral dissertation, University of Missouri, Columbia.

Cortina, J. M. (1993). What is coefficient alpha? An examination of theory and applications. Journal of Applied Psychology, 78, 98-104.

Coyne, J. C. (1985). Toward a theory of frames and reframing: The social nature of frames. Journal of Marital and Family Therapy, 11, 337-334.

Cronbach, L. J. (1951). Coefficient alpha and the internal structure of tests. Psychometrika, 16, 297-334.

Davey, G. C. (1994). Worrying, social problem-solving abilities, and social problemsolving confidence. Behavior Research \& Therapy, 32, 327-330.

Davis, G. A. (1966). Current status of research and theory in human problem-solving. Psychological Bulletin, 66, 36-54.

Dawis, R. V. (1987). Scale Development. Journal of Counseling Psychology, 34, 481189.

DeClue, G. S. (1983). Patterns of intellectual functioning, ability, personality, and problem-solving style. Unpublished doctoral dissertation, University of Missouri, Columbia. 
DeJong, P., \& Berg, I. K. (1998). Interviewing for solutions. Pacific Grove, CA:

Brooks/Cole.

de Shazer, S. (1982). Patterns of brief family therapy. New York: Guliford.

de Shazer, S. (1985). Keys to solution in brief therapy. New York: W.W. Norton.

de Shazer, S. (1986). An indirect approach to brief therapy. The Family Therapy

Collections, 19, 48-55.

de Shazer, S. (1988a). Clues: Investigating solutions in brief therapy. New York: W.W. Norton.

de Shazer, S. (1988b). Utilization: The foundation of solutions. In J. K. Zeig and S. R.

Lankton (Eds.), Developing Ericksonian therapy: State of the art (pp.112-124).

Philadelphia, PA: Brunner/Mazel.

de Shazer, S. (1991). Putting difference to work. New York:W.W. Norton.

de Shazer, S. (1993). Creative misunderstanding: There is no escape from language. In S. Gilligan \& R. Price (Eds.), Therapeutic conversations. New York: W. W. Norton \& Co.

de Shazer, S. (1994). Words were originally magic. New York: W.W. Norton.

de Shazer, S., \& Berg, I. K. (1992). Doing therapy: A post-structural re-vision. Journal of Marital and Family Therapy, 18, 71-81.

de Shazer, S., \& Berg, I. K. (1997). Interviewing for solutions. Stamford, CT: Brooks/Cole.

de Shazer, S., Berg, I. K., Lipchik, E., Nunnaly, E., Molnar, A., Gingerich, W., \& et al. (1986). Brief therapy: Focused solution development. Family Process, 25, $207-$ 221.

Dewey, J. (1933). How we think. New York: Heath.

Dixon, D. N., \& Glover, J. A. (1984). Counseling: A problem-solving approach. New York: Wiley.

Dohrenwend, B. S., \& Dohrenwend, B. P. (1978). Some issues in research on stressful life events. Journal of Nervous \& Mental Disease, 166, 7-15.

D'Zurilla, T. J. (1986). Problem-solving therapy: A social competence approach to clinical intervention. New York: Springer. 
D’Zurilla, T. J., \& Goldfried, M. R. (1971). Problem-solving and behavior modification. Journal of Abnormal Psychology, 78, 107-126.

D’Zurilla, T. J., Maydeu-Olivares, A., \& Kant, G. L. (1998). Age and gender differences in social problem-solving ability. Personality and Individual Differences, 25, 241252.

D'Zurilla, T. J., \& Nezu, A. M. (1990). Development and preliminary evaluation of the Social Problem-Solving Inventory (SPSI). Psychological Assessment: A Journal of Consulting and Clinical Psychology, 2, 156-163.

Elliott, T. R., Godshall, F. J., Herrick, S. M., Witty, T. E., \& Spruell, M. (1991). Problem solving appraisal and psychological adjustment following spinal cord injury. Cognitive Therapy and Research, 15, 387-398.

Erickson, R. C., Post, R. D., \& Paige, A. B. (1975). Hope as a psychiatric variable. Journal of Clinical Psychology, 31, 324-330.

Felton, G. M., Liu, Q., Parsons, M. A., \& Geslani, G. P. (1998). Health-promoting behaviors of rural adolescent women. Women \& Health, 27, 67-80.

Felton, G. M., Parsons, M. A., \& Bartoces, M. G. (1997). Demographic factors: Interaction effects on health and related factors. Public Health Nursing, 14, 361367.

Fisher, S. (1986). Stress and strategy. London: Lawrence Erlbaum.

Floyd, F. J., \& Widaman, K. F. (1995). Factor analysis I the development and refinement of clinical assessment instruments. Psychological Assessment, 7, 286-299.

Folkman, S., \& Lazarus, R. S. (1980). An analysis of coping in a middle-aged community sample. Journal of Health and Social Behavior, 21, 219-239.

Folkman, S., \& Lazarus, R. S. (1985). If it changes it must be a process: A study of emotion and coping during three stages of a college examination. Journal of Personality and Social Psychology, 48, 150-170.

Folkman, S., \& Lazarus, R. S. (1988). Manual for the Way of Coping Questionnaire: Research edition. Palo Alto, CA: Consulting Psychologists Press.

Franklin, C., Biever, J., Moore, K., Clemons, D., \& Scamardo, M. (2001). The effectiveness of solution-focused therapy with children in a school setting. Research on Social Work Practice, 11, 411-434. 
Fretz, B. R. (1981). Evaluating the effectiveness of career interventions. Journal of Counseling Psychology, 28, 77-90.

Gagne, R. M. (1964). Problem-solving. In A. W. Melton (Ed.), Categories of human learning. New York: Academic Press.

Garfield, S. L. (1989). The practice of brief psychotherapy. New York: Pergamon.

Gilligan, C. (1982). In a different voice: Psychological theory and women's development. Cambridge, MA: Harvard University Press.

Gingerich, W. J., \& de Shazer, S. (1991). The BRIEFER Project: Using expert systems as theory construction tools. Family Process, 30, 241-250.

Gingerich, W. J., \& Eisengart, S. (2000). Solution-focused brief therapy: A review of the outcome research. Family Process, 39, 477-498.

Goldfried, M. R., \& Goldfried, A. P. (1975). Cognitive change methods. In F. H. Kanfer \& A. P. Goldstein (Eds.), Helping people change. New York: Pergamon Press.

Guadagnoli, E., \& Velicer, W. F. (1988). Relation of sample size to the stability of component patterns. Psychological Bulletin, 103, 265-275.

Guterman, J. T., Mecias, A., \& Ainbinder, D. L. (2005). Solution-Focused Treatment of Migraine Headache. Family Journal: Counseling \& Therapy for Couples \& Families, 13, 195-198.

Haley, J. (1976). Problem-solving therapy. San Francisco: Jossey-Bass.

Harland, R. (1987). Superstructuralism: The philosophy of structuralism and poststructuralism. London: Methuen.

Harrison, H. A. (1994). The relationship among Jungian psychological type preferences, problems experienced, and perceived problem-solving capabilities for African Americans holding graduate degrees. Unpublished doctoral dissertation, St. Louis University.

Heppner, P. P. (1988). The Problem-Solving Inventory: Manual. Palo Alto, CA: Consulting Psychologists Press.

Heppner, P. P., Baumgardner, A., \& Jackson, J. (1985). Problem-solving self-appraisal, depression, and attributional styles: Are they related? Cognitive Therapy and Research, 9, 105-113. 
Heppner, P. P., Cook, S. W., Strozier, A. L., \& Heppner, M. J. (1991). An investigation of coping styles and gender differences with farmers in career transition. Journal of Counseling Psychology, 38, 167-174.

Heppner, P. P., Cook, S. W., Wright, D. M., \& Johnson, W. C., Jr. (1995). Progress in resolving problems: A problem-focused style of coping. Journal of Counseling Psychology, 42, 279-293.

Heppner, P. P., Cooper, C., Mullholland, A., \& Wei, M. (2001). A brief, multidimensional, problem-solving psychotherapy outcome measure. Journal of Counseling Psychology, 48, 330-343.

Heppner, P. P., Hibel, J. H., Neal, G. W., Weinstein, C. L., \& Rabinowitz, F. E. (1982). Personal problem-solving: A descriptive study of individual differences. Journal of Counseling Psychology, 24, 580-590.

Heppner, P. P., Kampa, M., \& Brunning, L. (1987). The relationship between problem solving self-appraisal and indices of physical and psychological health. Cognitive Therapy and Research, 11, 155-168.

Heppner, P. P., \& Krauskopf, C. J. (1987). An information-processing approach to personal problem-solving. The Counseling Psychologist, 15, 371-447.

Heppner, P. P., \& Lee, D. (2002). Problem-solving appraisal and psychological adjustment. In C. R. Snyder \& S. J. Lopez (Eds.), Handbook of positive psychology (pp. 288-298). New York: Oxford University Press.

Heppner, M. J., Lee, D., Heppner, P. P., McKinnon, L. C., Multon, K. D., \& Gysbers, N. C. (in press). Examining the role of problem-solving appraisal in the process and outcome of career counseling. Journal of Vocational Behavior.

Heppner, P. P. \& Petersen, C. H. (1978, March). The development, factor analysis, and initial validation of a problem-solving instrument. Paper presented at the meetings of the American Education Research Association, Toronto, Canada.

Heppner, P. P., \& Petersen, C. H. (1982). The development and implications of a personal problem-solving inventory. Journal of Counseling Psychology, 29, 6675. 
Heppner, P. P., Witty, T. E., \& Dixon, W. A. (2004). Problem-solving appraisal and human adjustment: A review of 20 years of research using the problem-solving inventory. The Counseling Psychologist, 32(3), 344-428.

Heppner, P. P., \& Wang, Y. (2003). Problem-solving appraisal. In S. J. Lopez \& C. R. Snyder (Eds.), Positive psychological assessment: A handbook of models and measures (pp. 127-138). Washington, DC: American Psychological Association.

Herrick, S., Elliott, T. R., \& Crow, F. (1994). Self-appraised problem-solving skills and the prediction of secondary complications among persons with spinal cord injuries. Journal of Clinical Psychology in Medical Settings, 1, 269-283.

Herth, K. (1991). Development and refinement of an instrument to measure hope. Scholarly Inquiry for Nursing Practice: An International Journal, 5, 39-51.

Holland, J. L. (1973). Making vocational choices: A theory of careers. Englewood Cliffs, NJ: Prentice Hall.

Jordan, J. V., Kaplan, A. G., Miller, J. B., Stiver, I. P., \& Surrey, J. L. (1991). Women's growth in connection: Writings from the Stone Center. New York: Guliford Press.

Kim, B. S., Atkinson, D. R., \& Umemoto, D. (2001). Asian cultural values and the counseling process: Current knowledge and directions for future research. The Counseling Psychologist, 29, 570-603.

Lambert, M. J., Burlingame, G. M., Umphress, V., Hansen, N. B., Vermeersch, D. A., Clouse, G. C., et al. (1998). The reliability and validity of the Outcome Questionnaire. Clinical Psychology and Psychotherapy, 3, 249-258.

Lambert, M. J., Okiishi, J. C., Finch, A. E., \& Johnson, L. D. (1998). Outcome assessment: From conceptualization to implementation. Professional Psychology: Research and Practice, 29, 63-70.

Larson, L. M. (1984). Training self-appraised effective and ineffective problem solvers in assertion. Unpublished master's thesis. University of Missouri, Columbia.

Larson, L. M., Allen, S. J., Imao, R. A., \& Piersel, W. C. (1993). Self-perceived effective and ineffective problem solvers' differential views of their partners' problemsolving styles. Journal of Counseling and Development, 71, 528-532.

Larson, L. M., \& Heppner, P. P. (1989). Problem-solving appraisal in an alcoholic population. Journal of Counseling Psychology, 36, 73-78. 
Larson, L. M., Piersel, W. C., Imao, R. A., \& Allen, S. J. (1990). Significant predictors of problem-solving appraisal. Journal of Counseling Psychology, 37, 482-490.

Larson, L. M., Potenza, M. T., Wennstedt, L. W., \& Sailors, P. J. (1995). Personal problem-solving simulated setting: Do perceptions accurately reflect behavior? Cognitive Therapy and Research, 19, 241-257.

Larson, L. M., \& Sailors, P. J. (1997). Perceived effective problem solvers' attributions concerning success and failure of a simulated real-life problem. Behavior Modification, 21, 341-354.

Lazarus, R. S., DeLongis, A., Folkman, S., \& Gruen, R. (1985). Stress and adaptational outcomes: The problem of confounded measures. American Psychologist, 40, 770-785.

Lazarus, R. S., \& Folkman, S. (1984). Stress, appraisal, and coping. New York: Springer.

Lee, M. Y. (1997). A study of solution-focused brief family therapy: Outcomes and issues. American Journal of Family Therapy, 25, 3-17.

Lee, M. Y., Uken, A., \& Sebold, J. (2004). Accountability for Change: Solution-Focused Treatment with Domestic Violence Offenders. Families in Society, 85, 463-476.

Lafountain, R. M., \& Garner, N. E. (1996). Solution-focused counseling groups: The results are in. Journal of Specialists in Group Work, 21, 128-143.

Lindforss, L., \& Magnusson, D. (1997). Solution-focused therapy in prison. Contemporary Family Therapy, 19, 89-103.

Littrell, J. M., Malia, J. A., \& Vanderwood, M. (1995). Single-session brief counseling in a high school. Journal of Counseling and Development, 73, 451-458.

Loevinger, J. (1957). Objective tests as instruments of psychological theory. Psychological Reports, 3, 635-694.

Long, B. C., Kahn, S. E., \& Schutz, R. W. (1992). Causal model of stress and coping: Women in management. Journal of Counseling Psychology, 39, 227-239.

Lopez, Snyder, \& Teramoto-Pedrotti, J. (2003). Hope: Many definitions, many measures. In Lopez, S. J. \& Snyder, C. R. (Eds.), Positive psychological assessment: A handbook of models and measures (pp. 91-107). Washington: American Psychological Association. 
Heppner, P. P., \& Wang, Y. (2003). Problem-solving appraisal. In S. J. Lopez \& C. R. Snyder (Eds.), Positive psychological assessment: A handbook of models and measures (pp. 127-138). Washington, DC: American Psychological Association.

Holmes, T., \& Rahe, R. (1967). The Social Readjustment Rating Scale. Journal of Psychomatic Research, 11, 213-218.

Kobasa, S. C. (1979). Stressful life events, personality, and health: An inquiry into hardiness. Journal of Personality and Social Psychology, 37, 1-11.

Macdonald, A. J. (1997). Brief therapy in adult psychiatry- further outcomes. Journal of Family Therapy, 19, 213-222.

Maier, N. R. F. (1970). Problem-solving and creativity. Belmont, CA: Brooks/Cole.

Marcotte, D., Alain, M., \& Gosselin, M. J. (1999). Gender differences in adolescent depression: Gender-typed characteristics or problem-solving skills deficits? Sex Roles, 41, 31-48.

Maruyama, G. M. (1998). Basics of structural equation modeling. Thousands Oaks, CA: Sage.

Mayo, V. D., \& Tanaka-Matsumi, J. (1996). Think aloud statements and solutions of dysphoric persons on a social problem-solving task. Cognitive Therapy and Research, 20, 97-113.

Molnar, A., \& de Shazer, S. (1987). Solution-focused therapy: Toward the identification of therapeutic tasks. Journal of Marital and Family Therapy, 13, 349-358.

Morrison, J. A., Olivos, K., Dominguez, G., Gomez, D., \& Lena, D. (1993). The application of family systems approaches to school behavior problems on a school-level discipline board: An outcome study. Elementary School Guidance \& Counseling, 27, 258-272.

McCrae, R. R. (1984). Situational determinants of coping responses: Loss, threat, and challenge. Journal of Personality and Social Psychology, 46, 919-928.

Mechanic, D. (1968). The study of social stress and its relationship to disease. In D. Mechanic (Ed.), Medical sociology (pp. 294-322). New York: Free Press.

Moss, S. (1983). Formal and informal problem-solving and age related differences. Unpublished master's thesis. University of Missouri, Columbia. 
Neal, G. W. (1983). Personal problem-solving: Awareness and utilization of campus helping resources. Unpublished doctoral dissertation, University of Missouri, Columbia.

Nelson, T. S., \& Kelley, L. (2001). Solution-focused couples group. Journal of Systemic Therapies, 20, 47-66.

Neville, H. A., Heppner, P. P., \& Wang, L. (1997). Relations among racial identity attitudes, perceived stressors, and coping styles in African American college students. Journal of Counseling and Development, 75, 303-311.

Newell, A. Shaw, J. C., \& Simon, H. A. (1958). Elements of a theory of human problem solving. Psychological Review, 65, 151-166.

Nezu, A. M. (1985). Differences in psychological distress between effective and ineffective problem solvers. Journal of Counseling Psychology, 32, 135-138.

Nezu, A. M., Nezu, C. M., Friedman, S. H., Faddis, S., \& Houts, P. S. (1998). Helping cancer patients cope: A problem-solving approach. Washington, DC: American Psychological Association.

Nezu, A. M., Nezu, C. M., \& Perri, M. G. (1989). Problem-solving therapy for depression: Theory, research, and clinical guidelines. New York: Wiley.

Nezu, A. M., \& Ronan, G. F. (1985). Life stress, current problems, problem-solving, and depressive symptoms: An integrative model. Journal of Consulting and Clinical Psychology, 53, 693-697.

Nezu, A. M., \& Ronan, G. F. (1988). Social problem-solving as a moderator of stressrelated depressive symptoms: A prospective analysis. Journal of Counseling Psychology, 35, 134-138.

Nicholas, M. P., \& Schwartz, R. C. (2001). Family Therapy: Concepts and Methods. Boston: Allyn and Bacon.

Orlinsky, D. E., Grawe, K., \& Parks, B. K. (1994). Process and outcome in psychotherapy: Noch einmal. In A. E. Bergin \& S. L. Garfield (Eds.), Handbook of psychotherapy and behavior change ( $4^{\text {th }}$ ed., pp. 270-376). Oxford, England: John Wiley \& Sons. 
Perlin, L. I., \& Schooler, C. (1978). The structure of coping. Journal of Health and Social Behavior, 19, 2-21.

Pichot, T., \& Dolan, Y. (2003). Miracles happen: One agency's journey to look beyond client problems. Binghampton, NY: Haworth.

Platt, J. J., \& Spivack, G. (1975). Manual for the Means-Ends Problem-Solving Procedure (MEPS): A measure of interpersonal cognitive problem-solving skill. Philadelphia: Hahnemann Medial College and Hospital, Department of Mental Health Sciences.

Rath, J. F., Simon, D., Langenbahn, D. M., Sherr, R. L., \& Diller, L. (2000). Measurement of problem-solving deficits in adults with acquired brain damage. Journal of Head Trauma Rehabilitation, 15, 724-733.

Rath, J. F., Hennessy, J. J., Diller, L. (2003). Social problem-solving and community integration in postacute rehabilitation outpatients with traumatic brain injury. Rehabilitation Psychology, 48, 137-144.

Rabin, L. A. (2001). Test usage patterns and perceived ecological utility of neuropsychological assessment techniques: A survey of North American clinical neuropsychologists. Unpublished doctoral dissertation. Fordham University.

Raykov, T., \& Marcoulides, G. A. (2000). A First Course in Structural Equation Modeling. New Jersey: Lawrence Erlbaum Associates.

Reid, J. K., \& Dixon, W. A. (2000). The relationships among grief experience, problemsolving appraisal, and depression: An exploratory study. Journal of Personal and Interpersonal Loss, 5, 77-93.

Rohde, P., Lewinsohn, P. M., Tilson, M., \& Seeley, J. R. (1990). Dimensionality of coping and its relation to depression. Journal of Personality and Social Psychology, 58, 499-511.

Sabourin, S., Laporte, L., \& Wright, J. (1990). Problem-solving self-appraisal and coping efforts in distressed and nondistressed couples. Journal of Marital and Family Therapy, 16, 89-97.

Sarmany, I., \& Sladekova, L. (1990). Personality aspects of strategy production in solving the anticipatory task. Studia Psychologica, 32, 97-106. 
Schorr, M. (1997). Finding solutions in a roomful of angry people. Journal of Systemic Therapies, 16, 201-210.

Seagram, B. C. (1997). The efficacy of solution-focused therapy with young offenders. Unpublished doctoral dissertation, York University, New York, Ontario, CA.

Shure, M. B. (1982). Interpersonal problem-solving: A cog in the wheel of social cognition. In F. C. Serafica (Ed.), Social-cognitive development in context (pp.133-166). New York: Guliford.

Smock, S. A. (2004, November). Comparing Intake Forms: Is it a Matter of Semantics? Poster session presented at the Solution-Focused Brief Therapy Association Conference, Park City, UT.

Smock, S. A., Trepper, T. S., Wetchler, J. L., Ray, R., Pierce, K., \& McCollum, E. E., (2005). Solution-Focused Group Therapy for Level 1 Substance Abusers. Manuscript submitted for publication.

Snyder, C. R. (1995). Conceptualizing, Measuring, and Nurturing Hope. Journal of Counseling \& Development, 73, 355-360.

Spivack, G., \& Shure, M. B. (1974). Social adjustment of young children: A cognitive approach to solving real-life problems. San Francisco: Jossey-Bass.

Staas, S. R., \& Stassen, M. A. (1985). Hope: An affective cognition. Social Indicators Research, 17, 235-242.

Sternberg, R. J. (1982). Reasoning, problem-solving, and intelligence. In R. J. Sternberg (Ed.), Handbook of human intelligence (pp. 225-307). New York: Cambridge University Press.

Sundman, P. (1997). Solution-focused ideas in social work. Journal of Family Therapy, 19, 159-172.

Sundstrom, S. M. (1993). Single-session psychotherapy for depression: Is it better to focus on problems or solutions? Unpublished doctoral dissertation, Iowa State University, Ames IA.

Suzuki, L. A., \& Ahluwalia, M. K. (2004). Two decades of research on the problem solving inventory: A call for empirical clarity. The Counseling Psychologist, 32, 429-438. 
Tabachnick, B. G., \& Fidell, L. S. (2001). Using multivariage statistics. Boston: Allen and Bacon.

Toblin, D. L., Holroyd, K. A., Reynolds, R. V., \&Wigal, J. K. (1989). The hierarchical factor structure of the coping strategies inventory. Cognitive Therapy and Research, 13, 343-361.

Triantafillou, N. (1997). A solution-focused approach to mental health supervision. Journal of Systemic Therapies, 16, 305-328.

Urban, H., \& Ford, H. (1971). Some historical and conceptual perspectives of psychotherapy and behavioral change. In A. Bergin \& S. Garfield (Eds.), Handbook of psychotherapy and behavior change. New York: Wiley.

Walter, J. L., \& Peller, J. E. (1992). Becoming solution-focused in brief therapy. New York: Brunner/Mazel.

Watzlawick, P., Weakland, J., \& Fisch, R. (1974). Change: Principles of problem formation and problem resolution. New York: Norton.

Wickelgren, W. (1974). How to solve problems. San Francisco: Freeman.

Zeig, J. K. (Ed.). (1985). Eriksonian psychotherapy. New York: Brunner/Mazel.

Zimmerman, T. S., Jacobsen, R. B., MacIntyre, M., \& Watson, C. (1996). Solutionfocused parenting groups: An empirical study. Journal of Systemic Therapies, 15, $12-25$.

Zimmerman, T. S., Prest, L. A., \& Wetzel, B. E. (1997). Solution-focused couples therapy groups: An empirical study. Journal of Family Therapy, 19, 125-144. 
Appendix A. IRB Synopsis, Informed Consent Forms, and IRB Approval Letters

\section{The Development of the Solution Building Inventory \\ Pilot Study: Rating Items \\ Sara A. Smock \\ Department of Human Development}

Narrative

\section{Justification}

Individuals have faced and solved problems since time began. Within the past several decades, the study of applied problem solving has become an area of focus (e.g., D'Zurilla \& Goldfried, 1971; Shure, 1982; Sternberg, 1982). Defining and testing effective and ineffective problem solving skills possesses a great relevance still today for helping professionals aiding individuals in handling life's obstacles.

Examining change solely from a problem focused approach can be limiting. Within the past few decades, there has been a growing interest in taking a different approach to change, one that focuses on creating solutions rather than solving problems (de Shazer, 1985; de Shazer, Berg, Lipchik, Nunnally, Molnar, Gingerich et al., 1986). Preliminary research indicates that taking a solution-focused approach has benefits in decreasing depression (Cockburn, Thomas \& Cockburn, 1997), increasing parenting skills (Sundstrom 1993), and increasing psychosocial adjustment in returning to work after orthopedic injuries (Zimmerman, Jacobsen, MacIntyre \& Watson, 1996).

The concept of solution building is central to solution focused brief therapy (SFBT) and is mentioned throughout the SFBT literature (Berg, 1994; DeJong \& Berg, 1998; de Shazer, 1988; 1991; 1993). DeJong and Berg (1998) state that the strategies used for solution building differ significantly from problem solving. Solution building helps people to ask where they want to be in life where problem solving is focused on developing a specific resolution for a specific problem. Although the idea of problems and solutions is discussed frequently, the components of solution building have not been identified. Thus, it is important for the factors of solution building to be discovered in order to offer additional means, besides problem solving, for aiding individuals with life situations. 
The purpose of this study is to have experts rate items to help develop a solution building inventory. Then, a later study will test the items of the solution building inventory. To date, a measure that identifies solution-building tenets does not exist. The importance of determining how solution building differs from problem solving approaches will become a question asked by grant funders. By developing a scale that is able to identify factors of solution-building, a greater awareness of how it differs from cognitive behavioral approaches seems valuable.

\section{Procedures}

In order to develop the solution building inventory, this study will recruit a group of experts on solution focused theory to rate potential items for the inventory. The subject pool will include 3-15 experts on solution focused theory. I will recruit experts from the membership of the Solution Focused Brief Therapy Association to serve as item raters. The experts will rate potential items for the solution building inventory. The items to be rated will be posted on a web-based survey site maintained by Virginia Tech (www.survery.vt.edu). Raters will be given the URL for the website that lists the items to be rated along with a username and password to log onto the site. This will allow the researcher to track which raters have completed the ratings. The identities of the raters will only be known to the researcher. Once the raters reach the website, an informed consent form will appear on the first page. The raters must check a box that they agree to the conditions of the study. This will serve as their electronic signature for the informed consent. The experts will be asked to rate each item on a Likert scale (see attached pool of items to be rated). Raters will have the chance to add new items or edit existing items. When all raters have completed their ratings, the researcher will refine the list of items based on the average score of each item resulting in a preliminary draft of the inventory. Then, the raters will repeat the above protocol for wave 2 of data collection using the preliminary draft. Based on the second rating, a final version of the questionnaire will be developed for testing in a future study.

Once this pilot study is complete, the researcher will conduct an additional study to test the created measure using undergraduates. A separate IRB request for this project will be submitted once the pilot study is complete. 


\section{Risks and Benefits}

Since raters are only asked to give their expert opinion on items to be used for the solution building inventory, no known risk is evident.

The benefit of using experts to rate items is to develop a theoretically grounded questionnaire that will further the work of solution focused brief therapy.

\section{Confidentiality}

During the rating process, the data will be kept on the university survey site under password protection, available only to the researcher. Once the ratings have been completed, the dataset will be downloaded onto a CD ROM that the researcher will keep in a locked filing cabinet when not being used for data analysis. This analysis database will not include the names of the raters. Data will only be accessed by the researcher and her committee members if necessary.

Raters names will be known to the researcher but names will not be included in the database used for data analysis of the data nor will they be linked to specific responses in any publications or presentations.

\section{Compensation}

Compensation will not be offered to the raters.

\section{Informed Consent}

Raters will complete the informed consent prior to their participation in the study.

\section{References}

Berg, I. K. (1994). Family-based services: A solution-focused approach. New York:

W. W. Norton.

Cockburn, J. T., Thomas, F. N., \& Cockburn, O. J. (1997). Solution-focused therapy and psychosocial adjustment to orthopedic rehabilitation in a work hardening program. Journal of Occupational Rehabilitation, 7(2), 97-106.

DeJong, P., \& Berg, I. K. (1998). Interviewing for solutions. Pacific Grove, CA: Brooks/Cole.

de Shazer, S. (1985). Keys to solution in brief therapy. New York: W.W. Norton.

de Shazer, S. (1988a). Clues: Investigating solutions in brief therapy. New York: W.W. Norton. 
de Shazer, S. (1991). Putting difference to work. New York:W.W. Norton.

de Shazer, S. (1993). Creative misunderstanding: There is no escape from language. In S. Gilligan \& R. Price (Eds.), Therapeutic conversations. New York: W. W. Norton $\&$ Co.

de Shazer, S., Berg, I. K., Lipchik, E., Nunnaly, E., Molnar, A., Gingerich, W., \& et al. (1986). Brief therapy: Focused solution development. Family Process, 25, 207221.

D’Zurilla, T. J., \& Goldfried, M. R. (1971). Problem solving and behavior modification. Journal of Abnormal Psychology, 78, 107-126.

Shure, M. B. (1982). Interpersonal problem solving: A cog in the wheel of social cognition. In F. C. Serafica (Ed.), Social-cognitive development in context (pp.133-166). New York: Guliford.

Sternberg, R. J. (1982). Reasoning, problem solving, and intelligence. In R. J. Sternberg (Ed.), Handbook of human intelligence (pp. 225-307). New York: Cambridge University Press.

Sundstrom, S. M. (1993). Single-session psychotherapy for depression: Is it better to focus on problems or solutions? Unpublished doctoral dissertation, Iowa State University, Ames IA.

Zimmerman, T. S., Jacobsen, R. B., MacIntyre, M., \& Watson, C. (1996). Solutionfocused parenting groups: An empirical study. Journal of Systemic Therapies, 15, $12-25$. 


\section{VIRGINIA POLYTECHNIC INSTITUTE AND STATE UNIVERSITY \\ Informed Consent for Inventory Raters \\ In Research Projects Involving Human Subjects}

Title of Project: The Development of the Solution Building Inventory Pilot Study:

\section{$\underline{\text { Rating Items }}$}

\section{Investigator(s): $\underline{\text { Sara A. Smock }}$}

\section{Purpose of this Research/Project}

The purpose of this project is to understand the components of solution building.

\section{Procedures}

- You are being asked to judge how closely proposed inventory items fit the concept of "solution-building" as a first step in developing a preliminary questionnaire to measure solution building.

- You will be asked to rate two sets of items - once to develop a preliminary draft of the inventory and again to finalize the inventory

\section{Risks}

Since raters are only asked to give their expert opinion on items to be used for the solution building inventory, no known risk is evident.

\section{Benefits}

The benefit of using experts to rate items is to develop a theoretically grounded questionnaire that will further the work of solution focused brief therapy.

\section{Extent of Anonymity and Confidentiality}

Raters names will be known to the researcher but names will not play a factor in the analysis of the data nor will they be linked to specific responses in any publications or presentations. Data will be kept on the university survey site under password protection, available only to the researcher. Once the ratings have been completed, the dataset will be downloaded onto a CD ROM that the researcher will keep in a locked filing cabinet when not being used for data analysis. This analysis database will not include the names of the raters. Data will only be accessed by the researcher and her committee members if necessary. 


\section{Compensation}

Compensation will not be offered to the raters.

\section{Freedom to Withdraw}

Participation in this study is completely voluntary. Whether or not you participate is up to you. Raters will not be allowed to rate items without signing this consent form.

Participant's Signature

Date

Should I have any pertinent questions about this research or its conduct, and research subject's rights, and whom to contact in the event of a research-related injury to the subject, I may contact:

Sara A. Smock $\quad$ (540) 231-1646 ssmock@,vt.edu Investigator

Eric E. McCollum (703) 538-8463 ericmccollum@vt.edu Committee Chair

David M. Moore (540) 231-4991_moored@,vt.edu

\section{Chair, Virginia Tech}




\section{The Development of the Solution Building Inventory \\ Sara A. Smock \\ Department of Human Development \\ Narrative}

\section{Justification}

Individuals have faced and solved problems since time began. Within the past several decades, the study of applied problem solving has become an area of focus (e.g., D’Zurilla \& Goldfried, 1971; Shure, 1982; Sternberg, 1982). Defining and testing effective and ineffective problem solving skills possesses a great relevance still today for helping professionals aiding individuals in handling life's obstacles.

Examining change solely from a problem focused approach can be limiting. Within the past few decades, there has been a growing interest in taking a different approach to change, one that focuses on creating solutions rather than solving problems (de Shazer, 1985; de Shazer, Berg, Lipchik, Nunnally, Molnar, Gingerich et al., 1986). Preliminary research indicates that taking a solution-focused approach has benefits in decreasing depression (Cockburn, Thomas \& Cockburn, 1997), increasing parenting skills (Sundstrom 1993), and increasing psychosocial adjustment in returning to work after orthopedic injuries (Zimmerman, Jacobsen, MacIntyre \& Watson, 1996).

The concept of solution building is central to solution focused brief therapy (SFBT) and is mentioned throughout the SFBT literature (Berg, 1994; DeJong \& Berg, 1998; de Shazer, 1988; 1991; 1993). DeJong and Berg (1998) state that the strategies used for solution building differ significantly from problem solving. Solution building helps people to ask where they want to be in life where problem solving is focused on developing a specific resolution for a specific problem. Although the idea of problems and solutions is discussed frequently, the components of solution building have not been identified. Thus, it is important for the factors of solution building to be discovered in order to offer additional means, besides problem solving, for aiding individuals with life situations.

The purpose of this study is to develop a solution building inventory in order to identify the components of solution building. To date, a measure that identifies solutionbuilding tenets does not exist. The importance of determining how solution building 
differs from problem solving approaches will become a question asked by grant funders. By developing a scale that is able to identify factors of solution-building, a greater awareness of how it differs from cognitive behavioral approaches seems valuable.

\section{Procedures}

In order to develop the online questionnaire, a group of experts on solution focused theory rated items on a likert scale according to how closely they illustrate the concept of solution building (completed in a previous study). Items were chosen from their rankings to develop the solution building inventory questions.

The subject pool of this study will include a total of between 400 and 500 undergraduate students. I will recruit 100-200 students for the first wave of data and 300 students for the second wave of data collection. Undergraduate students will be invited by their professors at Virginia Tech to participate in an online questionnaire. The questionnaire will be on a web-based survey site maintained by Virginia Tech (www.survery.vt.edu). Participants will be given the URL for the survey. The participants must check a box that they agree to the conditions of the study. This will serve as their electronic signature for the informed consent. The survey will then ask participants who would like to receive extra credit points to provide their name and their instructor's name. An email will be generated to the researcher once the survey is completed so that the student can receive extra credit points. The instructor will not receive the participants scores and the participants' names will not be saved in the data set. After electronically signing the informed consent, the participants will be asked to rate each item on a Likert scale. Items on the questionnaire will consist of items compiled from an earlier study (see attached). After the initial wave of data are collected, additional undergraduate students will be invited to complete another online questionnaire (the same students will not participate in both waves of data). Items on this questionnaire will consist of items from the first survey as well as the Dispositional Hope Scale and the Life Orientation Test Revised (see attached). An additional wave of data will be collected in order to increase the stability and replicability of structural analyses (see Guadagnoli \& Velicer, 1988). The online survey will track participants by their Virginia Tech personal identification username (PID) and will not allow the same individual to complete the 
survey more than one time. In addition, the researcher and her committee members will have access to the data but participants' names will not be listed in the data set.

\section{Risks and Benefits}

One possible risk for participants in this study includes self-analysis. When people look carefully at their experiences and beliefs, they might see things with which they are not pleased. However, because the questionnaire is solution focused the amount of negative self appraisal should be reduced.

The benefit of this study is to develop a theoretically grounded questionnaire that will further the work of solution focused brief therapy.

\section{Confidentiality}

The PIDs of the participants will be used by the survey to ensure each participant only takes the survey one time. Participant names will appear on the survey but will not been saved in the data set. The researcher will give instructors a list of participants for the purpose of extra credit but will not give out participants' responses. Professors offering extra credit will also provide another alternative for earning extra credit points.

\section{Compensation}

Participants may receive extra credit for completing the solution focused inventory by their professor. Professors offering extra credit will also provide another alternative for earning extra credit points.

\section{Informed Consent}

Participants will complete the informed consent online. The participants must check a box that they agree to the conditions of the study. This will serve as their electronic signature for the informed consent. The survey will ask participants who would like to receive extra credit points to provide their name and their instructor's name. An email will be generated to the researcher once the survey is completed so that the student can receive extra credit points. The instructor will not receive the participants scores.

\section{References}

Berg, I. K. (1994). Family-based services: A solution-focused approach. New York:

W. W. Norton. 
Cockburn, J. T., Thomas, F. N., \& Cockburn, O. J. (1997). Solution-focused therapy and psychosocial adjustment to orthopedic rehabilitation in a work hardening program. Journal of Occupational Rehabilitation, 7(2), 97-106.

DeJong, P., \& Berg, I. K. (1998). Interviewing for solutions. Pacific Grove, CA:

Brooks/Cole.

de Shazer, S. (1985). Keys to solution in brief therapy. New York: W.W. Norton.

de Shazer, S. (1988a). Clues: Investigating solutions in brief therapy. New York: W.W. Norton.

de Shazer, S. (1991). Putting difference to work. New York:W.W. Norton.

de Shazer, S. (1993). Creative misunderstanding: There is no escape from language. In S. Gilligan \& R. Price (Eds.), Therapeutic conversations. New York: W. W. Norton $\&$ Co.

de Shazer, S., Berg, I. K., Lipchik, E., Nunnaly, E., Molnar, A., Gingerich, W., \& et al. (1986). Brief therapy: Focused solution development. Family Process, 25, 207221.

D’Zurilla, T. J., \& Goldfried, M. R. (1971). Problem solving and behavior modification. Journal of Abnormal Psychology, 78, 107-126.

Guadagnoli, E., \& Velicer, W. F. (1988). Relation of sample size to the stability of component patterns. Psychological Bulletin, 103, 265-275.

Shure, M. B. (1982). Interpersonal problem solving: A cog in the wheel of social cognition. In F. C. Serafica (Ed.), Social-cognitive development in context (pp.133-166). New York: Guliford.

Sternberg, R. J. (1982). Reasoning, problem solving, and intelligence. In R. J. Sternberg (Ed.), Handbook of human intelligence (pp. 225-307). New York: Cambridge University Press.

Sundstrom, S. M. (1993). Single-session psychotherapy for depression: Is it better to focus on problems or solutions? Unpublished doctoral dissertation, Iowa State University, Ames IA.

Zimmerman, T. S., Jacobsen, R. B., MacIntyre, M., \& Watson, C. (1996). Solutionfocused parenting groups: An empirical study. Journal of Systemic Therapies, 15, $12-25$. 


\section{VIRGINIA POLYTECHNIC INSTITUTE AND STATE UNIVERSITY Informed Consent for Participants In Research Projects Involving Human Subjects}

Title of Project: The Development of the Solution Building Inventory

Investigator(s): $\underline{\text { Sara A. Smock }}$

\section{Purpose of this Research/Project}

The purpose of this project is to understand the components of solution building.

\section{Procedures}

- Participants will be asked to participate in an online questionnaire. The estimated amount of time to take the questionnaire is 10-20 minutes.

- Participants will be asked questions about how they perceive their life.

\section{Risks}

One possible risk for participants in this study includes self-analysis. When people look carefully at their experiences and beliefs, they might see things with which they are not pleased. However, because the questionnaire is solution focused the amount of negative self appraisal should be reduced.

\section{Benefits}

The benefit of this study is to develop a theoretically grounded questionnaire that will further the work of solution focused brief therapy.

\section{Extent of Anonymity and Confidentiality}

The survey will ask participants who would like to receive extra credit points to provide their name and their instructor's name. An email will be generated to the researcher once the survey is completed so that the student can receive extra credit points. The instructor will not receive the participants scores. The names of the participants will not be stored in the data set.

\section{Compensation}

Some instructors may offer extra credit for participants of this study. Professors offering extra credit will also provide another alternative for earning extra credit points. 


\section{Freedom to Withdraw}

Participation in this study is completely voluntary. Whether or not you participate is up to you.

Participant's Signature

Date

Should I have any pertinent questions about this research or its conduct, and research subject's rights, and whom to contact in the event of a research-related injury to the subject, I may contact:

Sara A. Smock $\quad$ (540) 231-1646 $\quad$ ssmock@,vt.edu Investigator

Eric E. McCollum (703) 538-8463 ericmccollum@,vt.edu

\section{Committee Chair}

David M. Moore (540) 231-4991_moored@,vt.edu

\section{Chair, Virginia Tech}




\section{The SBI}

For the following items, please respond by stating strongly agree, agree, neutral, disagree, or strongly disagree.

$5=$ Strongly agree

4= Agree

$3=$ Neutral

$2=$ Disagree

$1=$ Strongly disagree

1.I am able to cope well with difficult life circumstances

2. I can recognize small steps as important even though they are small.

3. I am able to generate solutions.

4. I have the ability to focus on what I want to occur in my life.

5. I can think about things that have made a positive difference for me.

6. I am able to focus on times when my situation is not so overwhelming, even a little bit.

7.There are times in my life where I am able to handle difficulties well.

8. It is important to focus on solutions.

9.I believe that it is more important to focus on solutions rather than problems.

10. I am able to notice good things in myself, others, and my situation.

11.I have been able to cope with life's challenges.

12. If I woke up tomorrow and a miracle happened in my life I would be able to notice differences in myself and others.

13. I am aware of small positive changes that I make.

14. There are times when I am really proud of how I am able to handle difficult situations.

15. I have successfully overcome challenges in the past.

16.I have make steps towards improving my life.

17. I can think of times when my problems are less overwhelming.

18.I can recognize in others when things may be going better for me. 
19. I am able to see good things in my situation, even though parts of it seem very difficult.

20. I am willing to try new things or old things in a different way.

21.Dwelling on my problems may not be the best way to find solutions.

22. I can recognize things that I can do, even though it seems that the problem is someone else.

\section{Dispositional Hope Scale}

Directions: Read each item carefully. Using the scale shown below, please select the number that best describes YOU and put that number in the blank provided.

1=Definitely False

2=Mostly False

$3=$ Mostly True

4=Definitely True

1. I can think of many ways to get out of a jam.

2. I energetically pursue my goals.

3. I feel tired most of the time.

4. There are lots of ways around any problem.

5. I am easily downed in an argument.

6. I can think of many ways to get the things in life that are most important to me.

7. I worry about my health.

8. Even when others get discouraged, I know I can find a way to solve the problem.

9. My past experiences have prepared me well for my future.

10. I've been pretty successful in life.

11. I usually find myself worrying about something.

12. I meet the goals that I set for myself. 


\section{Life Orientation Test Revised}

Please be as honest and accurate as you can throughout. Try not to let your response to one statement influence your responses to other statements. There are no "correct" or "incorrect" answers. Answer according to your own feelings, rather than how you think "most people" would answer.

$1=\mathrm{I}$ agree a lot

$2=\mathrm{I}$ agree a little

$3=$ I neither agree nor disagree

$4=$ I disagree a little

$5=\mathrm{I}$ disagree a lot

1. In uncertain times, I usually expect the best.

2. It's easy for me to relax.

3. If something can go wrong for me, it will.

4. I'm always optimistic about my future.

5. I enjoy my friends a lot.

6. It's important for me to keep busy.

7. I hardly ever expect things to go my way.

8. I don't get upset too easily.

9. I rarely count on good things happening to me.

10. Overall, I expect more good things to happen to me than bad. 


\section{Virginia}

CVM Phase II- Duckpond Dr., Blacksburg, VA 24061-0442

Office: 540/231-4991; FAX: 540/231-6033

email: moored@vt.edu

DATE: $\quad$ July 28,2005

\section{MEMORANDUM}

TO:

Eric E. McCollum HD 0362 Sara Smock HD 0515

FROM: David Moore

SUBJECT: IRB Exempt Approval: "Development of the Solution Building Inventory Pilot Study" IRB \# 05-442

I have reviewed your request to the IRB for exemption for the above referenced project. I concur that the research falls within the exempt status. Approval is granted effective as of July 28, 2005.

Virginia Tech has an approved Federal Wide Assurance (FWA00000572, exp. 7/20/07) on file with OHRP, and its IRB Registration Number is IRB00000667.

cc: File

Department Reviewer: Fred P. Piercy 


\section{Virginia}

DATE: $\quad$ September 9, 2005

MEMORANDUM

TO:

FROM: David Moore

SUBJECT: IRB Exempt Approval: “The Development of the Solution Building Inventory" IRB \# 05-533

I have reviewed your request to the IRB for exemption for the above referenced project. I concur that the research falls within the exempt status. Approval is granted effective as of September 9, 2005.

Virginia Tech has an approved Federal Wide Assurance (FWA00000572, exp. 7/20/07) on file with OHRP, and its IRB Registration Number is IRB00000667.

cc: File 
Appendix B

\author{
Recruitment Advertisement
}

ATTENTION FACULTY

My name is Sara Smock and I am a Ph.D. candidate in the Human Development department. I invite you to ask your students to participate in an online questionnaire. The short questionnaire will ask participants to reflect on how they view their life and takes between 10-20 minutes to complete. Feel free to offer extra credit for participating students but please make sure that an alternative extra credit option is available for students who do not wish to participate in this project. Have your students go to https://survey.vt.edu/survey/entry.jsp?id=1124314440257 (PLEASE COPY AND PASTE THE URL INSTEAD OF CLICKING ON IT AS A HYPERLINK) to complete the questionnaire. If you have any questions, feel free to email me at ssmock@,vt.edu

Thank you,

Sara A. Smock, M.S.

Ph.D. Candidate 


\section{Appendix C}

Items to be Evaluated for the Solution Building Inventory

Please rate the following items as to how closely they measure solution focused concepts using the statement below as a guide. Please rate each item individually and do not compare items to one another.

Solution building seems to possess the following three components: an individual's willingness to imagine and describe how they want their life to be different, their awareness of exceptions, and hope -- evidenced by a willingness to focus on future possibilities.

$5=$ Strongly measure $4=$ Somewhat measure $3=$ Neutral $2=$ Somewhat do not measure $1=$ Strongly do not measure

I am able to cope well with difficult life circumstances

I am able to generate solutions

I am confident in my ability to generate solutions

I am able to make good choices

I am able to create solutions

There are times when problems are absent from my life

I have the ability to focus on what I want to occur in my life

There are times in my life where I am able to handle difficulties well

I have hope for the future

I know where I would like to see myself 1 year from now

I am able to set goals

I am able to accomplish goals

It is helpful to focus on my future

The future is important to me

It is important to focus on solutions

I believe that it is more important to focus on solutions rather than problems 
In difficult life situations I have a hard time focusing on solutions

I am better than most at knowing what would make life better

Things are going fairly well right now

$\begin{array}{lllll}5 & 4 & 3 & 2 & 1\end{array}$

If I woke up tomorrow and a miracle happened in my life I would be able to notice differences in myself and others

I would know things had improved in my life if my friends/family noticed the changes

There are times when my problems are not as obvious

There have been times this week when you expected a problem to exist and it didn't (even a small absence)

I often make plans for the future

I believe I will enjoy my future

I am excited about the rest of my life

I believe that my circumstances will improve

I am a hopeful person

When I have a bad day I have hope that the next day will be better

Hope is important

Even in hard times, I have hope that things can improve

I am aware of small positive changes that I make

$\begin{array}{lllll}5 & 4 & 3 & 2 & 1\end{array}$

I have a clear picture of how I would like my life to be different

There are times when I am really proud of how I am able to handle difficult situations

I am better than most people at feeling hopeful about the future

I am confident in the future

I am confident in my ability to overcome everyday challenges

I am a hopeful person

I have successfully overcome challenges in the past

I have been able to cope with life's challenges

My life can improve

I am able to acknowledge my accomplishments 
I am confident that I can overcome future obstacles in my life

I can see myself happy in the future

I know how to make difficult situations better

$\begin{array}{lllll}5 & 4 & 3 & 2 & 1\end{array}$

I know what my life would look like if it were better

I am successful at making my life the best it can be

The future looks bright

I know what I want in life

I know how to get what I want in life

I have been able to get what I want in life

I believe that in the future I will know what I want from life

Life can be great despite problems

I have the ability to make my future better

I am able to deal with challenges

My life is better today than it has been in the past

I know when my life is better

I have made steps towards improving my life

I know what makes me happy

I have overcome many life challenges

Please list additional items (or items that should be altered from above) that measure solution building: 


\section{Appendix D}

Items to be Rated for the SBI

I am able to cope well with difficult life circumstances

I am able to generate solutions

I am confident in my ability to generate solutions

I have the ability to focus on what I want to occur in my life

There are times in my life where I am able to handle difficulties well

I am able to accomplish goals

It is helpful to focus on my future

The future is important to me

It is important to focus on solutions

I believe that it is more important to focus on solutions rather than problems

If I woke up tomorrow and a miracle happened in my life

I would be able to notice differences in myself and others

I would know things had improved in my life if my friends/family noticed the changes

I am aware of small positive changes that I make

I have a clear picture of how I would like my life to be different

There are times when I am really proud of how I am able to handle difficult situations

I am a hopeful person

I have successfully overcome challenges in the past

I have been able to cope with life's challenges

I know what my life would look like if it were better

I know what I want in life

I have made steps towards improving my life

I have overcome many life challenges

I am able to break goals into smaller steps

I have confidence in my ability to take steps toward goals 
I can think of times when my problems are less overwhelming

I can recognize in others when things may be going better for me

I can think of times when I have been able to solve problems

I can think about things that have made a positive difference for me

I can recognize small steps as important even though they are small

I can recognize things that I can do, even though it seems that the problem is someone

else

I have confidence in my ability to make small changes

I am able to notice good things in myself, others, and my situation

I am able to focus on times when my situation is not so overwhelming, even a little bit

I am able to see good things in my situation, even though parts of it seem very difficult

I am able to give myself pats on the back sometimes

I am able to take compliments in a positive way

I am willing to try new things or old things in a different way

I know that solutions to my problems may not be the same as others'

I know that some solutions that work for others may not work for me

Dwelling on my problems may not be the best way to find solutions 
Appendix E

The SBI

For the following items, please respond by stating strongly agree, agree, neutral, disagree, or strongly disagree.

$5=$ Strongly agree

4= Agree

$3=$ Neutral

$2=$ Disagree

$1=$ Strongly disagree

1.I am able to cope well with difficult life circumstances

2. I can recognize small steps as important even though they are small.

3. I am able to generate solutions.

4. I have the ability to focus on what I want to occur in my life.

5. I can think about things that have made a positive difference for me.

6. I am able to focus on times when my situation is not so overwhelming, even a little bit.

7.There are times in my life where I am able to handle difficulties well.

8. It is important to focus on solutions.

9.I believe that it is more important to focus on solutions rather than problems.

10. I am able to notice good things in myself, others, and my situation.

11.I have been able to cope with life's challenges.

12. If I woke up tomorrow and a miracle happened in my life I would be able to notice differences in myself and others.

13. I am aware of small positive changes that I make.

14. There are times when I am really proud of how I am able to handle difficult situations.

15. I have successfully overcome challenges in the past.

16.I have make steps towards improving my life.

17. I can think of times when my problems are less overwhelming.

18.I can recognize in others when things may be going better for me. 
19. I am able to see good things in my situation, even though parts of it seem very difficult.

20. I am willing to try new things or old things in a different way.

21.Dwelling on my problems may not be the best way to find solutions.

22. I can recognize things that I can do, even though it seems that the problem is someone else. 
Appendix F

Demographic Items.

For the following, please circle the item that applies:

\begin{tabular}{|c|c|c|c|}
\hline \multirow[t]{3}{*}{ Marital Status: } & Single & Engaged & Married \\
\hline & Living together & Separated & Divorced \\
\hline & Widow & Other: & \\
\hline \multirow{4}{*}{\multicolumn{2}{|c|}{ Number of biological children: }} & none & 1 child \\
\hline & & 2 children & 3 children \\
\hline & & 4 children & 5 children \\
\hline & & 6 or more children & \\
\hline Sexual orientation: & Heterosexual & Homosexual & Bisexual \\
\hline \multirow[t]{3}{*}{ Ethnicity: } & African American & Asian & Caucasian \\
\hline & Hispanic & Native American & \\
\hline & Other: & & \\
\hline \multirow[t]{3}{*}{ Religious Affiliation: } & Protestant & Catholic & Jewish \\
\hline & Mormon & Not Religious & \\
\hline & Other: & & \\
\hline
\end{tabular}




\title{
Appendix G
}

Syntax for Confirmatory Factor Analysis for Wave 1 of Data Analysis

\author{
TI SARA TRIAL 1 \\ DA $\mathrm{NI}=22 \mathrm{NO}=97 \mathrm{MA}=\mathrm{CM}$ \\ CM FU
}

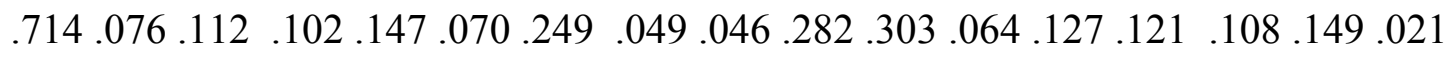

.058 .218 .066 .038 .146

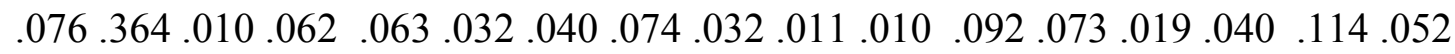

.021 .105 .072 .039 .011

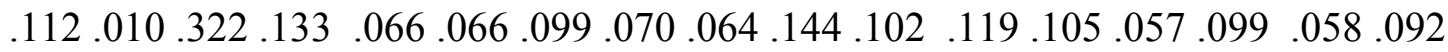

.019 .086 .069 .018 .074

.102.062.133.651. 164.069.104. 204.140.191.129. 079. 179 . 164 .154.

.039 .194 .105 .150 .128

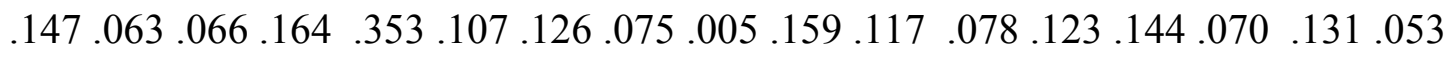

.078 .096 .009 .065 .105

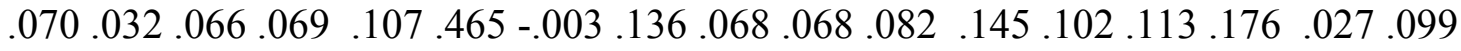

.048 .181 .150 .025 .080

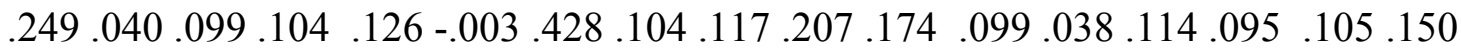

.152 .132 .099 .004 .063

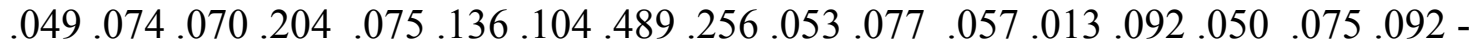

.002 .164 .032 .062 .044

180

$.014 .151-.054 .072 .070$

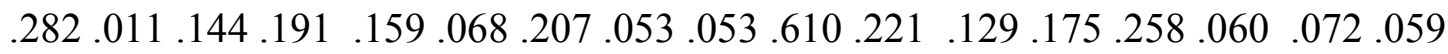

.088 .203 .094 .043 .176

.303.010.102.129. 117. 080. 144. 131. 144. 074. 074. 066. 221. 347.

.076 .153 .041 .078 .108

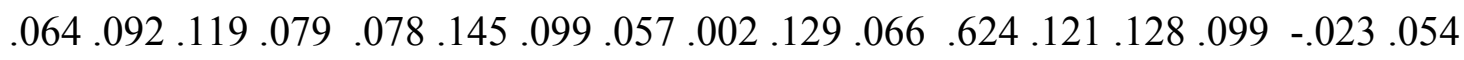

.204 .101 .097 .005 .102 


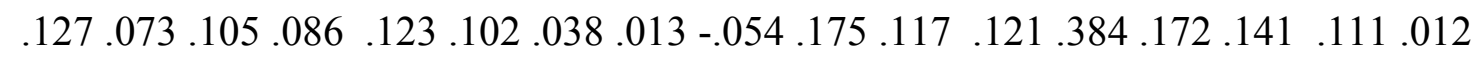
.054 .175 .098 .054 .176 .121.019.057.164. 144. 1138.114.092.022. 258.141. 128. 172. 569. .056 .224 .110 .117 .122

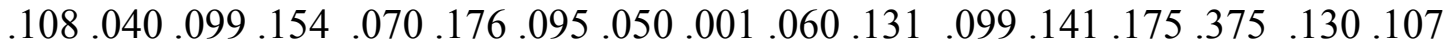
.058 .160 .164 .056 .070

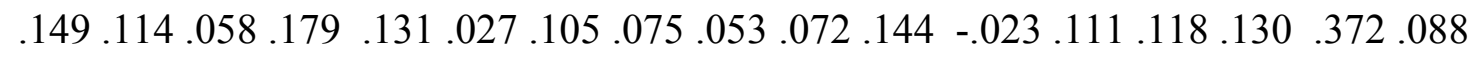
.058 .098 .018 .087 .061 .021.052.092.101. 053.099. 150.092. 180.059.080. 054.019. 138 .107 .128 .099 .104 .064

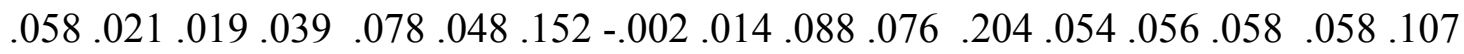
$.541 .095 .036-.040 .157$ .218.105.086.194.096.181. 132. 164.151.203. 153. 101. 175 . 224. .095 .493 .105 .097 .142

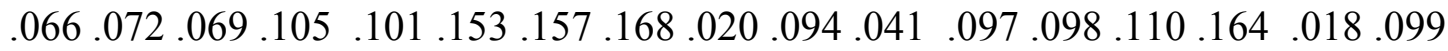
.036 .105 .596 .053 .037 .040 .097 .053 .442 .111 .064 061. 070. .157 .142 .037 .111 .373 MO NX=22 NK=8 PH=ST, FR FR LX(1,1) LX(7,1) LX(10,1) LX(11,1) LX(4,2) LX(5,2) LX(15,2) LX(16,2) LX(13,3) LX(14,3) LX(21,3) LX(22,3) LX(8,4) LX(9,4) LX(19,4) LX(6,5) LX(12,5) LX(18,5) $\operatorname{LX}(17,6) \operatorname{LX}(20,6) \operatorname{LX}(3,7) \operatorname{LX}(2,8)$

PD

OU ME=ML ALL 
Appendix $\mathrm{H}$

Syntax for Confirmatory Factor Analysis for Theoretical Model

\section{TI SARA TRIAL 1 PROPOSED}

DA $\mathrm{NI}=22 \mathrm{NO}=97 \mathrm{MA}=\mathrm{CM}$

\section{FU}

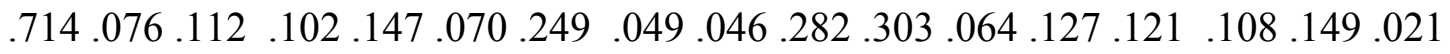

.058 .218 .066 .038 .146

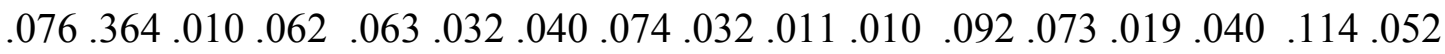

.021 .105 .072 .039 .011

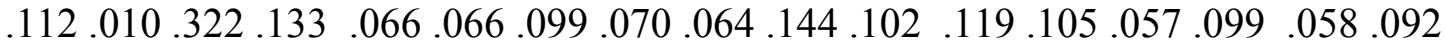

.019 .086 .069 .018 .074

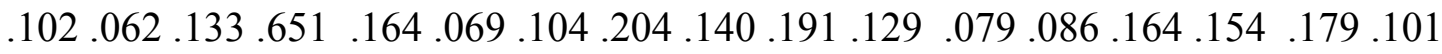

.039 .194 .105 .150 .128

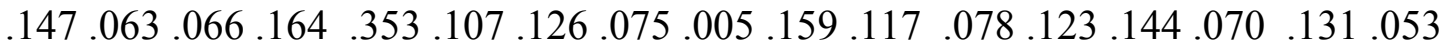

.078 .096 .009 .065 .105

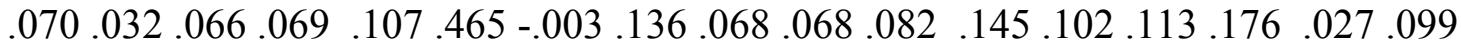

.048 .181 .150 .025 .080

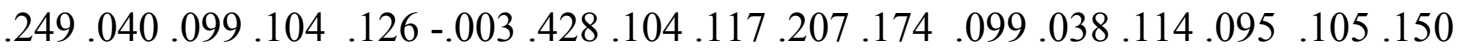

.152 .132 .099 .004 .063

-

.002 .164 .032 .062 .044

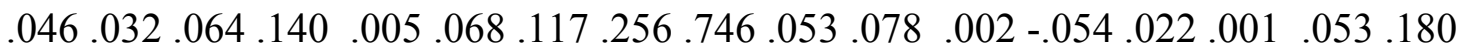

$.014 .151-.054 .072 .070$

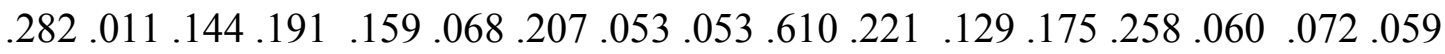

.088 .203 .094 .043 .176

.303.010.102.129. 117. 080. 144. 131. 144. 074. 066. 074. 221. 347.

.076 .153 .041 .078 .108

.064.092.119.079.078. 054.023. 099

.204 .101 .097 .005 .102 


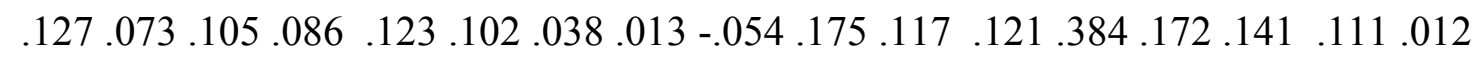
.054 .175 .098 .054 .176 .121.019.057.164. 144. 1138.114.092.022. 258.141. 128. 172. 569. .056 .224 .110 .117 .122

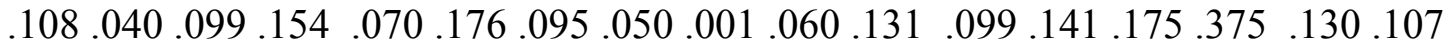
.058 .160 .164 .056 .070

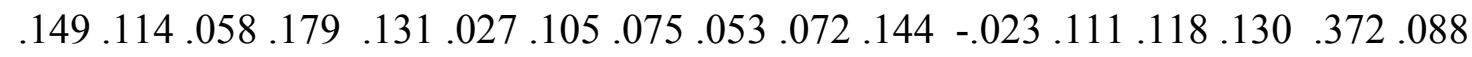
.058 .098 .018 .087 .061 .021.052.092.101. 053.099. 150.092. 180.059.080. 054.019. 138 .107 .128 .099 .104 .064

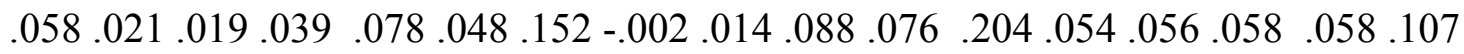
$.541 .095 .036-.040 .157$ .218.105.086.194.096.181. 132. 164.151.203.153. 101. 175. 224.160 .095 .493 .105 .097 .142

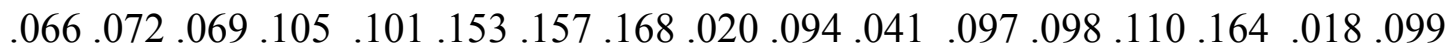
.036 .105 .596 .053 .037 .040 .097 .053 .442 .111 .064 061. 070. .157 .142 .037 .111 .373 $\mathrm{MO} \mathrm{NX}=22 \mathrm{NK}=3 \mathrm{PH}=\mathrm{ST}, \mathrm{FR}$ FR LX(4,1) LX(5,1) LX(15,1) LX(16,1) LX(6,1) LX(12,1) LX(18,1) LX(17,2) LX(20,2) $\operatorname{LX}(8,2) \operatorname{LX}(9,2) \operatorname{LX}(19,2) \operatorname{LX}(13,2) \operatorname{LX}(14,2) \operatorname{LX}(21,2) \operatorname{LX}(22,2) \operatorname{LX}(1,3) \operatorname{LX}(7,3)$ $\operatorname{LX}(10,3) \operatorname{LX}(11,3) \operatorname{LX}(2,3) \operatorname{LX}(3,3)$

PD

OU ME=ML ALL 
Appendix I

Syntax for CFA for $2^{\text {nd }}$ wave Data Driven Model

TI SARA SBI TRIAL 2

$\mathrm{DA} \mathrm{NI}=22 \mathrm{NO}=302 \mathrm{MA}=\mathrm{CM}$

CM FU

$\begin{array}{llllllllllll}.719 & .216 & .176 & .171 & .159 & .233 & .311 & .116 & .113 & .217 & .432 & .049\end{array}$

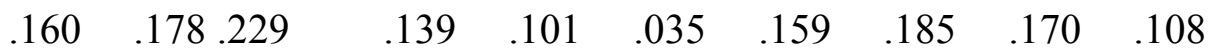

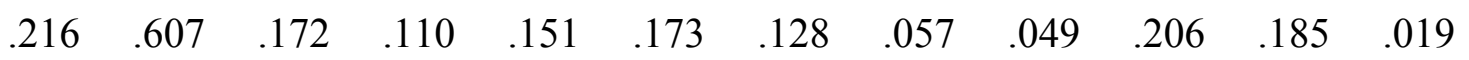

$\begin{array}{lllllllll}.251 & .154 .180 & .120 & .123 & .080 & .277 & .212 & .136 & .155\end{array}$

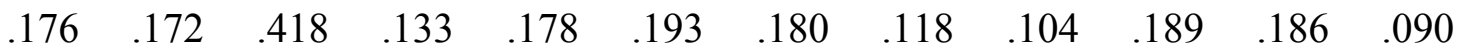

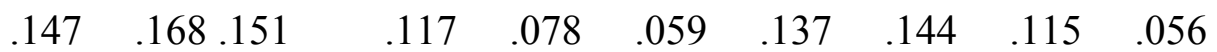

$\begin{array}{llllllllllll}.171 & .110 & .133 & .608 & .272 & .200 & .144 & .130 & .076 & .181 & .194 & .084\end{array}$

$\begin{array}{lllllllll}.204 & .168 .118 & .199 & .069 & .060 & .126 & .170 & .097 & .044\end{array}$

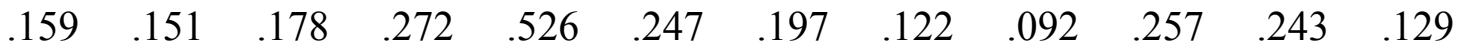

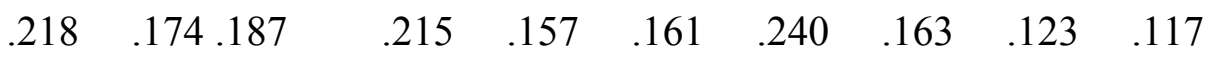

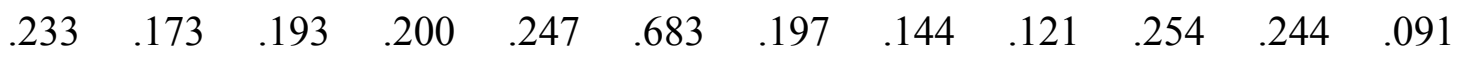

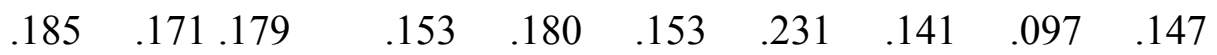

$\begin{array}{llllllllllll}.311 & .128 & .180 & .144 & .197 & .197 & .534 & .177 & .129 & .241 & .301 & .085\end{array}$

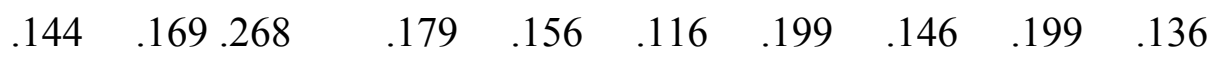

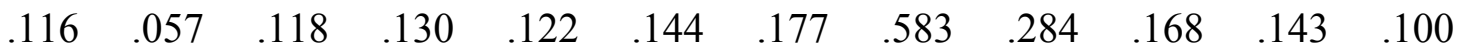

$\begin{array}{lllllllll}.108 & .145 .137 & .140 & .078 & .087 & .118 & .070 & .126 & .116\end{array}$

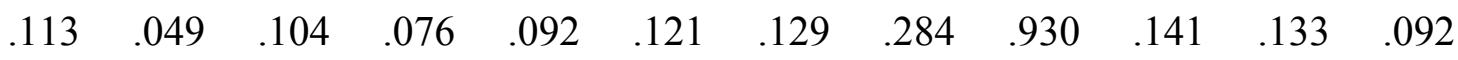

$\begin{array}{lllllllll}.069 & .074 .079 & .114 & .056 & .037 & .119 & .097 & .221 & .036\end{array}$

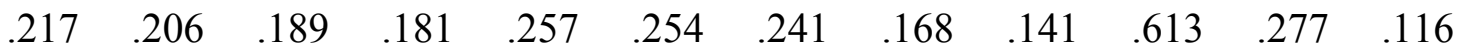

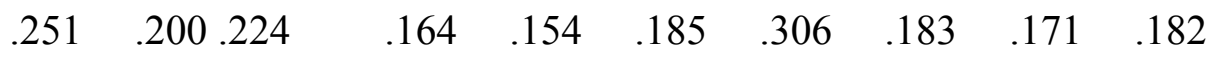

$\begin{array}{llllllllllll}.432 & .185 & .186 & .194 & .243 & .244 & .301 & .143 & .133 & .277 & .616 & .089\end{array}$

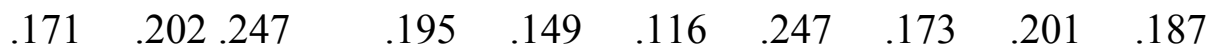

$\begin{array}{llllllllllll}.049 & .019 & .090 & .084 & .129 & .091 & .085 & .100 & .092 & .116 & .089 & .570\end{array}$

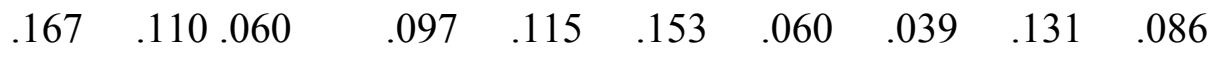


$\begin{array}{llllllllllll}.160 & .251 & .147 & .204 & .218 & .185 & .144 & .108 & .069 & .251 & .171 & .167\end{array}$ $\begin{array}{lllllllll}.606 & .246 .171 & .228 & .095 & .215 & .263 & .254 & .148 & .171\end{array}$

$\begin{array}{llllllllllll}.178 & .154 & .168 & .168 & .174 & .171 & .169 & .145 & .074 & .200 & .202 & .110\end{array}$ $\begin{array}{lllllllll}.246 & .593 .249 & .213 & .100 & .128 & .184 & .213 & .172 & .123\end{array}$

$\begin{array}{llllllllllll}.229 & .180 & .151 & .118 & .187 & .179 & .268 & .137 & .079 & .224 & .247 & .060\end{array}$ $\begin{array}{lllllllll}.171 & .249 .441 & .244 & .135 & .092 & .185 & .162 & .169 & .111\end{array}$

$\begin{array}{llllllllllll}.139 & .120 & .117 & .199 & .215 & .153 & .179 & .140 & .114 & .164 & .195 & .097\end{array}$ $\begin{array}{lllllllll}.228 & .213 .244 & .491 & .126 & .163 & .169 & .213 & .179 & .143\end{array}$

$\begin{array}{llllllllllll}.101 & .123 & .078 & .069 & .157 & .180 & .156 & .078 & .056 & .154 & .149 & .115\end{array}$ $\begin{array}{llllllllll}.095 & .100 .135 & .126 & .549 & .149 & .136 & .043 & .113 & .088\end{array}$

$\begin{array}{llllllllllll}.035 & .080 & .059 & .060 & .161 & .153 & .116 & .087 & .054 & .135 & .121 & .102\end{array}$ $\begin{array}{lllllllll}.292 & .244 .209 & .149 & .051 & .310 & .194 & .155 & .084 & .182\end{array}$

$\begin{array}{llllllllllll}.159 & .277 & .137 & .126 & .240 & .231 & .199 & .118 & .119 & .306 & .247 & .060\end{array}$ $\begin{array}{lllllllll}.263 & .184 .185 & .169 & .136 & .240 & .687 & .282 & .169 & .238\end{array}$

$\begin{array}{llllllllllll}.185 & .212 & .144 & .170 & .163 & .141 & .146 & .070 & .097 & .183 & .173 & .039\end{array}$ $\begin{array}{lllllllll}.254 & .213 .162 & .213 & .043 & .155 & .282 & .737 & .182 & .161\end{array}$

$\begin{array}{llllllllllll}.170 & .136 & .115 & .097 & .123 & .097 & .199 & .126 & .221 & .171 & .201 & .131\end{array}$ $\begin{array}{lllllllll}.148 & .172 .169 & .179 & .113 & .084 & .169 & .182 & .584 & .152\end{array}$ $\begin{array}{llllllllllll}.108 & .155 & .056 & .044 & .117 & .147 & .136 & .116 & .036 & .182 & .187 & .086\end{array}$ $\begin{array}{lllllllll}.171 & .123 .111 & .143 & .088 & .182 & .238 & .161 & .152 & .555\end{array}$

MO NX=22 NK=6 PH=ST, FR

FR LX(1,1) LX(7,1) LX(11,1) LX(15,1) LX(2,2) LX(10,2) LX(18,2) LX(19,2) LX(22,2) $\operatorname{LX}(13,3) \operatorname{LX}(14,3) \operatorname{LX}(16,3) \operatorname{LX}(20,3) \operatorname{LX}(21,3) \operatorname{LX}(3,4) \operatorname{LX}(4,4) \operatorname{LX}(5,4) \operatorname{LX}(6,4)$ $\operatorname{LX}(12,5) \operatorname{LX}(17,5) \operatorname{LX}(8,6) \operatorname{LX}(9,6)$

$\mathrm{PD}$

OU ME=ML ALL 
Appendix J

Syntax for CFA for Original Theoretical Model Using Wave 2 Data

\section{TI SARA TRIAL 1 PROPOSED}

$\mathrm{DA} \mathrm{NI}=22 \mathrm{NO}=302 \mathrm{MA}=\mathrm{CM}$

CM FU

$\begin{array}{llllllllllll}.719 & .216 & .176 & .171 & .159 & .233 & .311 & .116 & .113 & .217 & .432 & .049\end{array}$

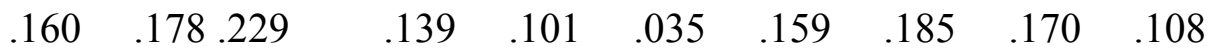

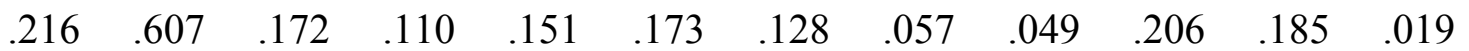
$\begin{array}{lllllllll}.251 & .154 .180 & .120 & .123 & .080 & .277 & .212 & .136 & .155\end{array}$

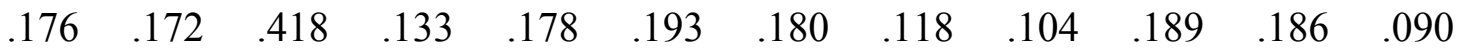

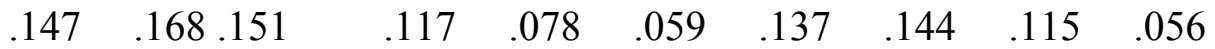

$\begin{array}{llllllllllll}.171 & .110 & .133 & .608 & .272 & .200 & .144 & .130 & .076 & .181 & .194 & .084\end{array}$ $\begin{array}{lllllllll}.204 & .168 .118 & .199 & .069 & .060 & .126 & .170 & .097 & .044\end{array}$

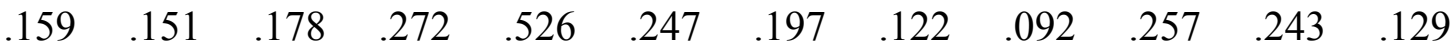
$\begin{array}{lllllllll}.218 & .174 .187 & .215 & .157 & .161 & .240 & .163 & .123 & .117\end{array}$

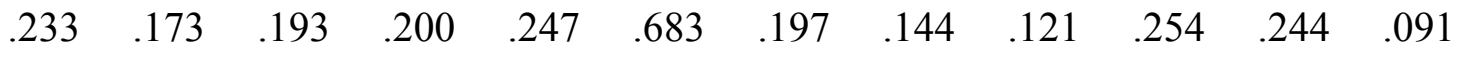

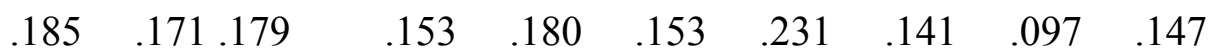

$\begin{array}{llllllllllll}.311 & .128 & .180 & .144 & .197 & .197 & .534 & .177 & .129 & .241 & .301 & .085\end{array}$

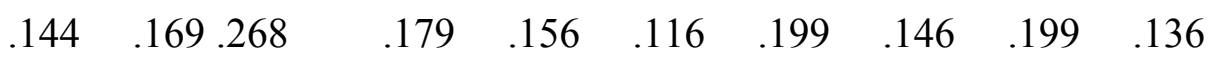

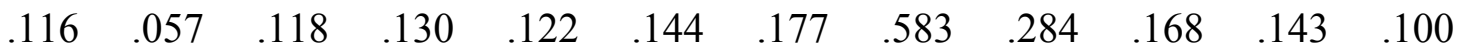

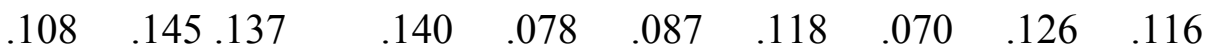

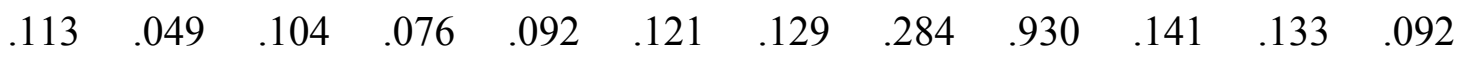
$\begin{array}{lllllllll}.069 & .074 .079 & .114 & .056 & .037 & .119 & .097 & .221 & .036\end{array}$

$\begin{array}{llllllllllll}.217 & .206 & .189 & .181 & .257 & .254 & .241 & .168 & .141 & .613 & .277 & .116\end{array}$

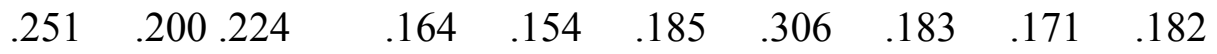

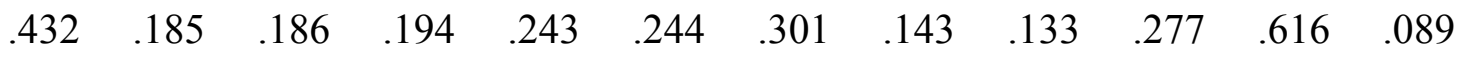
$\begin{array}{lllllllll}.171 & .202 .247 & .195 & .149 & .116 & .247 & .173 & .201 & .187\end{array}$

$\begin{array}{llllllllllll}.049 & .019 & .090 & .084 & .129 & .091 & .085 & .100 & .092 & .116 & .089 & .570\end{array}$

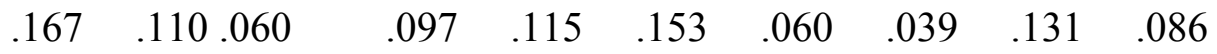


$\begin{array}{llllllllllll}.160 & .251 & .147 & .204 & .218 & .185 & .144 & .108 & .069 & .251 & .171 & .167\end{array}$ $\begin{array}{lllllllll}.606 & .246 .171 & .228 & .095 & .215 & .263 & .254 & .148 & .171\end{array}$

$\begin{array}{llllllllllll}.178 & .154 & .168 & .168 & .174 & .171 & .169 & .145 & .074 & .200 & .202 & .110\end{array}$ $\begin{array}{lllllllll}.246 & .593 .249 & .213 & .100 & .128 & .184 & .213 & .172 & .123\end{array}$

$\begin{array}{llllllllllll}.229 & .180 & .151 & .118 & .187 & .179 & .268 & .137 & .079 & .224 & .247 & .060\end{array}$ $\begin{array}{lllllllll}.171 & .249 .441 & .244 & .135 & .092 & .185 & .162 & .169 & .111\end{array}$

$\begin{array}{llllllllllll}.139 & .120 & .117 & .199 & .215 & .153 & .179 & .140 & .114 & .164 & .195 & .097\end{array}$ $\begin{array}{lllllllll}.228 & .213 .244 & .491 & .126 & .163 & .169 & .213 & .179 & .143\end{array}$

$\begin{array}{llllllllllll}.101 & .123 & .078 & .069 & .157 & .180 & .156 & .078 & .056 & .154 & .149 & .115\end{array}$ $\begin{array}{llllllllll}.095 & .100 .135 & .126 & .549 & .149 & .136 & .043 & .113 & .088\end{array}$

$\begin{array}{llllllllllll}.035 & .080 & .059 & .060 & .161 & .153 & .116 & .087 & .054 & .135 & .121 & .102\end{array}$ $\begin{array}{lllllllll}.292 & .244 .209 & .149 & .051 & .310 & .194 & .155 & .084 & .182\end{array}$

$\begin{array}{llllllllllll}.159 & .277 & .137 & .126 & .240 & .231 & .199 & .118 & .119 & .306 & .247 & .060\end{array}$ $\begin{array}{lllllllll}.263 & .184 .185 & .169 & .136 & .240 & .687 & .282 & .169 & .238\end{array}$

$\begin{array}{llllllllllll}.185 & .212 & .144 & .170 & .163 & .141 & .146 & .070 & .097 & .183 & .173 & .039\end{array}$ $\begin{array}{lllllllll}.254 & .213 .162 & .213 & .043 & .155 & .282 & .737 & .182 & .161\end{array}$

$\begin{array}{llllllllllll}.170 & .136 & .115 & .097 & .123 & .097 & .199 & .126 & .221 & .171 & .201 & .131\end{array}$ $\begin{array}{lllllllll}.148 & .172 .169 & .179 & .113 & .084 & .169 & .182 & .584 & .152\end{array}$ $\begin{array}{llllllllllll}.108 & .155 & .056 & .044 & .117 & .147 & .136 & .116 & .036 & .182 & .187 & .086\end{array}$ $\begin{array}{lllllllll}.171 & .123 .111 & .143 & .088 & .182 & .238 & .161 & .152 & .555\end{array}$

MO NX=22 NK=3 PH=ST,FR

FR LX(4,1) LX(5,1) LX(15,1) LX(16,1) LX(6,1) LX(12,1) LX(18,1) LX(17,2) LX(20,2) $\operatorname{LX}(8,2) \operatorname{LX}(9,2) \operatorname{LX}(19,2) \operatorname{LX}(13,2) \operatorname{LX}(14,2) \operatorname{LX}(21,2) \operatorname{LX}(22,2) \operatorname{LX}(1,3) \operatorname{LX}(7,3)$ $\operatorname{LX}(10,3) \operatorname{LX}(11,3) \operatorname{LX}(2,3) \operatorname{LX}(3,3)$

$\mathrm{PD}$

OU ME=ML ALL 
Appendix K

Syntax for CFA Revised Theoretical Model Using Wave 2 Data

TI SARA TRIAL 1706

DA $\mathrm{NI}=22 \mathrm{NO}=302 \mathrm{MA}=\mathrm{CM}$

CM FU

$\begin{array}{llllllllllll}.719 & .216 & .176 & .171 & .159 & .233 & .311 & .116 & .113 & .217 & .432 & .049\end{array}$

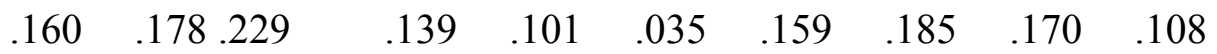

$\begin{array}{llllllllllll}.216 & .607 & .172 & .110 & .151 & .173 & .128 & .057 & .049 & .206 & .185 & .019\end{array}$

$\begin{array}{lllllllll}.251 & .154 .180 & .120 & .123 & .080 & .277 & .212 & .136 & .155\end{array}$

$\begin{array}{llllllllllll}.176 & .172 & .418 & .133 & .178 & .193 & .180 & .118 & .104 & .189 & .186 & .090\end{array}$

$\begin{array}{lllllllll}.147 & .168 .151 & .117 & .078 & .059 & .137 & .144 & .115 & .056\end{array}$

$\begin{array}{llllllllllll}.171 & .110 & .133 & .608 & .272 & .200 & .144 & .130 & .076 & .181 & .194 & .084\end{array}$

$\begin{array}{lllllllll}.204 & .168 .118 & .199 & .069 & .060 & .126 & .170 & .097 & .044\end{array}$

$\begin{array}{llllllllllll}.159 & .151 & .178 & .272 & .526 & .247 & .197 & .122 & .092 & .257 & .243 & .129\end{array}$

$\begin{array}{lllllllll}.218 & .174 .187 & .215 & .157 & .161 & .240 & .163 & .123 & .117\end{array}$

$\begin{array}{llllllllllll}.233 & .173 & .193 & .200 & .247 & .683 & .197 & .144 & .121 & .254 & .244 & .091\end{array}$

$\begin{array}{lllllllll}.185 & .171 .179 & .153 & .180 & .153 & .231 & .141 & .097 & .147\end{array}$

$\begin{array}{llllllllllll}.311 & .128 & .180 & .144 & .197 & .197 & .534 & .177 & .129 & .241 & .301 & .085\end{array}$

$\begin{array}{lllllllll}.144 & .169 .268 & .179 & .156 & .116 & .199 & .146 & .199 & .136\end{array}$

$\begin{array}{llllllllllll}.116 & .057 & .118 & .130 & .122 & .144 & .177 & .583 & .284 & .168 & .143 & .100\end{array}$

$\begin{array}{lllllllll}.108 & .145 .137 & .140 & .078 & .087 & .118 & .070 & .126 & .116\end{array}$

$\begin{array}{llllllllllll}.113 & .049 & .104 & .076 & .092 & .121 & .129 & .284 & .930 & .141 & .133 & .092\end{array}$

$\begin{array}{lllllllll}.069 & .074 .079 & .114 & .056 & .037 & .119 & .097 & .221 & .036\end{array}$

$\begin{array}{llllllllllll}.217 & .206 & .189 & .181 & .257 & .254 & .241 & .168 & .141 & .613 & .277 & .116\end{array}$

$\begin{array}{lllllllll}.251 & .200 .224 & .164 & .154 & .185 & .306 & .183 & .171 & .182\end{array}$

$\begin{array}{llllllllllll}.432 & .185 & .186 & .194 & .243 & .244 & .301 & .143 & .133 & .277 & .616 & .089\end{array}$

$\begin{array}{lllllllll}.171 & .202 .247 & .195 & .149 & .116 & .247 & .173 & .201 & .187\end{array}$

$\begin{array}{llllllllllll}.049 & .019 & .090 & .084 & .129 & .091 & .085 & .100 & .092 & .116 & .089 & .570\end{array}$

$\begin{array}{lllllllll}.167 & .110 .060 & .097 & .115 & .153 & .060 & .039 & .131 & .086\end{array}$ 
$\begin{array}{llllllllllll}.160 & .251 & .147 & .204 & .218 & .185 & .144 & .108 & .069 & .251 & .171 & .167\end{array}$ $\begin{array}{lllllllll}.606 & .246 .171 & .228 & .095 & .215 & .263 & .254 & .148 & .171\end{array}$

$\begin{array}{llllllllllll}.178 & .154 & .168 & .168 & .174 & .171 & .169 & .145 & .074 & .200 & .202 & .110\end{array}$ $\begin{array}{lllllllll}.246 & .593 .249 & .213 & .100 & .128 & .184 & .213 & .172 & .123\end{array}$

$\begin{array}{llllllllllll}.229 & .180 & .151 & .118 & .187 & .179 & .268 & .137 & .079 & .224 & .247 & .060\end{array}$ $\begin{array}{lllllllll}.171 & .249 .441 & .244 & .135 & .092 & .185 & .162 & .169 & .111\end{array}$

$\begin{array}{llllllllllll}.139 & .120 & .117 & .199 & .215 & .153 & .179 & .140 & .114 & .164 & .195 & .097\end{array}$ $\begin{array}{lllllllll}.228 & .213 .244 & .491 & .126 & .163 & .169 & .213 & .179 & .143\end{array}$

$\begin{array}{llllllllllll}.101 & .123 & .078 & .069 & .157 & .180 & .156 & .078 & .056 & .154 & .149 & .115\end{array}$ $\begin{array}{llllllllll}.095 & .100 .135 & .126 & .549 & .149 & .136 & .043 & .113 & .088\end{array}$

$\begin{array}{llllllllllll}.035 & .080 & .059 & .060 & .161 & .153 & .116 & .087 & .054 & .135 & .121 & .102\end{array}$ $\begin{array}{lllllllll}.292 & .244 .209 & .149 & .051 & .310 & .194 & .155 & .084 & .182\end{array}$

$\begin{array}{llllllllllll}.159 & .277 & .137 & .126 & .240 & .231 & .199 & .118 & .119 & .306 & .247 & .060\end{array}$ $\begin{array}{lllllllll}.263 & .184 .185 & .169 & .136 & .240 & .687 & .282 & .169 & .238\end{array}$

$\begin{array}{llllllllllll}.185 & .212 & .144 & .170 & .163 & .141 & .146 & .070 & .097 & .183 & .173 & .039\end{array}$ $\begin{array}{lllllllll}.254 & .213 .162 & .213 & .043 & .155 & .282 & .737 & .182 & .161\end{array}$

$\begin{array}{llllllllllll}.170 & .136 & .115 & .097 & .123 & .097 & .199 & .126 & .221 & .171 & .201 & .131\end{array}$ $\begin{array}{lllllllll}.148 & .172 .169 & .179 & .113 & .084 & .169 & .182 & .584 & .152\end{array}$ $\begin{array}{llllllllllll}.108 & .155 & .056 & .044 & .117 & .147 & .136 & .116 & .036 & .182 & .187 & .086\end{array}$ $\begin{array}{lllllllll}.171 & .123 .111 & .143 & .088 & .182 & .238 & .161 & .152 & .555\end{array}$

SE

$1234567101112131415161718192021 /$

MO NX=19 NK=3 PH=ST, FR

FR LX(3,1) LX(4,1) LX(5,1) LX(6,1) LX(10,1) LX(15,1) LX(11,2) LX(12,2) LX(14,2)

LX(18,2) LX(19,2) LX(16,3) LX(17,3) LX(13,3) LX(9,3) LX(8,3) LX(7,3) LX(2,3) $\operatorname{LX}(1,3)$

PD

OU ME=ML ALL 


\section{Appendix L}

\section{The SBI}

For the following items, please respond by stating strongly agree, agree, neutral, disagree, or strongly disagree.

$5=$ Strongly agree

4= Agree

$3=$ Neutral

$2=$ Disagree

$1=$ Strongly disagree

I am able to generate solutions.

I have the ability to focus on what I want to occur in my life.

I can think about things that have made a positive difference for me.

I am able to focus on times when my situation is not so overwhelming, even a little bit.

There are times in my life where I am able to handle difficulties well.

I am able to notice good things in myself, others, and my situation.

I have been able to cope with life's challenges.

If I woke up tomorrow and a miracle happened in my life I would be able to notice differences in myself and others.

I am aware of small positive changes that I make.

There are times when I am really proud of how I am able to handle difficult situations.

I have successfully overcome challenges in the past.

I have make steps towards improving my life.

I am able to see good things in my situation, even though parts of it seem very difficult.

Dwelling on my problems may not be the best way to find solutions. 
Sara Ann Smock

727 Highland Ave SE

Roanoke, VA 24013

(540) 342-7964 (home)

ssmock@vt.edu

February 2006

\section{Education}

Ph.D. Candidate, Virginia Polytechnic Institute and State University, Marriage and Family Therapy, anticipated graduation May 2006.

M.S., Purdue University Calumet, Child Development and Family Studies (with a concentration in Marriage and Family Therapy), 2003.

B.A., Olivet Nazarene University, Psychology and Christian Education, 2000.

\section{Current Positions}

2004-present Editorial assistant for Family Relations.

2005-2006 Program Chair for the 2006 SFBTA conference

2005-present Doctoral Intern, Family Service, Roanoke, VA

\section{Previous Positions}

2003-2004 Graduate clinical research assistant, Virginia Polytechnic Institute and State University, Blacksburg, VA.

2003-2004 Appointed graduate representative for the department of human development, Virginia Polytechnic Institute and State University, Blacksburg, VA.

2000-2003 Graduate teaching assistant, Purdue University Calumet. Possessed full responsibility for the following courses: general psychology, child development, adolescent development, and human development.

1998-2000 Professors' assistant, Olivet Nazarene University.

1999-2000 Statistics Tutor, Olivet Nazarene University.

1998-2000 Receptionist, Alexander Funeral Homes, Evansville, IN. 


\section{Previous Internship/Practicum Placements}

2003-2005 Virginia Tech's Marriage and Family Therapy Center, Virginia Polytechnic Institute and State University, Blacksburg, VA.

2002-2003 Samaritan Counseling Center, Munster, IN.

2001-2002 Purdue's Marriage and Family Therapy Center, Hammond, IN.

1999 Indian Oaks Academy, Manteno, IL.

\section{Courses Taught}

2001-2003 Adolescent Development, Purdue University Calumet, Hammond, IN. Taught three sections.

2002-2003 Child Development, Purdue University Calumet, Hammond, IN. Taught four sections.

2000-2002 General Psychology, Purdue University Calumet, Hammond, IN. Taught three sections.

2001 Lifespan Development, Purdue University Calumet, Hammond, IN. Taught one section.

\section{Awards and Honors}

Awarded the AAMFT's Dissertation/Thesis Award for the project "Solution-Focused Group Therapy for Level 1 Substance Abusers” 2004.

Nominated by peers to interview candidates for Purdue Calumet's Marriage and Family Therapy Class of 2003-2004.

Recipient of Purdue Calumet's Graduate Research Award, 2002.

Nominated to participate in Purdue Calumet's Spotlight on Graduate Research, 2002.

Elected President of local Psi Chi chapter at Olivet Nazarene University, 1999-2000.

Elected Psychology Club President at Olivet Nazarene University, 1999-2000.

Dean's list, Olivet Nazarene University, 1996-2000.

Graduated Summa Cum Laude, Olivet Nazarene University, 2000.

Phi Delta Lambda (Nazarene National Honor Society), 2000-present. 


\section{Research}

2005-present Dissertation, Virginia Polytechnic Institute and State University, Blacksburg, VA.

2004-2005 It's hard to be a Father, Virginia Polytechnic Institute and State University, Blacksburg, VA.

2004 Reflections on a Dialog of Diversity: The Experience of the Process, Virginia Polytechnic Institute and State University, Blacksburg, VA.

2003-2004 Comparing Intake Forms: Is it a Matter of Semantics?, Virginia Polytechnic Institute and State University, Blacksburg, VA.

2003-2004 Comparing Rural and Urban Factors in MFT Clinics, Virginia Polytechnic Institute and State University, Blacksburg, VA.

2003 "Where do we stand?" A call to build intergenerational community, Virginia Polytechnic Institute and State University, Blacksburg, VA.

2003 Supporting community through an intergenerational summer program involving persons with dementia and pre-school children, Virginia Polytechnic Institute and State University, Blacksburg, VA.

2001-2003 Master's Thesis, Purdue University Calumet, Hammond, IN. Completed an outcome study comparing solution-focused therapy with traditional treatment for substance abusers.

1999 Undergraduate Independent Research Project, Olivet Nazarene University, Bourbonnais, IL. Conducted research and presented at the Symposium sponsored by the Associated Colleges of the Chicago Area.

1998-2000 Aided in Institutional Research at Olivet Nazarene University.

\section{Professional Presentations}

Smock, S. A. (November, 2005). The Development of the Solution Building Inventory. Workshop at the $3^{\text {rd }}$ annual conference of Solution-Focused Practices, Ft. Lauderdale, FL.

Parkman, T., Smock, S. A., \& Arditti, J. A. (November, 2005). Fathering Behind Walls: A Look at Fathering Identity and Incarceration. Poster session presented at the $67^{\text {th }}$ annual conference of the National Council on Family Relations, Phoenix, AZ. 
Smock, S. A., McWey, L., \& Moore, D. (October, 2005). Rural Versus Urban Clinical Needs: Are There Differences? Poster presented at the $63^{\text {rd }}$ annual conference of the American Association for Marriage and Family Therapy, Kansas City, MO.

Arditti, J. A., Smock, S. A., \& Parkman, T. (June, 2005). Families and incarceration: An ecological approach. Poster presented at the Hawaii International Conference on Social Sciences, Honolulu, Hawaii.

Glass, V., Issenman, T., Smock, S. A., \& Stone, D. (March, 2005). Reflections on a Dialog of Diversity: The Experience of the Process. Poster presented at the Virginia Tech Diversity Conference, Roanoke, VA.

Smock, S. A. (September, 2004). Comparing Intake Forms: Is it a Matter of Semantics? Poster presented at the $62^{\text {nd }}$ annual conference of the American Association for Marriage and Family Therapy, Atlanta, GA.

Pichot, T., Simon, J., \& Smock, S. A. (November, 2004). Solution-Focused Brief Therapy 101. Pre-conference workshop at the $2^{\text {nd }}$ annual conference of Solution-Focused Practices, Park City, UT.

Smock, S. A. (November, 2004). Comparing Intake Forms: Is it a Matter of Semantics? Workshop at the $2^{\text {nd }}$ annual conference of Solution-Focused Practices, Park City, UT.

Gigliotti, C., Jarrott, S., Morris, M., \& Smock, S. A. (November, 2004). Supporting community through an intergenerational summer program involving persons with dementia and pre-school children. Symposium presented at the meetings of the Gerontological Society of America, Washington, DC.

Jarrott, S., Gigliotti, C., \& Smock, S. (November, 2004). Where do we stand? A call to build intergenerational community. Symposium presented at the meetings of the Gerontological Society of America, Washington, DC.

Smock, S. A. (November, 2003). Solution-Focused Group Therapy for Level 1 Substance Abusers. Poster presented at the $1^{\text {st }}$ conference of Solution-Focused Practices, Loma Linda, CA.

Pichot, T., \& Smock, S. A. (November, 2003). Co-Creating Solutions for Substance Abuse Treatment. Workshop at the $1^{\text {st }}$ conference of Solution-Focused Practices, Loma Linda, CA.

Smock, S. A. (April, 2002). Solution-Focused Group Therapy for Level 1 Substance Abusers. Presentation at the Purdue Calumet's Spotlight on Graduate Research, Hammond, IN. 
Clymer, S., Hoogestrat, T., Smock, S. A., Walker, A. (April, 2002). Stereotyping in Family Therapy: Activities to Promote Therapist Awareness. Poster presented at the Indiana Association for Marriage and Family Therapy Conference, Indianapolis, IN.

Smock, S. A. (April, 2002). Solution-Focused Group Therapy for Level 1 Substance Abusers. Poster presented at the Indiana Association for Marriage and Family Therapy Conference, Indianapolis, IN.

Arneson, C., Clymer, S., Flores, C., \& Smock, S. A. (April, 2001). Ethical considerations of therapists' to clients: A preventative model. Poster presented at the Indiana Association for Marriage and Family Therapy Conference, Indianapolis, IN.

Smock, S. A. (April, 2001). Adult Learning Disabilities: A Structural Family Therapy Approach. Poster presented at the Indiana Association for Marriage and Family Therapy Conference, Indianapolis, IN.

\section{Publications}

McCollum, E. E., Trepper, T. S., \& Smock, S. (2004). Solution-focused brief group therapy for drug abuse: Rationale, content, and approaches. Journal of Family Psychotherapy, 14(4), 27-42.

McWey, L. M., James, E. J., \& Smock, S. A. (2005). The Graduate Student Guide to Conducting Research in Marriage and Family Therapy. In F. Piercy \& D. Sprenkle (Eds.), Research Methods in Family Therapy (pp. 19-40). Guilford Press: New York.

Smock, S. (2005). A student's response to the SFBT training meetings: The Future Looks Bright. Journal of Family Psychotherapy, 16(1/2), 11-13.

Gigliotti, C. M., Morris, M., Smock, S. A., Jarrott, S. E., \& Graham, B. (2005). An Intergenerational Summer Program Involving Persons with Dementia and Preschool Children. Educational Gerontology, 31, 425-441.

Nelson, T. \& Smock, S. (2005). Challenges of an Outcome-based Perspective for Marriage and Family Therapy Education. Family Process, 44, 355-362.

Arditti, J. A., Smock, S. A., \& Parkman, T. S. (2005). "It's been hard to be a father": A qualitative exploration of incarcerated fatherhood. Fathering, 3, 267-288.

Smock, S. (2005). A student's response to the SFBT training meetings: The Future Looks Bright. In T. S. Nelson (Ed.), Solution-focused brief therapy training. Haworth Press: New York. 
Jarrott, S. E., Gigliotti, C. M., \& Smock, S. (2006). Using Contact Theory to Build the Foundation of an Intergenerational Community Between Pre-school Children and Older Adults with Dementia. Journal of Intergenerational Relationships, 4(2), 73-92.

Smock, S. A., McWey, L. M., \& Ward, D. (2006). Rural Versus Urban Clinical Needs: Are There Differences? Journal of Family Psychotherapy, 17(2), 37-49.

Smock, S. A., Trepper, T. S., Wetchler, J., Ray, R., Pierce, K., \& McCollum, E. (revise and resubmit). Solution-Focused Group Therapy for Level 1 Substance Abusers. Submitted to Journal of Marriage and Family Therapy.

\section{Professional Memberships}

2004-2005 Proposal review committee member for the SFBTA conference of Solution-Focused Practices.

2004-present National Council on Family Relations, Student member.

2003-2004 Conference committee member for the SFBTA conference of SolutionFocused Practices.

2002-2003 Conference committee member for the SFBTA conference of SolutionFocused Practices.

2002-present A member of the Founders Group for the Solution-Focused Brief Therapy Association (SFBTA).

A new association formed by Steve deShazer, Insoo Kim Berg, and accomplished solution-focused therapists.

2000-present American Association of Marriage and Family Therapy, Student member.

2000-2002 Indiana Association for Marriage and Family Therapy.

\section{Volunteer Work}

2003 Volunteered at the $61^{\text {th }}$ annual conference of the American Association for Marriage and Family Therapy, Cincinnati, $\mathrm{OH}$.

2002 Volunteered at the $60^{\text {th }}$ annual conference of the American Association for Marriage and Family Therapy, Nashville, TN.

2001 Volunteered at the $59^{\text {th }}$ annual conference of the American Association for Marriage and Family Therapy, Denver, CO. 


\section{References}

Dr. Eric McCollum, Professor of Marriage and Family Therapy at Virginia Tech Virginia Polytechnic Institute and State University

Human Development

7054 Haycock Road

Falls Church, VA 22043

(703) 538-8463

e.mccollum@vt.edu

Dr. Terry Trepper, Family Studies Center Director and Professor of Marriage and Family Therapy at Purdue University Calumet

Marriage \& Family Therapy Program

Entrepreneurship Center

Room 144

2200169 th Street

Hammond, Indiana 46323-2094

(219) 989-2027

trepper@calumet.purdue.edu

Dr. Joseph Wetchler, Program Director and Professor of Marriage and Family

Therapy at Purdue University Calumet

Marriage \& Family Therapy Program

Entrepreneurship Center

Room 144

2200169 th Street

Hammond, Indiana 46323-2094

(219) 989-2027

wetchler@calumet.purdue.edu

Dr. Joyce A. Arditti, Editor of Family Relations

Virginia Polytechnic Institute and State University

Human Development

311 Wallace Hall

Blacksburg, VA 24061

(540) 231-5758

arditti@vt.edu

Dr. Lenore M. McWey, Assistant Professor, MFT Training Director

Florida State University

Department of Family \& Child Sciences

210 Sandels Building

Tallahassee, FL 32306-1491

(850) 644-4451

lmcwey@fsu.edu 